\title{
Suboptimal mobility in spring calving, pasture-based dairy systems: causes and economic consequences.
}

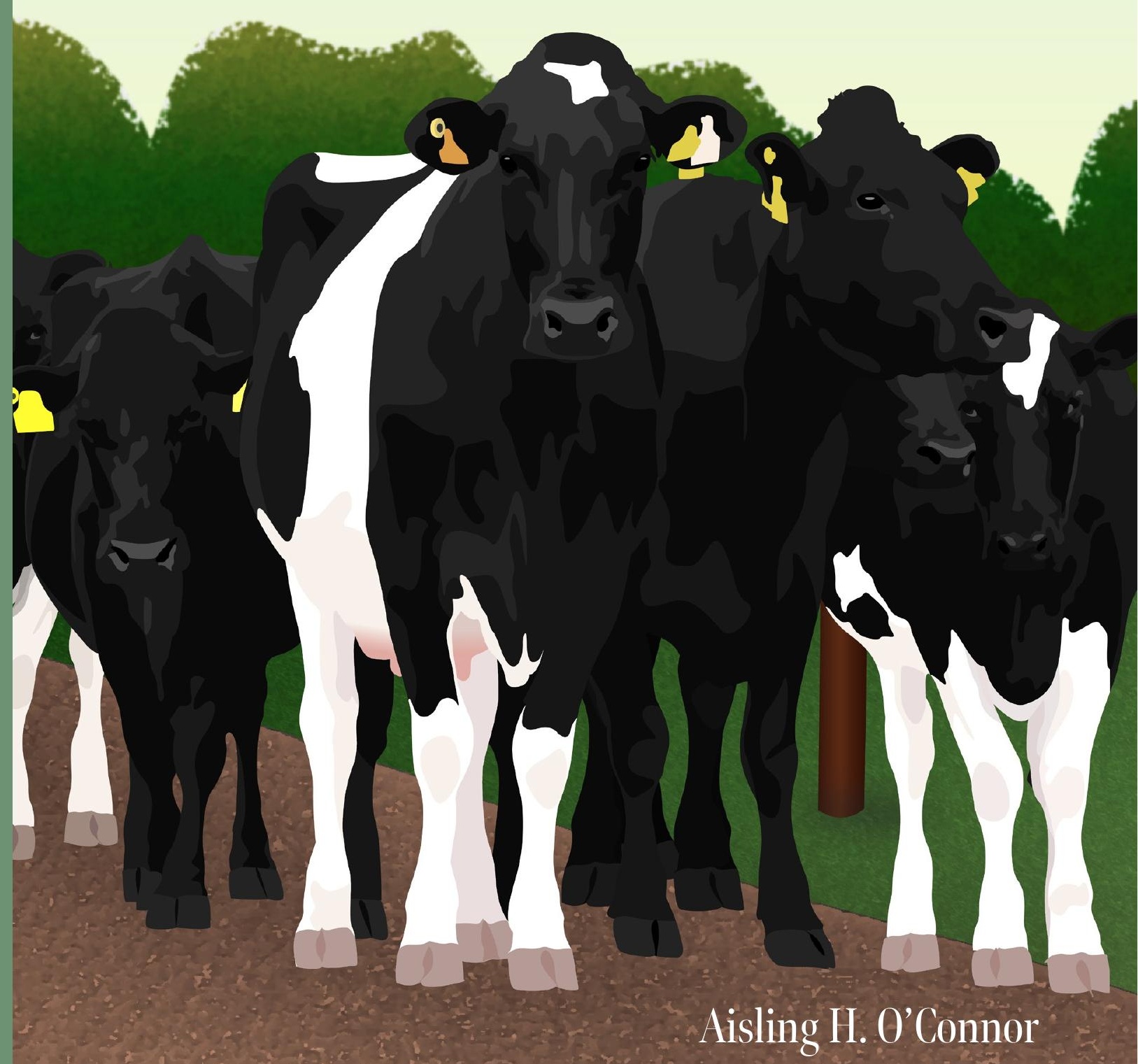




\section{Propositions}

1. The use of the word lameness is lame.

(this thesis)

2. The prevalence of suboptimal mobility alone, is not a good indicator for its economic consequence.

(this thesis)

3. Science will be more valued after a global pandemic.

4. A weekly weather forecast for Northeast Atlantic regions can be one of two things: lucky or wrong.

5. Social isolation due to the Covid19 pandemic is positively associated with the probability of finalising a $\mathrm{PhD}$ thesis.

6. Women's Gaelic football is not for ladies.

Propositions belonging to the thesis, entitled

'Suboptimal mobility in spring calving, pasture-based dairy systems: causes and economic consequences.'

Aisling H. O’Connor

Wageningen, 12 October 2020 

Suboptimal mobility in spring calving, pasture-based dairy systems: causes and economic consequences

Aisling H. O’Connor 


\section{Thesis committee}

\section{Promotors}

Prof. Dr I.J.M. de Boer

Professor of Animal Production Systems

Wageningen University \& Research

Prof. Dr H. Hogeveen

Personal chair at the Business Economics Group

Wageningen University \& Research

\section{Co-promotors}

Dr L. Shalloo

Senior research officer, Livestock Production Systems,

Teagasc, Moorepark, Ireland

Dr E.A.M. Bokkers

Associate professor, Animal Production Systems Group

Wageningen University \& Research

\section{Other members}

Prof. Dr E.N. Stassen, Wageningen University \& Research

Prof. Dr S. Østergaard, Aarhus University, Denmark

Dr M. Holzhauer, Animal Health Service, Deventer

Dr K. Frankena, Wageningen University \& Research

This research was conducted under the auspices of the Graduate School of Wageningen Institute of Animal Sciences (WIAS) 
Suboptimal mobility in spring calving, pasture-based dairy systems: causes and economic consequences

Aisling H. O’Connor

\section{Thesis}

Submitted in fulfilment of the requirements for the degree of doctor at

Wageningen University

by the authority of the Rector Magnificus

Prof. Dr A.P.J. Mol,

in the presence of the

Thesis Committee appointed by the Academic Board

to be defended in public

on Monday 12 October 2020

at 4:00 p.m. in the Aula. 
O’Connor, Aisling H.

Suboptimal mobility in spring calving, pasture-based dairy systems: causes and economic consequences, 144 pages.

$\mathrm{PhD}$ thesis, Wageningen University, Wageningen, NL (2020)

With references, with summary in English

ISBN: 978-94-6395-425-9

DOI-link: https://doi.org/10.18174/523626 


\begin{abstract}
Suboptimal mobility (any deviation from optimal mobility) is an important area of concern in modern dairy production systems. Up to now, suboptimal mobility in dairy cows managed in spring calving, pasture-based systems have been overlooked. Therefore, the aim of this thesis was to gain a better understanding of the potential causes and impacts of all levels of sub optimal mobility in spring calving, pasture-based dairy cows.

First, the associations between claw disorders and mobility scores were investigated. The mobility scoring method utilized in this thesis is a four-point scale from 0 , which refers to a cow with optimal mobility, to 3 which refers to a cow with severely impaired mobility. The presence of most types of claw disorders were associated with an increased likelihood of a cow having any level of suboptimal mobility. Therefore, it is implied that mobility scoring of cows should be routinely practiced to identify cows with imperfect mobility at an earlier stage.
\end{abstract}

Second, potential risk factors were identified for suboptimal mobility. Potential cow-level risk factors for suboptimal mobility included body condition score, milk yield, genetics for 'lameness', somatic cell score, calving month and cow breed. While, potential herd-level risk factors for suboptimal mobility included the length of time taken to complete the milking process, farm layout factors and foot bathing practices. These factors should be considered by farm advisors when advising and implementing a cow/herd health program for dairy cows in spring calving, pasture-based systems.

Third the production and reproductive impacts of specific levels of suboptimal mobility were analysed. Yield losses of up to $4.7 \%$ were associated with mobility score 3 . Elevated somatic cell count, and longer calving intervals were associated with all levels of suboptimal mobility. Cows with any level of suboptimal mobility were more likely to be culled. This demonstrates associations between specific mobility scores and production and reproductive performance in spring calving, pasture-based dairy cows scored during the summer grazing period.

Finally, the economic impact of varying prevalence of suboptimal mobility was determined within typical spring calving, pasture-based dairy herds. A new sub model predicting suboptimal mobility was developed and integrated within the Pastured Based Herd dynamic model. The impact on profitability was simulated based on production and reproductive effects of individual animals as well as the associated treatment costs. For a very poor mobility herd the overall farm net profit was $€ 16,500$ less compared to a good mobility herd. The substantial decrease in farm net profit is due to reduced milk yield, increased culling, and treatment costs for mobility issues. Therefore, as the prevalence of cows with suboptimal mobility scores (even mild suboptimal mobility scores) increases within a herd, the overall farm next profit decreases.

Based on this thesis it is concluded that although the prevalence of severe suboptimal mobility with spring calving, pasture-based herds is less than that in other types of systems, the potential impact of the less severe states of suboptimal mobility have a substantial effect on production and reproductive performance, and the overall profitability of the farm. 



\section{Contents}

Chapter 1 General Introduction 1

Chapter 2 Associating cow characteristics with mobility scores in 13 pasture-based dairy cows

Chapter 3 Cow and herd-level risk factors associated with mobility scores in pasture-based dairy cows

Chapter 4 Associating mobility scores with production and 55 reproductive performance in pasture-based dairy cows

Chapter 5 The economic impact of suboptimal mobility in dairy 83 cows under seasonal pasture-based management

Chapter 6 General Discussion

Summary

References

Acknowledgements

About the author

Publications 

General introduction | 1

Chapter 1

General Introduction 


\section{2 | Chapter 1}

\section{Background}

Lameness is one of the major problems associated with dairy production, affecting all three pillars of sustainability. Lameness is associated with negative animal welfare impacts (Rushen, 2001, O'Callaghan, 2002, Mee and Boyle, 2020), substantial economic losses (Bruijnis et al., 2010), and environmental consequences, including increased emissions of greenhouse gases (Mostert et al., 2018), acidifying gases or eutrophying substances (Chen et al., 2016). Focusing on economics, Bruijnis et al. (2010) reported that lameness is amongst the most important health related economic losses after mastitis.

From a global view point, the highest prevalence of lameness reported in a study in recent years is reported by Barker et al. (2010). They found a mean prevalence of $37 \%$ within a variety of production systems (year round calving, seasonal calving, grazing systems, zero grazing systems, as well as conventional and organic type systems) in the United Kingdom (UK). Focusing on confinement type systems Espejo et al. (2006) reported the prevalence of lameness to be $25 \%$, while for pasture-based systems the reported prevalence throughout the literature is lower. Fabian et al. (2014), for example, reported a prevalence of $8 \%$ in a pasturebased system in New Zealand, while Ranjbar et al. (2016) reported a prevalence of $19 \%$ in a pasture-based system in Australia. According to European Food Safety Authority (EFSA, 2009), a lameness prevalence of up to $2 \%$ is achievable on well managed commercial herds. Therefore, it is quite evident that there is quite some room for improvement across all system types to reduce the prevalence of lameness on farm. Potentially to achieve this target level of $2 \%$ lameness prevalence, it is probably necessary to make and implement significant changes related to cow and herd level management on farm. Some promising changes could include both the earlier detection and treatment of cows with lameness, as well as improving breeding and feeding strategies, and other cow and herd level management factors for dairy systems. However, since the reported prevalence of lameness is based on the binary characteristic of this parameter, lame - not lame, it ignores the prevalence of cows with mild deviations or imperfections relative to optimal mobility, which leads to the question of 'what is optimal mobility'?

\section{Optimal mobility of dairy cows and methods to measure it}

To understand any debilitating disease, a clear understanding of optimal health and normal functioning of the animal is necessary. Therefore, in order to understand what a mobility issue is, the first step is to determine what the normal mobility of a dairy cow should be. Van Nuffel et al. (2015) describe normal mobility as 'a gait of four evenly spaced beats with no suspension phase (i.e., the phase in which the animal moves forward without any limb touching the ground) but with alternate support by two or three limbs. The usual succession of ground-contacting limbs during walk is LH-LF-RH-RF (where L, R, H, F indicate left, right, hind, and front, respectively) with a regular rhythm and even spacing between footfalls. With the normal function of a dairy cow's mobility system in mind, it seems logical that the simplest or 'most straightforward' description of mobility issues in general is to state what it 
is not: a disorder when dairy cow mobility no longer matches her normal or optimal gait. However, this is still quite vague, and includes cows with quite mild deviations to optimal gait as well as cows with severe deviations possibly describing a cow with an inability to bear weight on a certain limb.

Therefore, in this thesis, we describe normal gait as optimal mobility, and varying specific levels of suboptimal mobility as imperfect, impaired, or severely impaired mobility. With this approach, we are moving away from the binary categorization of 'lame' versus 'nonlame' and move towards a more spectrum focus for dairy cow mobility.

Mobility scoring scales (also referred to as locomotion scoring scales) are used to evaluate dairy cow mobility. There are a vast number of mobility scoring scales available for both researchers and farm practitioners. Schlageter-Tello et al. (2014), for example, identified 247 different scales in their review of 244 studies. A relevant complication associated with mobility scoring scales is related to farmers willingness and ability to use them, which prompted the development of the DairyCo mobility scoring scale, later adapted to the UK Agricultural and Horticulture Development Board (AHDB) mobility scoring scale (AHDB DairyCo, 2007). The UK AHDB mobility scoring scale is the scale utilized in this thesis and is a four-point scale, specifically developed to provide an industry standard to be used to mobility score cows on commercial farms. One key difference between other scales and the UK AHDB scale is that specific actions are recommended based on the score (Table 1). However, mobility scoring cows is often part of a treatment routine rather than a preventative routine on farm, therefore knowing and understanding the causes and risk factors associated with mobility issues should also be considered. 


\section{4 | Chapter 1}

Table 1. The United Kingdom Agricultural and Horticulture Development Board (AHDB) mobility scoring scale; description of cow behaviours and recommended actions.

\begin{tabular}{|c|c|c|}
\hline Mobility Score & $\begin{array}{l}\text { Description of cow } \\
\text { behaviour }\end{array}$ & Suggested action \\
\hline 0 & $\begin{array}{l}\text { Walks with even weight } \\
\text { bearing and rhythm on all four } \\
\text { feet, with a flat back. } \\
\text { Long, fluid strides possible. }\end{array}$ & $\begin{array}{l}\text { - } \\
\text { - } \\
\text { Routine (preventative) foot trimming } \\
\text { when/if required } \\
\text { - Record mobility at next scoring } \\
\text { session }\end{array}$ \\
\hline 1 & $\begin{array}{l}\text { Steps uneven (rhythm or } \\
\text { weight bearing) or strides } \\
\text { shortened; affected limb or } \\
\text { limbs not immediately } \\
\text { identifiable. }\end{array}$ & $\begin{array}{l}\text { (preventative) foot trimming when/if } \\
\text { required } \\
\text { - } \quad \text { Further observation recommended }\end{array}$ \\
\hline 2 & $\begin{array}{l}\text { Uneven weight bearing on a } \\
\text { limb that is immediately } \\
\text { identifiable and/or obviously } \\
\text { shortened strides (usually an } \\
\text { arch to the centre of the back) }\end{array}$ & $\begin{array}{l}\text { Lame and likely to benefit from } \\
\text { treatment } \\
\text { Foot should be lifted to establish the } \\
\text { cause of lameness before treatment } \\
\text { - } \\
\text { should be attended to as soon as } \\
\text { practically possible }\end{array}$ \\
\hline 3 & $\begin{array}{l}\text { Unable to walk as fast as a } \\
\text { brisk human pace (cannot keep } \\
\text { up with the healthy herd). } \\
\text { Lame leg easy to identify - } \\
\text { limping; may barely stand on } \\
\text { lame leg/s; back arched when } \\
\text { standing and walking. } \\
\text { Very lame }\end{array}$ & $\begin{array}{l}\text { This cow is very lame and requires } \\
\text { urgent attention, nursing and further } \\
\text { professional advice } \\
\text { - } \quad \text { examine as soon as possible } \\
\text { - cow will benefit from treatment } \\
\text { cow should not be made walk far and } \\
\text { kept on a straw yard or at grass } \\
\text { in the most severe cases, culling may } \\
\text { be the only possible solution }\end{array}$ \\
\hline
\end{tabular}




\section{Causes and risk factors of suboptimal mobility}

Suboptimal mobility is caused by multifactorial problems. For example, some cases of suboptimal mobility can develop due to injury to the nervous system or the musculoskeletal system (Merck, 2015). It is also been reported that there are non-locomotor system related causes of suboptimal mobility, like severe udder distension (Flower et al., 2006). However, it is widely accepted that the single most common cause of suboptimal in dairy cows is due to the presence of claw disorders (Murray et al., 1996, Van Nuffel et al., 2015), since they account for up to $90 \%$ of suboptimal mobility according to Murray et al. (1996).

Broadly speaking, claw disorders can be categorized into two groups, which are noninfectious and infectious type disorders. Non-infectious claw disorders (e.g., overgrown claw, sole hemorrhage, white line disease, and sole ulcer) are sometimes referred to as mechanical type claw disorders, and are generally caused by physical disturbance or damage to the claw, whereas infectious claw disorders (e.g., digital dermatitis) are caused by an infectious disease and are often be associated with a sudden onset of suboptimal mobility (Blowey and Chesterton, 2012). Non-infectious claw disorders appear to be far more prevalent in grazing systems compared to non-grazing systems. Somers and O'Grady (2015) reported on the type of claw disorder presence from a study comprising of 10 pasture-based herds in Ireland. In this study Somers and O'Grady (2015) found that of all the claw disorders recorded, on average non-infectious claw disorders made up $86 \%$, while infectious claw disorders made up $14 \%$ of the cases. Common claw disorders in pasture-based systems include; overgrown claw, white line disease, sole hemorrhage, sole ulcer, and digital dermatitis. These claw disorders are displayed in Figure 1 and described in Table 2 according to the ICAR claw health atlas (International Committee for Animal Recording (ICAR, 2015)). 


\section{6 | Chapter 1}

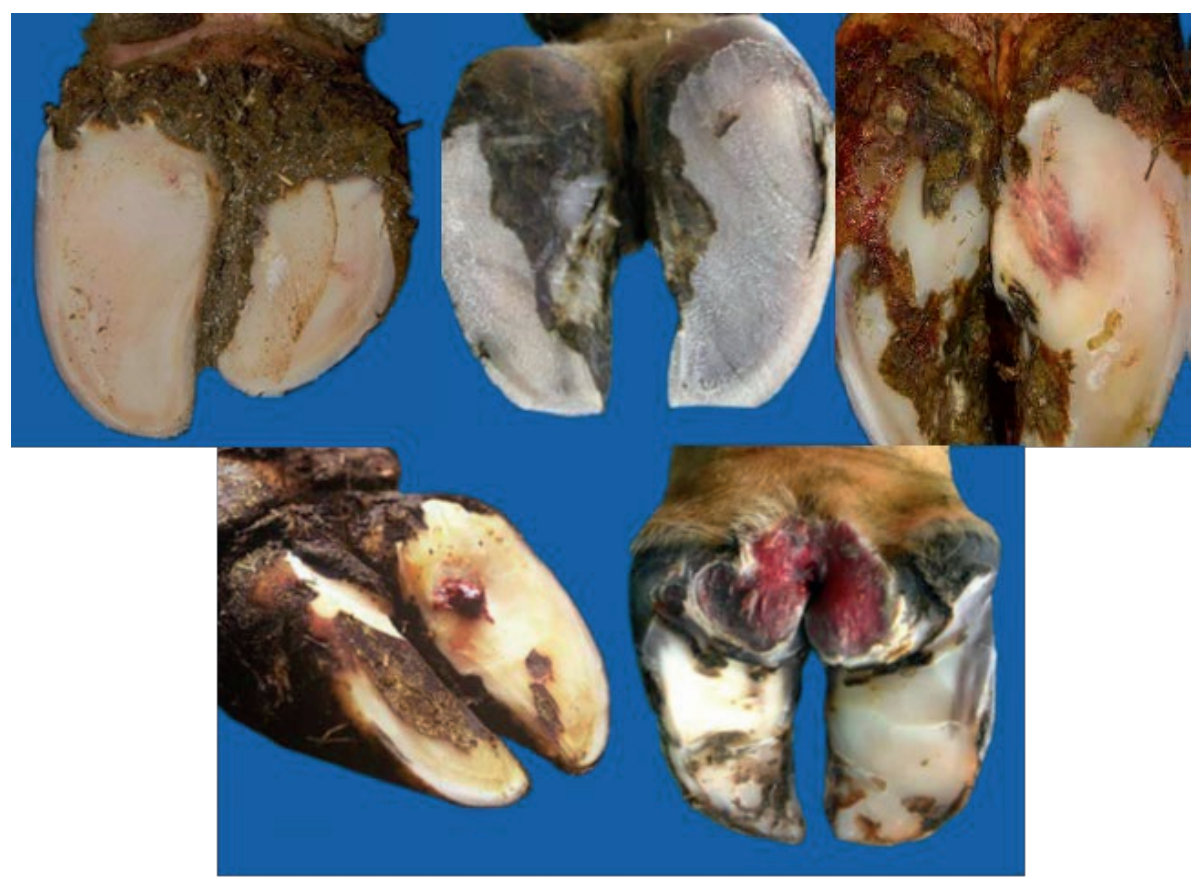

Figure 1. Claw disorders common to pasture-based systems; overgrown claw (top left), white line disease (top middle), sole hemorrhage (top right), sole ulcer (bottom left), digital dermatitis (bottom right). Photo source: International Committee for Animal Recording (International Committee for Animal Recording (ICAR, 2015)). 
Table 2. Descriptions used by the assessors to identify claw disorders

\begin{tabular}{|c|c|c|}
\hline Claw Disorder & Type & Description \\
\hline Overgrown claw & Non-infectious & $\begin{array}{l}\text { Significant difference in width, height and/or length } \\
\text { between outer and inner claw which cannot be } \\
\text { balanced by trimming }\end{array}$ \\
\hline White line disease & Non-infectious & $\begin{array}{l}\text { The sole separates from the side wall of the claw and } \\
\text { foreign material then penetrates. Separation of the } \\
\text { white line which remains after balancing both soles }\end{array}$ \\
\hline Sole haemorrhage & Non-infectious & $\begin{array}{l}\text { Clear differentiation between discoloured and normal } \\
\text { coloured horn }\end{array}$ \\
\hline Sole ulcer & Non-infectious & $\begin{array}{l}\text { Penetration through the sole horn exposing fresh or } \\
\text { necrotic corium/ulcer located at the toe }\end{array}$ \\
\hline Digital dermatitis & Infectious & $\begin{array}{l}\text { Infection of the digital and/or interdigital skin with } \\
\text { erosion, mostly painful ulcerations and/or chronic } \\
\text { hyperkeratosis/proliferation. }\end{array}$ \\
\hline
\end{tabular}

As already mentioned, the presence of non-infectious claw disorders are more common compared to infectious type claw disorders for cows in pasture-based systems, and these noninfectious type claw disorders are more often than not due to physical disturbance of damage to the claw itself. Therefore, it is hypothesized that there are potential risk factors capable of increasing or decreasing a cow's likelihood to develop such claw disorders. So far throughout the literature, various cow and environmental type risk factors associated with mobility issues have been reported on with a particular emphasis on housing and management type risk factors (De Vries et al., 2015). Some of these risk factors include; flooring type (Somers et al., 2003), the availability, cleanliness of cubicles, and type of bedding (Cook et al., 2004, Chapinal et al., 2013), and access to pasture (Hernandez-Mendo et al., 2007, Olmos et al., 2009). As also mentioned by Alawneh et al. (2011) and Bran et al. (2018) up to now, there is less known surrounding the potential cow and herd level risk factors associated with varying levels of suboptimal mobility in pasture-based systems, specifically during the grazing season. Similarly, the impacts of mild and moderate suboptimal mobility is also less known in comparison to what is already know about severe forms of suboptimal mobility. 


\section{8 | Chapter 1}

\section{Impacts of suboptimal mobility}

For the dairy cow, the adverse effects of claw disorders (and the resulting mobility issues) on their welfare has been well reported throughout the literature, see for example; O'Callaghan (2002), Leach et al. (2009), and Navarro et al. (2013). For farmers, it is also well known that dairy cows within their herd with mobility issues are associated with substantial production losses. Similarly, it is known that severe mobility issues have the potential to reduce the overall lifetime performance of dairy cows due to milk yield reduction and culling (Huxley, 2013). So far the focus of these studies examining mobility issues has revolved around the binary idea of a cow being categorized as 'lame' or 'non-lame', or even some studies focus on the presence of specific claw disorders causing lameness. For example lameness has been shown to be negatively associated with milk yield (Green et al., 2002) and reproductive performance, while the presence of specific claw disorders has also been shown to be associated with significant yield losses (Amory et al., 2008). However there is a little knowledge on the potential negative impacts of various performance indicators associated with different levels of suboptimal mobility. Moreover, the focus of many of these studies has also been on confinement type systems (Bicalho et al., 2008), and non-seasonal calving pasture-based systems (Archer et al., 2010).

Similarly, given the substantial impacts of mobility issues in dairy cows on the various performance indicators, it is reasonable to assume that various levels of suboptimal mobility is potentially associated with economic consequences. Previously throughout the literature, studies have reported on the economic consequences related to lameness or specific claw disorders causing lameness (Bruijnis et al., 2010, Ettema et al., 2010). Ettema et al. (2010) estimated the economic loss associated with lameness to be up to $€ 192$ per cow per year, while Bruijnis et al. (2010) estimated the cost of specific claw disorders to be $€ 53$ per cow. There have been relatively few studies examining the impact of imperfect and impaired suboptimal mobility, especially in spring calving, pasture-based systems, like those typically seen in Ireland. This thesis focusses on understanding suboptimal mobility in pasture-based systems. 


\section{Suboptimal mobility in spring calving, pasture-based systems the case of Ireland}

Ireland enjoys temperate climate conditions and fertile soils, which create ideal conditions for producing large quantities of pasture (Shalloo et al., 2004). For that reason, typically dairy production in Ireland is predominantly based on a spring calving, pasture-based systems. The main aim in such a system is to manage the interface between peak cow milk production and peak grass growth (Dillon et al., 2005), which is achieved by synchronizing herd feed demands with grass growth (Horan et al., 2005). In such a system, the majority of milk produced comes from grazed grass keeping costs of production low. As a result, these systems aim to achieve a compact calving pattern at the onset of grass growth (February through April), whereby over $70 \%$ of cows calve between January and March (Irish Cattle Breeding Statistics, 2018). In this system cows are turned out to pasture directly after calving and remain outside grazing for the summer and autumn months, and are partially or fully housed during the winter months (December to January). A key focus of systems of milk production systems like this is cost control.

According to Somers and O'Grady (2015) there is a perception that suboptimal mobility is less of a problem in pasture-based systems (like those in Ireland), compared to zero-grazing systems (Olmos et al., 2009). This perception is backed up throughout the literature, whereby Chapinal et al. (2013) reported that access to pasture during the dry period was associated with a decreased prevalence of lameness (referring to a cow with a score $\geq 3$ using a fivepoint scale). Other studies have also reported that claw and limb health is better for cows with access to pasture compared to cows in confinement type systems (Burow et al., 2012, Armbrecht et al., 2019).

In recent years, particularly after the removal of the European Union milk quota restriction were lifted in April 2015, expansion of the average national dairy herd has been evident. Dillon (2017) showed that the average herd size had increased from 45 cows in 2005 to 84 cows in 2018. Coupled with this, has been a major increase in milk production for both milk volume and milk constituents, resulting in an even greater increase in milk solids production (Department of Agriculture, Food and the Marine (DAFM), 2018). Expansion so far has been achieved by a combination of many factors, including; advancements in dairy cow genetics and greater levels of grassland management (Shalloo et al., 2014) and an increase in land area under dairying (Hanrahan et al., 2018). However, there is a perceived concern among veterinarian professionals that further intensification through herd expansion could pose challenges for cow welfare, particularly related to a potential increased risk of sub optimal mobility (Mee et al., 2019) with cows walking longer distances within bigger herds.

While it is widely accepted that access to pasture is beneficial for reducing the risk for a cow to have suboptimal mobility (Hernandez-Mendo et al., 2007, Olmos et al., 2009, Chapinal et al., 2013), pasture-based cows are by default associated with longer walking distances, potentially on poor roadway conditions (Hund et al., 2019) and are often herded mechanically increasing the walking speed beyond desirable. Therefore, keeping the prevalence of 


\section{0 | Chapter 1}

suboptimal mobility low should be at the forefront of the aim of pasture based systems from an economic and animal welfare perspective.

Although the prevalence of severe forms of severe suboptimal mobility within herds managed in pasture-based systems may be lower (Chapinal et al., 2013, Somers and O'Grady, 2015), the prevalence of mild to moderate forms of suboptimal is not well known. Similarly, the association between these claw disorders and severe mobility issues has been reported on, but there is a knowledge gap throughout the literature in terms of the potential associations between mild forms of these claw disorders and mild forms of suboptimal mobility (i.e., imperfect and impaired mobility). This is especially the case for pasture-based systems where the association between presence, type, and severity of claw disorders and mobility scores has not been investigated.

As discussed above, there are various types of risk factors previously shown to be associated with severe types of mobility issues, particularly in non-pasture-based systems, or during the winter housing period for pasture-based systems. Up to now there is a gap in the knowledge regarding the potential risk factors associated with varying levels of suboptimal mobility during the grazing period for pasture-based systems.

As well as this, the impacts on milk yield, culling, and the economic consequences of suboptimal mobility within pasture-based systems are also less studied throughout the literature. Hence, due to such pasture-based systems being dependent on low inputs and cost control to maximize profitability, it is paramount to minimize sub optimal mobility within herds.

\section{General aim and outline of the thesis}

The general aim of this thesis is to understand suboptimal mobility in spring calving, pasturebased dairy systems, with a focus on risk factors, production performance and the economic consequences. The outline for this thesis is illustrated in Figure 2. In chapter 2, cow level traits, including the presence and severity/absence of specific claw disorders, body condition score (BCS), and cow parity were examined for their association with specific mobility scores. In chapter 3, a risk factor analyses was completed to determine both the cow and herd level risk factors associated with the prevalence of suboptimal mobility among cows and within herds. In chapter 4, the production effects (including; milk yield and somatic cell count), the reproductive effects (including calving interval length), and the culling effects of suboptimal mobility were analysed. In chapter 5 a predictive sub model was developed to predict mobility scores in a typical Irish spring calving, pasture-based dairy farm. This model was then utilized to determine the economic consequences of varying prevalence of mobility scores with herds. Finally, in chapter 6 results from the previous four chapters are discussed in relation to each other and linking these results to wider implications for the dairy sector. 
General introduction | 11

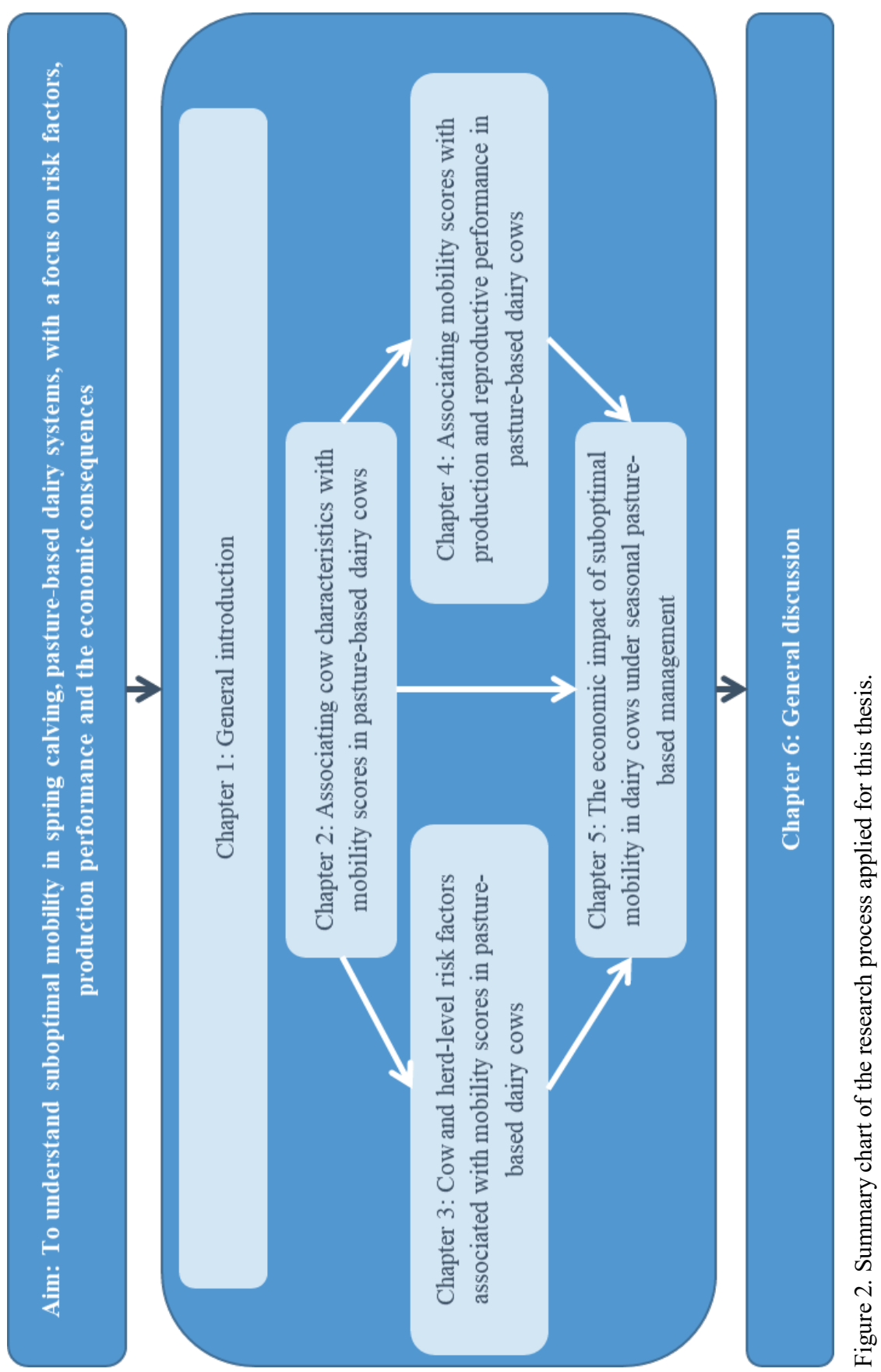




\title{
Chapter 2
}

\section{Associating cow characteristics with mobility scores in pasture-based dairy cows}

\author{
A. H. O’Connor, ${ }^{*} \dagger$ E. A. M. Bokkers, $\uparrow$ I. J. M. de Boer, $\dagger$ H. Hogeveen, + R. Sayers*, N. \\ Byrne,* E. Ruelle,* and L. Shalloo* \\ * Teagasc, Animal and Grassland Research and Innovation Centre, Moorepark, Fermoy, Co. \\ Cork, Ireland \\ $\dagger$ Animal Production Systems group, Department of Animal Sciences, Wageningen \\ University \& Research, the Netherlands \\ \$ Business Economics group, Department of Social Sciences, Wageningen University \& \\ Research, the Netherlands
}

Journal of Dairy Science 102 (2019) 8332-8342 


\title{
14 | Chapter 2
}

\begin{abstract}
The quality of dairy cow mobility can have significant welfare, economic, and environmental consequences which have yet to be extensively quantified for pasture-based systems. The objective of this study was to characterise mobility quality, by examining associations between specific mobility scores, claw disorders (both the type and severity), body condition score (BCS) and cow parity. Data were collected for 6,927 cows from 52 pasture-based dairy herds, including; mobility score $(0=$ optimal mobility, 1,2 , or $3=$ increasing severities of sub-optimal mobility), claw disorder type and severity, BCS and cow parity. Multinomial logistic regression was used for analysis. The outcome variable was mobility score and the predictor variables were BCS, type and severity of claw disorders, and cow parity. Three models were run, each with one reference category (mobility score 0,1 , or 2). Each model also included claw disorders (overgrown claw, sole hemorrhage, white line disease, sole ulcer, and digital dermatitis), BCS, as well as cow parity as predictor variables. The presence of most types of claw disorders had odds ratios $>1$ indicating an increased likelihood of a cow having sub-optimal mobility. Low BCS (BCS < 3.00) was associated with an increased risk of a cow having sub-optimal mobility, and cows with relatively higher parity were also associated with an increased risk of sub-optimal mobility. These results confirm an association between claw disorders, BCS, cow parity, and dairy cow mobility score. Therefore, mobility score should be routinely practiced to identify cows with slight deviations from the optimal mobility pattern, to ensure preventative measures can be taken to avoid the problem worsening.
\end{abstract}

Keywords: lameness, claw disorder, body condition, parity, grass-based system 


\section{INTRODUCTION}

Worldwide, sub-optimal mobility in dairy cows is considered to be among the most significant disease challenges throughout the dairy industry (Huxley, 2012). Sub-optimal mobility is a major animal welfare concern, due to the associated pain (e.g., Rushen, 2001, O'Callaghan, 2002), and a substantial cause of economic concern, due to sub-optimal mobility being the third most important health-related economic loss, after fertility and mastitis (Bruijnis et al., 2010, Huxley, 2013). In north-west European pasture-based systems, whereby cows are housed during the winter months but are managed at pasture for the remainder of the year, sub-optimal mobility is often overlooked due to a perception that the quality of dairy cow mobility is better than for cows in non-pasture systems (Somers and O'Grady, 2015). The incidence of sub-optimal mobility, however, has been shown to be similar in both grazing and non-grazing systems (Olmos et al., 2009). This is most likely due to grazing cows being exposed to different risks for sub-optimal mobility compared to nongrazing cows. Cows in pasture-based systems, for example, are exposed to elements identified as risk factors like poor quality roadway surfaces, longer walking distances to the milking parlour (O' Doherty et al., 2014) and poor herding skills/management practices (Westwood et al., 2003), whereas cows managed in non-pasture-based systems are exposed to elements identified as risk factors like slatted concrete flooring and continuous exposure of claws to slurry (Cook et al., 2004).

It is well known that claw disorders are a major risk to dairy cow mobility and account for the majority of all cases of severe mobility problems (Murray et al., 1996). Literature shows, for example, that the likelihood of many claw disorders (e.g., sole hemorrhage, white line disease, digital dermatitis and other disorders) causing mobility problems, such as lameness, is larger in non-pasture than in pasture-based systems (Olmos et al., 2009). The association of claw disorders with less severe forms of mobility problems, however, has been less extensively researched. Especially in pasture-based systems, the association between presence, type and severity of claw disorders and mobility score has not been investigated so far. Studies that do address these associations in non-pasture based systems mainly focus on lameness. The term lameness, however, is not defined conclusively. For example, using the five point scoring method developed by Sprecher et al. (1997), a cow is often defined as lame when she is scored greater than or equal to three (Solano et al., 2015, Cook et al., 2016). Using the same scoring method, however, Olechnowichz and Jaskowski (2015) refer to a cow as lame when she is scored greater or equal to two. Other studies only refer to a cow as lame when her score is greater than or equal to four (Kovács et al., 2015). In this study, we use a specific mobility scoring system to describe varying levels of mobility quality rather than focussing on lameness.

The focus of this study is to better understand the quality of dairy cow mobility and the causes behind sub-optimal mobility using cow-level attributes, in pasture-based systems. Therefore, besides understanding the impact of claw disorders on mobility scores, we will also explore the impact of other parameters proven to be related to mobility, such as body condition score 


\section{6 | Chapter 2}

(BSC), and parity (Lim et al., 2015). We define sub-optimal mobility as 'any abnormality to a cow's gait which causes a deviation from the optimal walking pattern of a cow', i.e. any deviation that resembles any form of variation so that the cows' mobility can no longer be classified as optimal. Optimal mobility is defined in this study as perfect dairy cow mobility with no abnormalities. Optimal versus sub-optimal is not to be interpreted the same as clinical versus sub-clinical, often used throughout the literature to describe abnormal mobility (Green et al., 2002). 'Clinical' and 'sub-clinical' can refer to diseases severe enough that they are either associated or not associated with some form of (re)productive losses, whereas, 'optimal' and 'sub-optimal'(Cambridge dictionary online., 2008) refer only to the quality of mobility relative to what is accepted as optimal for dairy cows. The severity of sub-optimal mobility can vary greatly from slight deviations from normal gait and walking pattern to severe immobility and inability to bear weight on a limb causing difficulty when walking (Beusker, 2007).

Therefore, the objective of this study was to more specifically characterise mobility scores by determining their association with cow-level attributes, namely; the presence, type and severity of claw disorders, BCS, and cow parity.

\section{MATERIALS AND METHODS}

\section{Cow Data}

Data for 11,472 cows from 68 pasture-based dairy herds located in the Munster region of Southern Ireland were collected as part of a larger research project. The aim of the project was to collect hoof health traits from a large sample of cows, representative of the Irish dairy population, for the estimation of variance components of hoof health for consideration in national genetic evaluations (Ring et al., 2018). The average herd size was 169 (standard deviation $=115$ ) cows. The main breed of the cows were $75 \%$ Holstein, $13 \%$ Jersey, and $9 \%$ Friesian breeds, which is representative of the national population (Ring et al., 2018). Cow parity records were only available for 6,927 of the total number of cows. Herds were selected for inclusion in the study based on the following criteria; 1) maximum of $100 \mathrm{~km}$ from Teagasc, Moorepark in Fermoy, 2) must be registered to the Irish Cattle Breeding Federation (ICBF) milk recording system, 3) herd owners must be willing to have their herd genomically tested, and 4) must be operating a pasture-based system. The Irish pasture-based system refers to one in which cows are turned out to pasture post calving during the spring once ground conditions allow, (whereby over $70 \%$ of cows calve between January and March (Irish Cattle Breeding Statistics, 2018) and remain outside grazing for the summer and autumn months, and are partially/fully housed during the winter months (December to January). The mean calving date for the study population was 23/02/2015 (standard deviation equal to 24).Cows' calf to grass with supplementary feed offered post calving to individual cows. The system focus is not to maximize milk yield per cow but to manage the interface between the cow and the pasture with an ultimate balance to maximize intake while maximizing grass utilization (Dillon et al., 2005). A typical diet for a dairy cow in an Irish 
pasture-based system consists mainly of grazed-pasture, predominantly perennial rye grassbased (accounting for $60.2 \%$ of the dry matter intake (O'Brien et al., 2018), followed by concentrate feed, accounting for $19 \%$ of the diet on a dry matter basis (Hanrahan et al., 2018). The remainder of the typical diet is made up of grass silage and alternative forages (O'Brien et al., 2018).

\section{Mobility Score, BCS and Claw Disorder data}

Mobility Score and BCS. Each herd was visited twice by two trained technicians from Teagasc, Moorepark in 2015. The first visit was conducted in early lactation (March through May) and the second visit was conducted in late lactation (June through November). During each herd visit, every lactating cow was assessed for BCS (by one technician) and mobility score (by the other technician). Body condition of each cow was scored using both visual and tactile appraisal on a scale of 1 to 5 with 0.25 increments, as described by Edmonson et al. (1989). Mobility quality of each cow was scored using the UK Agriculture and Horticulture Development Board four point scale (https://dairy.ahdb.org.uk/technicalinformation/animal-health-welfare/lameness/husbandry-prevention/mobilityscoring/\#.WXnhULuFOr8), using the following definitions.

- A score of 0 describes a cow with optimal mobility that walks with even weight bearing and rhythm on all four feet, with a flat back. Long and fluid strides are possible.

- A score 1 describes a cow with imperfect mobility (any mobility score $>0$ is defined as sub-optimal mobility) with uneven steps or shortened strides affecting one or more limbs and it may not be immediately identifiable.

- A score 2 describes a cow with impaired mobility, which is a cow with uneven weight bearing on one or more limbs that is immediately identifiable and/or shortened strides, usually associated with an arched back.

- A score of 3 describes a cow with severely impaired mobility, a cow with this score is unable to walk as fast as the rest of the 'healthy' herd due to more severe symptoms compared to score 2 .

Claw Disorder data. On a separate (third) herd visit, claw-trimming professionals from one commercial company (Farm Relief Services (FRS), Roscrea, Co. Tipperary, Ireland) lifted both the hind claws of each lactating cow for identification and scoring of claw disorders in 52 of the total 68 herds; amounting to 7,602 cows examined during July through December 2015. The claw disorder data were collected mainly after the second farm visit. The range in dates for claw disorder data collection was from 14/07/2015 through $10 / 12 / 2015$, with an average date equal to 18/09/2015 (median date equal to 28/09/2015). The claw disorders were identified, recorded and severity scored by one of two Teagasc technicians (not the same technicians who scored BCS and mobility). Both technicians recorded a similar number of animals and a similar prevalence for each of the claw health 


\section{8 | Chapter 2}

traits, differing by only $4 \%$ on average (Ring et al., 2018). The claw disorders were identified using the claw atlas of the International Committee for Animal Recording (ICAR), 2015. A scoring method was developed whereby the claw disorders were scored based on visual severity of each disorder and where doubts occurred with severity scoring, the photos of the disorders (that were taken at the time of scoring) were used for clarification with the other technician. Two types of claw disorders were recorded by the assessors; 1) non-infectious and 2) infectious type claw disorders. The non-infectious type claw disorders recorded included: overgrown claw, white line disease, sole hemorrhage, and sole ulcer, while just one infectious type claw disorder was recorded: digital dermatitis. See Table 1 for a description of each claw disorder. Overgrown claw, sole hemorrhage, and white line disease were each severity scored using a scale ( 0 through 3 ), whereby $0=$ not affected (no visual evidence of the disorder present), $1=$ mildly affected (visual evidence of the disorder present in a mild form), $2=$ moderately affected (visual evidence of the disorder present in a moderate form), and 3 = severely affected (visual evidence of the disorder present in a severe form). Sole ulcer and digital dermatitis were scored as binary traits (i.e., $0=$ not affected (no visual evidence of the disorder present) or $1=$ affected (visual evidence of the disorder present in any form). After scoring, the claw trimmer treated the claws if necessary. 
Table 1. Descriptions used by the assessors to identify claw disorders

\begin{tabular}{lll}
\hline Claw Disorder & Type & Description \\
\hline Overgrown claw & Non-infectious & $\begin{array}{l}\text { Significant difference in width, height and/or length } \\
\text { between outer and inner claw which cannot be balanced } \\
\text { by trimming }\end{array}$ \\
White line disease & Non-infectious & $\begin{array}{l}\text { The sole separates from the side wall of the claw and } \\
\text { foreign material then penetrates. Separation of the } \\
\text { white line which remains after balancing both soles }\end{array}$ \\
Sole hemorrhage & Non-infectious & $\begin{array}{l}\text { Clear differentiation between discoloured and normal } \\
\text { coloured horn }\end{array}$ \\
Sole ulcer & Non-infectious & $\begin{array}{l}\text { Penetration through the sole horn exposing fresh or } \\
\text { necrotic corium/ulcer located at the toe } \\
\text { Infection of the digital and/or interdigital skin with } \\
\text { erosion, mostly painful ulcerations and/or chronic } \\
\text { hyperkeratosis/proliferation. }\end{array}$ \\
\hline
\end{tabular}




\section{Data Management}

There were 52 herds amounting to a total number of 6,927 cows (average herd size was 163 cows and standard deviation equal to 111) used in the analyses (Figure 1). Of the original 11,472 cows from 68 farms (average herd size 169 cows and standard deviation equal to

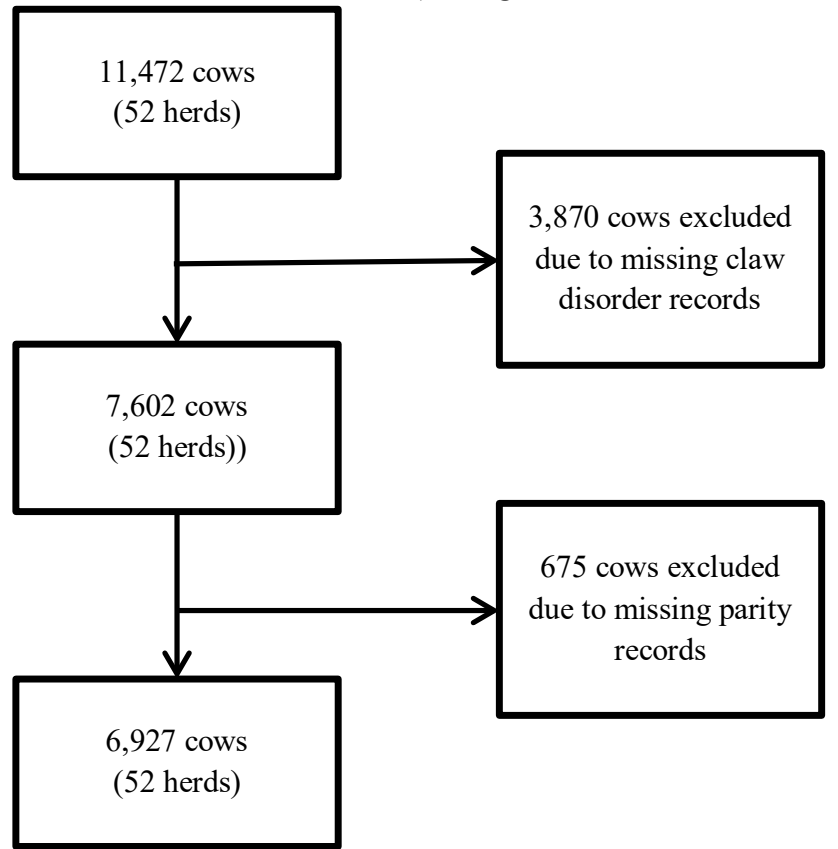

Figure 1 Flow chart illustrating the number of cows deleted from the original data set.
115), 3,870 were excluded from the analyses (leaving 7,602 cows) as no claw disorder data (claw disorder presence and severity) was present. No difference in herd attributes is known by the authors between the subset of 52 herds and the original 68 herds, claw disorder data were only collected from 52 herds due to time and budget constraints. A further 675 cows were excluded from the analyses (leaving 6,927 cows) as no cow parity data was available for these cows. Two mobility scores and two BCSs were recorded for each

cow, with just one of each being included in the analyses. The specific mobility score and BCS used in the analyses were chosen based on the specific date the first and second herd visit occurred relative to the third herd visit. The first herd visit was in early lactation, and the second herd visit was in late lactation, both for mobility score and BCS data collection. The third herd visit (for claw health data collection) might be between visit one and two, or after visit two. For example; cow "A" had her mobility score and BCS recorded twice, both during the early lactation herd visit on $3^{\text {rd }}$ March 2015 and during the late lactation visit on 8th July 2015. This same cow had her hind claws lifted and recorded for the presence and the severity of any claw disorder present during the third herd visit on $21^{\text {st }}$ July 2015 . For this example, the recorded mobility score and BCS used in the analysis were the scores taken on 8th July 2015 (the late lactation visit) because they were closer in time to the third and final visit. Another example, cow "A" had her mobility score, and BCS recorded only once, namely during the early lactation herd visit on $3^{\text {rd }}$ March 2015. Her mobility score and BCS are not available for the second herd visit, during the late lactation period, possibly because she was removed from the herd. For this instance, obviously the available mobility score and $\mathrm{BCS}$ are used irrespective of the date that her claws were lifted and recorded for the presence and severity of any claw disorders. The mean date for mobility score and BCS used in the 
analysis was 22/07/2015 with a standard deviation equal to 49 days. The time difference (in days) between, the date on which mobility score and BCS data were collected, and the date on which claw disorder data were collected ranged, whereby the recording of claw disorder data were collected up to 29 days prior to or 252 days after the recording of mobility score and BCS data with a mean equal to 58 days and a standard deviation equal to 51 .

\section{Statistical Analysis}

Analyses were performed using the R statistical software (R Development Core Team, 2009; function 'multinom' for multinomial logistic regressions).

Mobility Score, BCS, claw disorders and Cow Parity. The associations between the predictor variables (BCS, specific claw disorders (presence and severity score), and cow parity) on mobility score (outcome variable) were assessed using a forward stepwise regression approach. Each individual predictor variable was modelled first alone (a univariate analysis) to predict mobility score, and as each predictor variable was statistically significant $(\mathrm{P}<0.05)$, they were all kept and included in the final model (a multivariate model (Hosmer and Lemeshow, 1989)). Multinomial logistic regression was used to model nominal outcome variables, in which the log odds of the outcomes are modelled as a linear combination of the predictor variables. The outcome variable was mobility score (a categorical variable). The predictor variables were BCS (a categorical variable, put into three groups, which are; BCS $<3.00, \mathrm{BCS}=3.00$, and $\mathrm{BCS}>3$ i.e., less than the median, the median and greater than the median BCS), the presence and severity of each claw disorder, (a categorical variable), and cow parity 1,2, or $3+$ (a categorical variable). The time difference in days (a continuous variable) between the visit for mobility score and BCS recording, and the visit for claw disorder recording was included as a confounding factor in the model. Farm was included in the model was a random effect. Output variables were analysed with multinomial logistic regressions. The assumption of proportional odds was tested for the data and was violated, thus multinomial logistic regression was used, assuming no order in the categories. Three multinomial logistic regression models were run with the same predictor and confounding variables, one model used mobility score 0 as a reference category, a second model used mobility score 1 as a reference category, and a third model used mobility score 2 as a reference category. In each of the three regression analyses, three of the four output categories (mobility score $0,1,2$, or 3 ) were compared to a different reference category (mobility score 0,1 , and 2). In all three regression analyses, all of the claw disorders, BCS and cow parity were included as predictor variables. The association between the reference categorical outcome variables with three other categorical outcome variables (e.g., mobility score 1, 2, or 3 in reference to mobility score 0 ), and with the predictor variables was expressed as odds ratios. The interpretation of odds ratios differs when considering categorical predictor variables and continuous predictor variables. For the categorical predictor variables (claw disorder presence and severity, cow parity, and BCS) an odds ratio $>1$ indicates that an increase in the predictor variables increases the risk of occurrence of a specific category 


\section{Chapter 2}

rather than the occurrence of the reference category, whereas an odds ratio $<1$ indicates than an increase in the predictor variable decreases the risk of occurrence of a specific category rather than the occurrence of the reference category. For the continuous predictor variable (time difference (in days) between the first farm visit when mobility score and BCS were recorded and the second farm visit when claw disorders were recorded and severity scored), an odds ratio $>1$ indicates that a one-unit increase in the predictor variables increases the risk of occurrence of a specific category rather than the occurrence of the reference category, whereas an odds ratio $<1$ indicates than a one-unit increase in the predictor variable decreases the risk of occurrence of a specific category rather than the occurrence of the reference category. An odds ratio $=1$ indicates that the outcome is the same for all mobility scores. For example, in a multinomial logistic regression predicting the occurrence of mobility score 1 , 2,3 , or the occurrence of the reference category mobility score 0 , an odds ratio (for mobility score 3 vs. mobility score 0 ) $>1$ indicates an increase in the risk of occurrence of mobility score 3 rather than mobility score 0 in these multinomial models, the reference category is thus important for the interpretation of the results, bearing in mind the reference category can be altered to reduce bias interpretations from the results. Predicted probabilities for mobility score were used to assess model fit by visual comparison with observed data (Gelman et al., 1996) and using the Hosmer-Lemeshow test statistic (Hosmer and Lemeshow, 1989). This test compares how well the observed data matches the predicted probabilities calculated from the model. Results from the test $(\mathrm{P}>0.05)$ indicated good model fit.

\section{RESULTS}

\section{Mobility Score, Body Condition Score, and Cow Parity}

Figure 2 presents the distribution of mobility score (a), BCS (b) and cow parity (c) for all cows analysed. Of all cows, $38 \%$ were scored as 1, 2, or 3 for mobility, and thus defined as sub-optimally mobile. The BCS followed a normal distribution with $91 \%$ of all the cows falling within the range of 2.75 through 3.25 . Cow parity ranged from 1 through 13 , with $30 \%$ in parity $1,21 \%$ in parity $2,49 \%$ in parity 3 or greater.

\section{Claw Disorder prevalence}

The distributions of severity scores for each claw disorder for all cows are presented in Figure 2, specifically for overgrown claw (d), sole haemorrhage (e), white line disease (f), sole ulcer (g), and digital dermatitis (h). Cows were on average 207 days (standard deviation equal to 53 ) in milk when claws were assessed. Non-infectious claw disorders (overgrown claw, sole hemorrhage, white line disease and sole ulcer) were the most prevalent; with $84.5 \%(5,850)$ of all cows severity scored $>0$ for having at least one of these disorders, further referred to as the non-infectious claw disorder group. Of the non-infectious claw disorder group $(5,850$ cows), sole hemorrhage was the most prevalent, with 3,639 of the non-infectious group severity scored $>0$, followed by overgrown claw, with 3,537 of the non-infectious group 
severity scored $>0$, then white line disease, with 3,420 of the non-infectious group severity scored $>0$, and finally sole ulcer, with just 80 of the non-infectious group severity scored $>$ 0 . Digital dermatitis was found in $194(2.8 \%)$ of the cows. The remaining cows $(1,044$ or $15.1 \%$ ) had none of the assessed claw disorders on the day of recording.

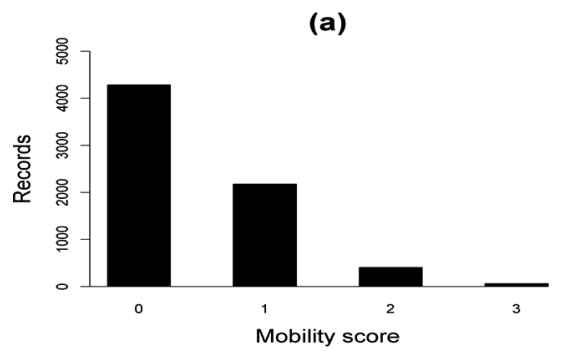

(c)

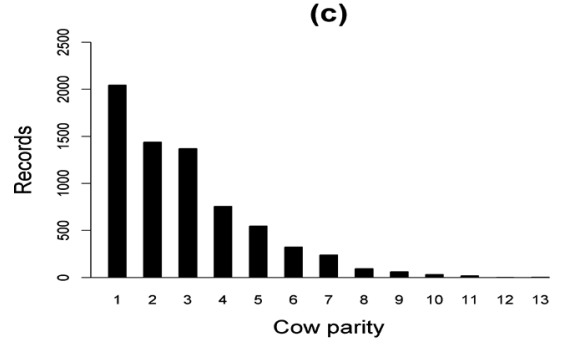

(e)

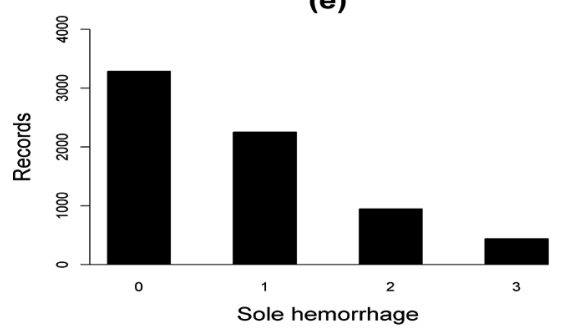

(g)

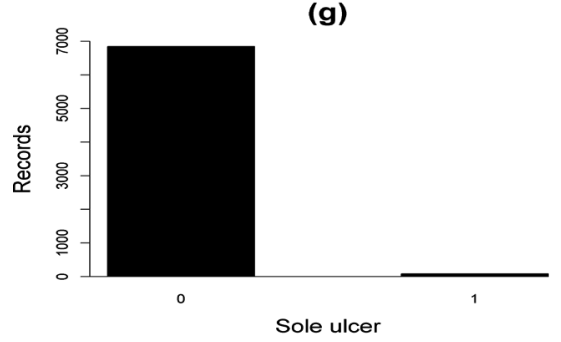

(b)

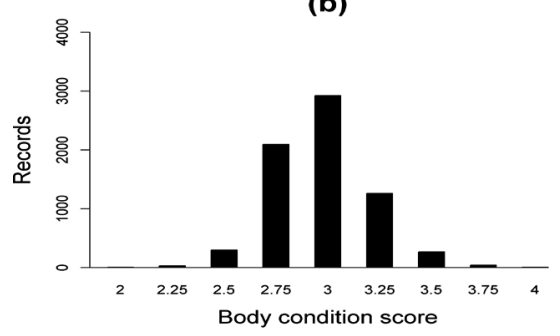

(d)

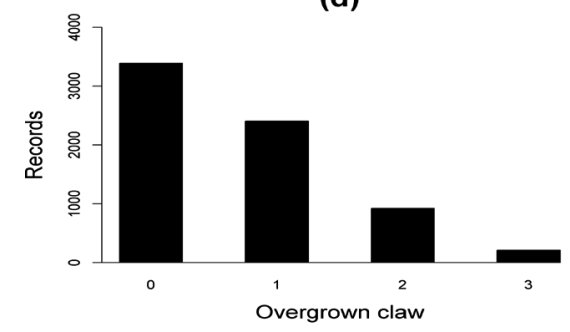

(f)

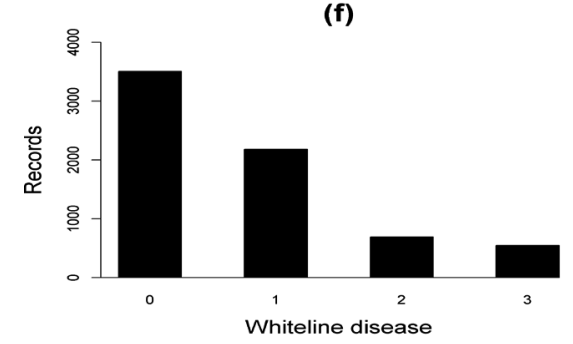

(h)

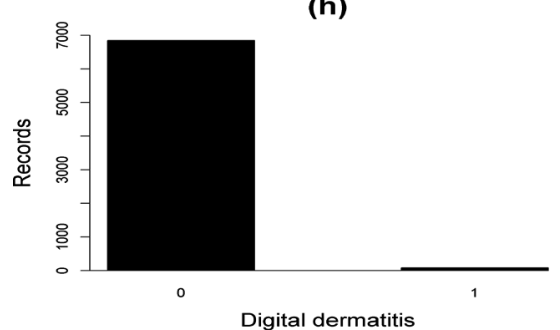

Figure 2. Distribution of (a) mobility scores (scale 0 through 3), (b) body condition score (scale 1 through 5), (c) cow parity, (d) overgrown claw, (e) sole hemorrhage, (f) white line disease, (g) sole ulcer, and (h) digital dermatitis. 


\section{Mobility Score, BCS, Claw disorders, and Cow Parity Associations}

Claw Disorders; Model Reference Category-Mobility Score 0. When the risk of being in mobility score 1 versus the reference category mobility score 0 was evaluated, the odds ratios for all severities of overgrown claw, sole hemorrhage and white line disease (severity scored 1, 2, or 3), sole ulcer, and digital dermatitis (severity score 1) were consistently $>1$. This indicates that not only do all severities of each claw disorder increase the risk of occurrence of a cow being scored mobility score 1 versus mobility score 0 , but also, that even the mild forms of these claw disorders (severity score 1 for overgrown claw, sole hemorrhage, and white line disease) increased the risk of occurrence of mobility score 1 rather than mobility score 0 (Table 2). When the risk of being in mobility score 2 versus the reference category mobility score 0 was compared, moderate (severity score 2 ) and severe forms (severity score 3), of overgrown claw, severe forms (severity score 3) of sole hemorrhage, all severities (severity score 1, 2, and 3) of white line disease had odds ratios $>1$, indicating an increased risk for the occurrence of mobility score 2 rather than mobility score 0 (Table 2). When the risk of being in mobility score 3 versus the reference category mobility score 0 was compared, only the severe forms of overgrown claw and white line disease (severity score 3 ) had significant odds ratios (odds ratios $>1$ ) (white line disease severity score 1 and 2 had a tendency for odds ratio values $>1$ ), indicating an increased risk for the occurrence of mobility score 3 rather than mobility score 0 associated with cows that had these specific severities of these claw disorders. The mild and moderate forms (severity score 1 and 2) of overgrown claw and white line disease, and all forms (severity score 1, 2, and 3) of sole hemorrhage did not have an impact when comparing the risk of occurrence of mobility score 3 versus mobility score 0 (Table 2 ).

The binary severity scored claw disorders were sole ulcer (non-infectious type) and digital dermatitis (infectious type). The odds ratios for both sole ulcer and digital dermatitis had relatively greater odds ratios compared to the other claw disorder, across all levels of mobility $(1,2$, and 3 ) versus the reference category mobility score 0 (Table 2 ).

Claw Disorders; Model Reference Category-Mobility Score 1. When the model was run with the reference category mobility score 1 (Table 2), the results in terms of odds ratios indicated (i.e., odds ratios $>1$ ) that overgrown claw severity scores 1, 2, and 3, sole hemorrhage severity score 1 (and a tendency for sole hemorrhage severity score 3 ), and white line disease severity score 2 and $3 \mathrm{had}$ an increased risk for the occurrence of mobility score 2 rather than the occurrence of the reference category, mobility score 1 . When comparing mobility score 3 versus the reference category mobility score 1, overgrown claw severity score 3 , and white line disease severity score 3 resulted in odds ratios $>1$, indicating an increased risk for the occurrence of mobility score 2 rather than mobility score 1 . Sole ulcer and digital dermatitis had odds ratios $>1$ when comparing the risk of occurrence for mobility score 2 , and 3 versus the reference category mobility score 1 in (Table 2).

Claw Disorders; Model Reference Category - Mobility Score 2. When the model was run with the reference category mobility score 2 (Table 2), white line disease severity 
score 1 increased the risk of occurrence of mobility score 3 versus mobility score 2 and overgrown claw severity score 3 had a tendency for an increased risk in mobility score 3 compared to the reference category. Digital dermatitis was associated with increasing the risk of occurrence of mobility score 3 versus mobility score 2, while sole ulcer had a tendency for an increased risk of occurrence of mobility score 3 versus mobility score 2 (Table 2)

Body Condition Score. The odds ratios for BCS across all models (except the model run whereby mobility score 2 is the reference value) were consistently $<1$ (Table 2) indicating that; (1) cows with a high $\mathrm{BCS}(\mathrm{BCS}=3.00$ and $\mathrm{BCS}>3.00)$ are associated with a decreased risk of occurrence of mobility score 1,2, and 3 rather than the reference category (mobility score 0), compared to cows with a BCS < 3; (2) cows with a high BCS are associated with a decreased risk of the occurrence of mobility score 2 and 3 rather than the reference category, mobility score 1 ; and (3) cow with a $\mathrm{BCS}=3.00$ have a tendency for a decreased risk for being mobility score 3 rather than the reference category, mobility score 2.

Cow Parity. Cow parity was also included in the model as a predictor variable for mobility. The odds ratios for cow parity across all models were mainly $>1$ (Table 2) indicating that (1) parity 2 and $3+$ cows are associated with an increased risk of the occurrence of mobility score 1 and 2, and just parity $3+$ cows are associated with an increased risk of occurrence of mobility score 3 , rather than the reference category mobility score 0 (compared to parity 1 cows); (2) parity $3+$ cows are associated with an increased risk of occurrence of mobility score 2, and a tendency for an increased risk of occurrence of mobility score 3, rather the reference category, mobility score 1 (compared to parity 1 cows); and (3), parity was not significant in the model with mobility score 2 as the reference category.

Days between farm visits. The number of days between the farm visit when mobility score and BCS were recorded and the farm visit when claws were assessed was included in the model as a confounding effect. The odds ratios for this variable are consistently between 0 and 0.99 , resulting in odds ratio values equal to 1.00 (rounded to two decimal places) indicating that the outcome of this variable is the same for all levels of mobility score. 
26 | Chapter 2

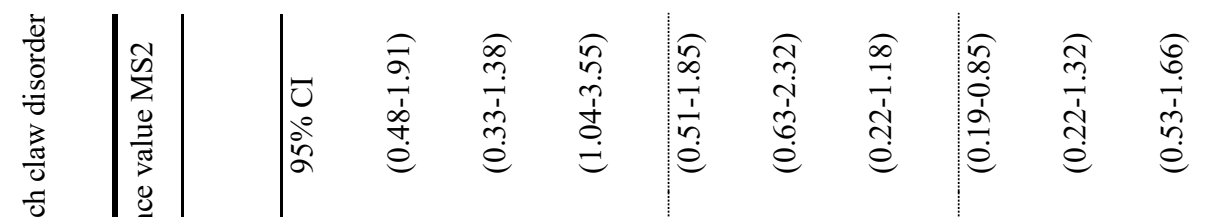

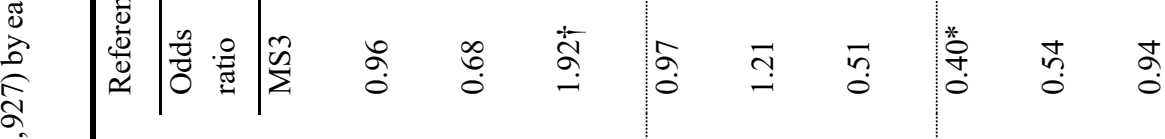

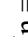

总

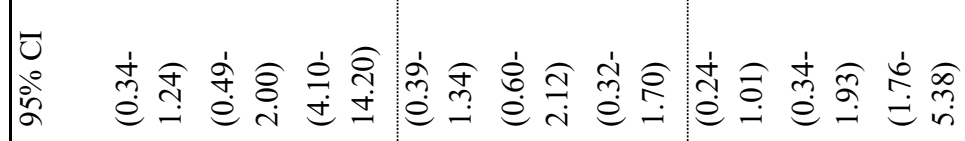

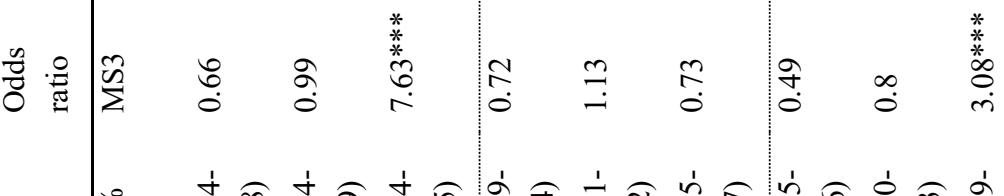

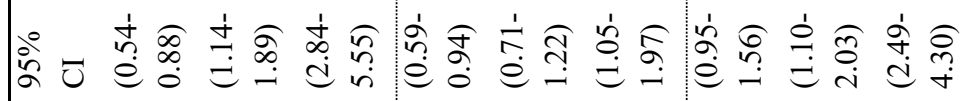

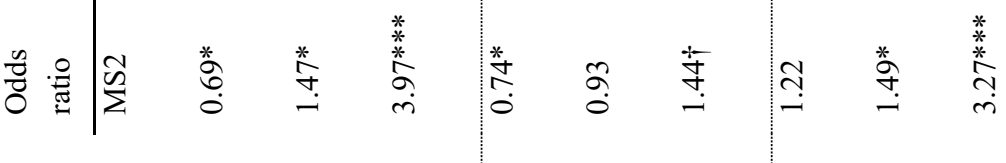

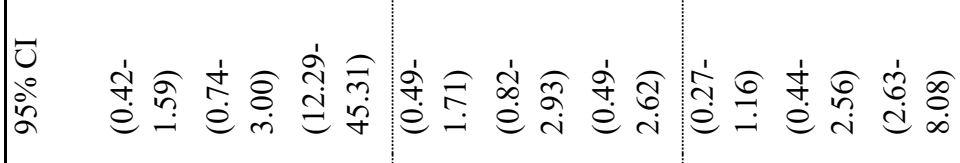

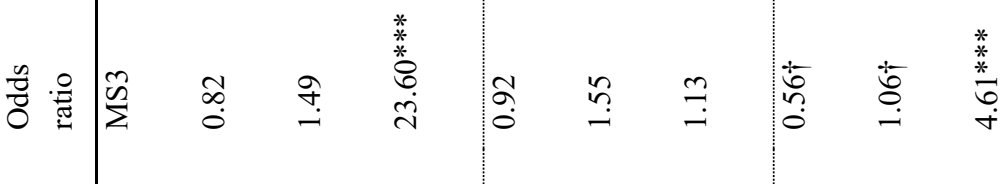

t

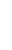

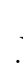

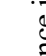

这

ठำ

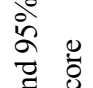

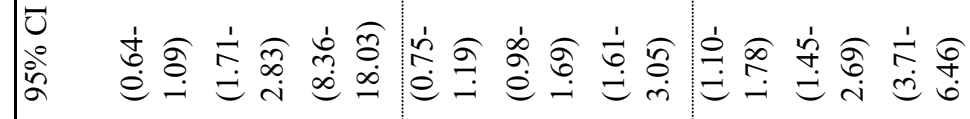

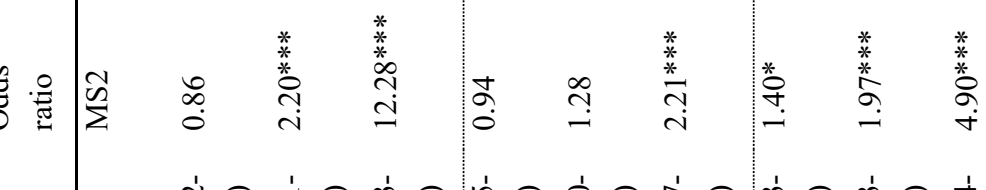

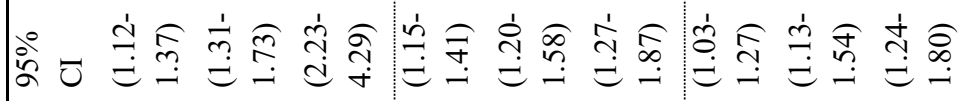
惫

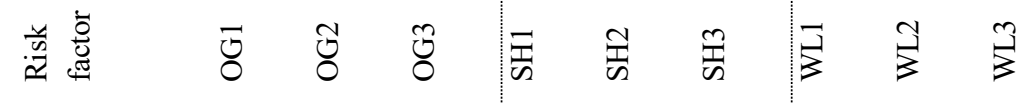


Claw disorders \& Mobility scores $\mid 27$

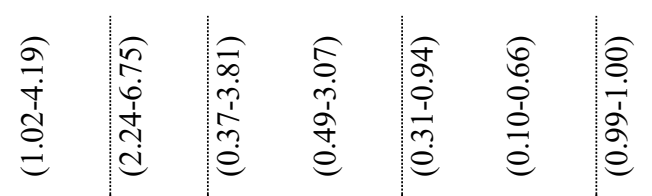

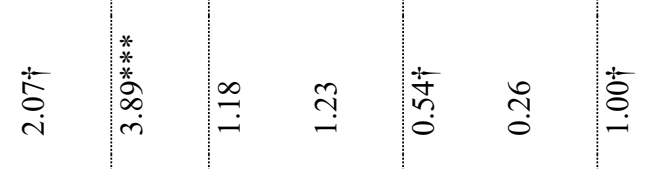

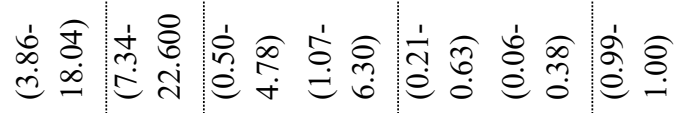

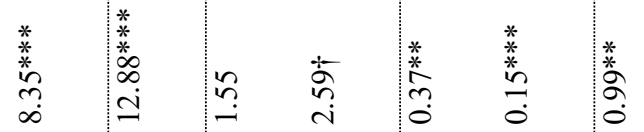

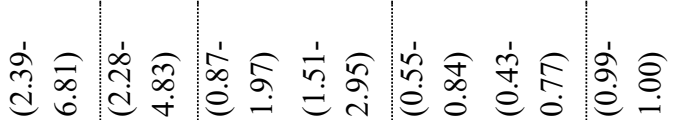

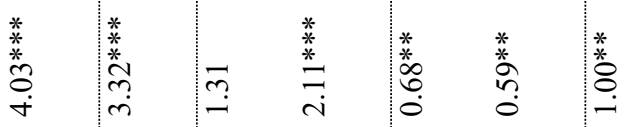

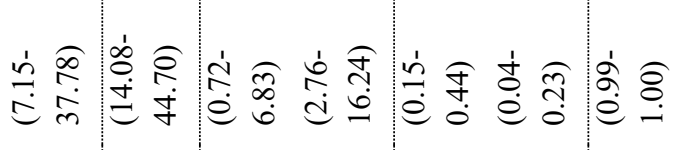

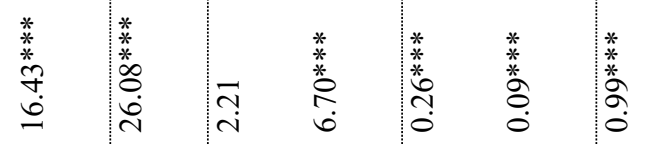

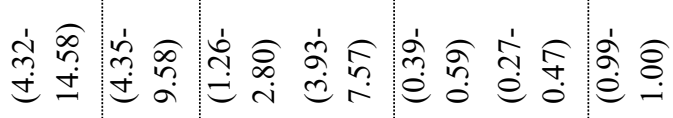

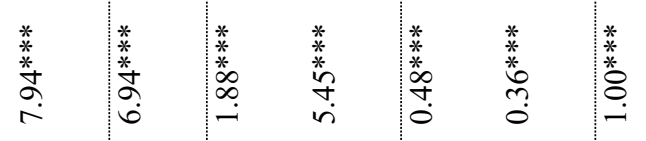

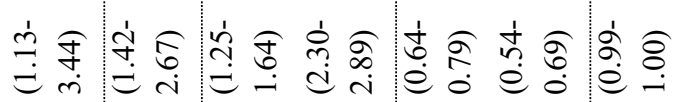

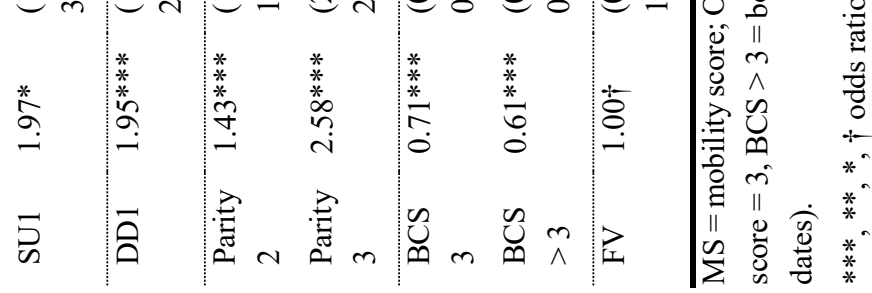




\section{DISCUSSION}

\section{Claw Disorders}

Non-infectious claw disorders were by far the most prevalent, for the cows included in this study, wherein about $85 \%$ of all the cows had some form of non-infectious claw disorder (a severity score $>0$ for an overgrown claw, sole hemorrhage, white line disease, and/or sole ulcer) on the day they were recorded. The prevalence of non-infectious claw disorders is relatively higher to what is reported throughout the literature. This high prevalence is most likely due to the method of data collection used in this study, wherein, claw disorders were recorded using a severity score, which resulted in extremely mild cases of claw disorders being recorded as disorders. Other studies may have overlooked these mild forms of claw disorders. This is in agreement with another study based on dairy cows in similar type pasture-based systems (Somers and O'Grady, 2015). The infectious claw disorder digital dermatitis only affected $2.8 \%$ of all the cows. It is widely accepted that infectious type claw disorders are less prevalent in pasture-based systems compared to confinement systems, primarily due to the cows being exposed to different environments and risks, i.e. cows in zero-grazing systems have increased exposure of their claws to slurry, thus develop different types of claw disorders (Cook et al., 2004).

Ideally, mobility score, BCS and claw disorders would have been scored and recorded on the same day, by the same people, however this was not possible due to time and budget constraints. An interesting finding from this study was that the claw disorders with severity score 1, such as overgrown claw, sole hemorrhage, and white line disease all increased the risk of occurrence of mobility score 1 versus mobility score 0 . Mobility score 1 in this study is essentially a cow with imperfect gait, thus these cows are generally not picked up as being lame, due to the mild nature of their 'imperfect' mobility. Whereas mobility score 2 or above is more likely to be what is described as 'lame' in many other studies. Thus, the results of this study found that mildly scored claw disorders are associated with mobility score 1 (cows with imperfect mobility). It is important to note, that the level of mobility associated with 'mobility score 1' described in this study is likely to be equivalent to the level of mobility that would not have been reported in many other studies. This is because more often than not, only severely sub-optimally mobile cows (often referred to as clinically or visually lame cows) are reported throughout the literature (Norring et al., 2014). This finding could be similar to the findings reported by Manske et al. (2002) and O'Callaghan (2002) wherein an association between "non-lame" cows and claw disorders were reported. On the flip side, it was similarly interesting to note that severely scored versions of the same claw disorders (severity scores 2 and 3 of overgrown claw and white line disease), increase the risk of occurrence of mobility score 3 versus 0 , but the mild forms (severity score 1 ) did not increase the risk of occurrence of mobility score 3 versus 0 . This finding indicates that the severity of the claw disorder has a direct association on mobility score, therefore, mildly severity scored claw disorders (severity score $1 / 2$ ) are not associated with severe sub-optimal mobility

(mobility score 3 ) but are associated with mild sub-optimal mobility (mobility score 1 ). In 
other words, cows with an overgrown claw severity score 3 have an increased risk of being classed as mobility score 3 instead of mobility score 0 , but do not have a significant increased risk for being classed as mobility score 1 instead of 0 . Therefore, it could be anticipated that the associated effects would follow a similar pattern.

In terms of the odds ratios for the various severities of the claw disorders included in the analysis, a trend was apparent, whereby the more severely scored claw disorder's (overgrown claw, sole hemorrhage, and white line disease) have odds ratios (for an increased risk of having sub-optimal mobility vs. optimal mobility) greater than their mildly scored forms. For example, for cows with an overgrown claw severity score 3 , the odds ratio is 3.09 , while the odds ratio for an overgrown claw severity score 1 is 1.24 , when comparing the risk of occurrence of mobility score 1 versus the reference category mobility score 0 . Similarly, when comparing the risk of occurrence of mobility score 2 versus mobility score 0 , the odds ratio is 12.28 for an overgrown claw severity score 3 , and is just 0.86 for an overgrown claw severity score 1 . When comparing the risk of occurrence of mobility score 3 versus mobility score 0 , the odds ratio for an overgrown claw severity score 3 is 23.60 , while the odds ratio for an overgrown claw severity score 1 is 0.82 . This increase in odds ratio associated with the severely scored forms of these claw disorders indicate the greater impact they have on the risk of occurrence of sub-optimal mobility in dairy cows in a pasture-based system.

Sole ulcer and digital dermatitis are both considered to be quite severe forms of claw disorders, associated with a substantial amount of pain and inability to bear weight on the affected limb(s) (International committee for animal recording (ICAR), 2015). The results from our study were in agreement with this inability to bear weight and increased pain, which may be associated with these more severe types of claw disorders. This is seen in our results, whereby, a cow with some form of sole ulcer or digital dermatitis had relatively greater odds ratios, compared to the other claw disorders, for an increased risk of having sub-optimal mobility (mobility score 1, 2, or 3 ) versus optimal mobility (mobility score 0 ). These results are similar to those reported by Manske et al. (2002), whereby, the risk of lameness was increased for a cow with a sole ulcer and or digital dermatitis.

\section{Body Condition Score}

The results presented in Table 2 provide evidence that a relatively low BCS is associated with the increased likelihood of the occurrence of sub-optimal mobility (mobility score 1, 2, and 3) versus optimal mobility (mobility score 0 ). These results are in agreement with findings of Green et al. (2014), who reported that a BCS of $<2.5$ was a risk factor particularly for non-infectious type claw disorders, which was by far the most prevalent type of claw disorders in the present study. Lim et al. (2015) reported that a loss of BCS increased a cow's probability of becoming identifiably lame and decreased her likelihood of recovery. This predisposition for cows with relatively lower BCS being classed as sub-optimally mobile could be explained by a low BCS being associated to a reduction in the depth of the digital fat cushion, which in turn is associated with sub-optimal mobility as a result of claw disorders 


\section{0 | Chapter 2}

(Bicalho et al., 2008). In contrast to the findings of this study, however, Lim et al. (2015) also reported that an increase in BCS increases the risk of becoming lame. Regular condition scoring of cows to allow for research into regular changes in BCS is urgently required in this field in order to fully understand the effect of variation in BCS and mobility score in dairy cows in pasture-based systems.

\section{Cow Parity}

The findings of this study indicate a clear association between increased cow parity and an increase in the risk of occurrence of sub-optimal mobility score versus optimal mobility score, across both types of models (Table 2). This is in agreement with the findings of Wells et al. (1993), whereby, parity was reported to be associated with 'clinical' lameness, (referred to as sub-optimal mobility in this study) 'with higher prevalence of clinical lameness' (similar to mobility score $\geq 2$ in this study) found in cows of higher parity. Interestingly, our study also showed an increase in the risk of occurrence of sub-optimal mobility even when comparing parity 1 cows to parity 2 cows in terms of odds ratios (Table 2).

\section{Model}

The model created for this study uses various cow health traits in order to characterise mobility score for dairy cows in pasture-based systems. The health traits used as predictors in this model include; claw disorders and their severity scores, BCS, and cow parity. The model created in this study is different to others, in that it uses dairy cow health traits in order to determine associations directly to a mobility score, rather than to a term such a 'lame/subclinically/clinically lame". This reduces the likelihood of misinterpretation of the results. This model could be included in other models, for example, to determine various impacts of production at each level of mobility.

\section{CONCLUSIONS}

From the findings of this study, we conclude that there is an association between claw disorders (including both type and severity) and mobility score in dairy cows in pasture-based systems, as well as an association between BCS, cow parity and mobility score. Mild severity scored claw disorders, such as overgrown claw, sole hemorrhage, and white line disease all increased the risk of occurrence of mobility score 1 versus mobility score 0 , whereby, mobility score 1 is similar to cows referred to as non-lame, or sub-clinically lame in other studies. More severely scored claw disorders, such as overgrown claw, white line disease, and sole hemorrhage severity scores $>2$, were associated with an increased risk in the occurrence of mobility score 3 versus mobility 0 . Low BCS, as well as an increase in cow parity was also associated with sub-optimal mobility score versus optimal mobility score. From this, mobility scoring can be used to identify problem cows, i.e. cows with mild forms of claw disorders, relatively earlier. 


\section{ACKNOWLEDGEMENTS}

This study was funded by DAFM's Research Stimulus project. Project name and no. : Healthy Genes $14 \mathrm{~S} 801$. The authors also wish to acknowledge the co-operation of all participating farmers. 


\section{Chapter 3}

Cow and herd-level risk factors associated with mobility scores in pasture-based dairy cows

A. H. O'Connor* ${ }^{*}$, E. A. M. Bokkers $\dagger$, I. J. M. de Boer $\dagger$, H. Hogeveen Byrne*, and E. Ruelle*, B. Engel, L. Shalloo*

${ }^{*}$ Teagasc, Animal and Grassland Research and Innovation Centre, Moorepark, Fermoy, Co. Cork, Ireland

$\dagger$ Animal Production Systems group, Department of Animal Sciences, Wageningen University \& Research, the Netherlands

$¥$ Business Economics group, Department of Social Sciences, Wageningen University \& Research, the Netherlands

$\S$ Mathematical and Statistical Methods - Biometris, Department of Plant Sciences, Wageningen University \& Research, the Netherlands

Preventative Veterinary Medicine 108 (2020) 105077 


\title{
34 | Chapter 3
}

\begin{abstract}
Lameness in dairy cows is an area of concern from an economic, environmental and animal welfare point of view. While the potential risk factors associated with suboptimal mobility in non-pasture-based systems are evident throughout the literature, the same information is less abundant for pasture-based systems specifically those coupled with seasonal calving, like those in Ireland. Therefore, the objective of this study was to determine the potential risk factors associated with specific mobility scores $(0=$ good, $1=$ imperfect, $2=$ impaired, and 3 = severely impaired mobility) for pasture-based dairy cows. Various cow and herd-level potential risk factors from Irish pasture-based systems were collected and analysed for their association with suboptimal mobility, whereby a mobility score of 0 refers to cows with optimal mobility and a mobility score $\geq 1$ refers to a cow with some form of suboptimal mobility. Combined cow and herd-level statistical models were used to determine the increased or decreased risk for mobility score 1, 2, and 3 (any form of suboptimal mobility) compared to the risk for mobility score 0 (optimal mobility), as the outcome variable and the various potential risk factors at both the cow and herd-level were included as predictor type variables. Cow-level variables included body condition score, milk yield, genetic predicted transmitting ability for 'lameness', somatic cell score, calving month and cow breed. Herdlevel variables included various environmental and management practices on farm. These analyses have identified several cow-level risk factors (including low body condition score, high milk yield, elevated somatic cell count, stage of lactation, calving month, and certain breed types), as well as various herd-level risk factors (including the amount of time taken to complete the milking process, claw trimmer training, farm layout factors and foot bathing practices) which are associated with suboptimal mobility. The results of this study should be considered by farm advisors when advising and implementing a cow/herd health program for dairy cows in pasture-based systems.
\end{abstract}

Keywords: lameness, risk-factors, grass-based, locomotion, animal-health 


\section{INTRODUCTION}

Lameness is an area of increasing concern facing the dairy sector worldwide, being considered one of the most important disease challenges by Huxley (2012). Lameness is the third most important disease related economic loss, after both fertility and mastitis (Bruijnis et al., 2010), whereby lameness has been shown to have negative associations with various aspects of both production and reproduction (Bicalho et al., 2008; Alawneh et al., 2011; O'Connor et al., (2020) In prep. With compromised production effects associated with lameness, it is not surprising that recent findings have also reported on the negative environmental consequences, such as increased greenhouse gas emissions (Mostert et al., 2018), acidification, eutrophication and fossil fuel depletion (Chen et al., 2016). As well as this, the welfare of lame cows is also at risk due to the pain and behavioral changes associated with this debilitating disease (O'Callaghan, 2002; Navarro et al., 2013).

Most cases of lameness are as a result of various types of claw disorders (Huxley, 2012; O'Connor et al., 2019), with the majority of claw disorders causing lameness found in the hind limbs (Murray et al., 1996). However, it is important to note that cows can become lame as a result of other factors, such as for example udder distention in heifers (Flower et al., 2006). Therefore, the use of visual locomotion or mobility scoring rather than visual inspection solely for the presence of claw disorders is a preferred and a less invasive technique for detecting lameness. Given the multifactorial nature of lameness and how it is measured, in the present study we use the four-point mobility scoring scale for lameness as defined by the UK Agriculture and Horticulture Development Board (AHDB), whereby a mobility score 0 refers to a cow with good or 'optimal' mobility, and a mobility score 1, 2, or 3 refer to a cow with increasing severities of suboptimal mobility (imperfect, impaired and severely impaired mobility, respectively).

While various cow and environmental type risk factors associated with lameness have been reported in the literature, there is a particular emphasis on housing and management type risk factors (De Vries et al., 2015), including flooring type (Somers et al., 2003), the availability, cleanliness, and type of bedding (Cook et al., 2004; Chapinal et al., 2013), and access to pasture (Hernandez-Mendo et al., 2007; Olmos et al., 2009). There is less known about potential cow and herd-level risk factors in pasture-based systems, specifically during the grazing season (Alawneh et al., 2011; Bran et al., 2018). A reason for this may be the presumed perception that pasture-based cows are less at risk for succumbing to mobility issues. This perception is most likely due to the reported positive effect that access to pasture has for cows compared to confinement type systems (Chapinal et al., 2013). However, cows in pasture-based systems are exposed to a variety of potential risk factors such as cow roadway conditions, distance walked each day, and other management type factors.

In north-west Europe, a pasture-based system generally refers to a system in which cows are housed during the winter period and are managed at pasture for the remainder of the year. A key difference between pasture-based systems in Ireland compared to other countries is the seasonal calving aspect, whereby cows are turned out to pasture post calving once ground 


\section{6 | Chapter 3}

conditions allow (Shalloo et al., 2014), wherein over 70\% of cows calve between January and March (Irish Cattle Breeding Statistics, 2018). In such a system, it was previously reported by O'Connor et al. (2019), that up to $38 \%$ of cows were recorded as having some form of suboptimal mobility (a mobility score $\geq 0$ using the AHDB scale). Therefore, the objective of the present study was to investigate the potential cow and herd-level risk factors associated with suboptimal mobility in spring calving, pasture-based systems. 


\section{MATERIALS AND METHODS}

This section will describe the data collection, data edits, and statistical analysis for the both the cow and herd-level risk factors analysis. For the statistical analyses, a combined cow and herd-level analyses that incorporated repeated cow-level measures was completed.

\section{Cow-level data collection and edits}

Data used in this analysis were collected from a sample of Irish pasture-based dairy cows as part of another research project entitled "Healthy-Genes". Herds were selected for inclusion based on the following criteria: 1) maximum of $100 \mathrm{~km}$ from Teagasc, Moorepark in Fermoy, 2) must have been registered to the Irish Cattle Breeding Federation (ICBF) milk recording system, 3) herd owners must have been willing to have their herd genomically tested, and 4) must have been operating a spring calving pasture-based system. The Irish spring calving, pasture-based system refers to compact seasonal calving systems, whereby cows are turned out to pasture post calving. The system focus is to manage the interface between the cow and the pasture, with a focus on maximizing grass intake and grass utilisation (Dillon et al., 2015). Participation was on a voluntary basis. Sixty-eight pasture-based dairy herds (consisting of 11,116 cows) fitted the criteria and were included in the data collection. The average herd size was 169 (standard deviation of 115) cows. However, due to missing or incomplete records the number of cows included in each of the cow-level analyses differed (described in Table 2 and Table 3). No difference in cow or herd-level attributes is known by the authors between the subset of cows used in the analyses (due to deletions of some data) and the excluded cows/herds.

Body condition score and mobility score. Each herd was visited twice by two trained technicians from Teagasc, Moorepark during the 2015 calendar year. The first visit took place during March through May and the second visit took place during June through November. During each herd visit, each lactating cow was assessed for their body condition score (BCS) (by one technician) and mobility score (by the other technician). Body condition of each cow was scored using both visual and tactile appraisal on a scale of 1 to 5 with 0.25 increments, as described by Edmonson et al. (1989). As a categorical variable, BCS data was regrouped based on the median. The categories were $<3,=3$, and $>3$ (less the median, the median, and greater than the median). Mobility quality of each cow was scored using the UK Agriculture and Horticulture Development Board four point scale (https://dairy.ahdb.org.uk/technicalinformation/animal-health-welfare/'lameness'/husbandry-prevention/mobilityscoring/\#.WXnhULuFOr8; accessed December 16, 2017), using the following definitions.

- A score of 0 describes a cow with good mobility that walks with even weight bearing and rhythm on all four feet, with a flat back. Long and fluid strides are possible.

- A score 1 describes a cow with imperfect mobility (any mobility score $>0$ is defined as suboptimal mobility) with uneven steps or shortened strides affecting one or more limbs and it may not be immediately identifiable. 
- A score 2 describes a cow with impaired mobility, which is a cow with uneven weight bearing on one or more limbs that is immediately identifiable and/or shortened strides, usually associated with an arched back.

- A score of 3 describes a cow with severely impaired mobility; a cow with this score is unable to walk as fast as the rest of the 'healthy' herd due to more severe symptoms compared to score 2 .

Production data and somatic cell count. Production data were extracted from the ICBF database for the full lactation of the calendar year 2015, for all cows. Production data included; milk, fat, and protein yield (corrected for a 305 day lactation), and the average somatic cell count for the entire lactation. To account for variability in fat and protein content of different farms, the functional unit chosen was a $\mathrm{kg}$ of fat and protein corrected milk $($ FPCM $)($ One $\mathrm{kg} \mathrm{FPCM}=1 \mathrm{~kg}$ milk $\times(0.337+0.116 \times$ Fat $\%+0.06 \times$ Protein $\%)$ (Yan et al., 2011). The statistical models initially failed to converge when FPCM was used as continuous variable, therefore FPCM was converted into three approximately equal groups; $<6,000 \mathrm{~kg}$, $6,000-7,100 \mathrm{~kg}$, and $>7,100 \mathrm{~kg}$. Somatic cell count (SCC) data was transformed to somatic cell score $\left(\log _{10} \mathrm{SCC}\right)$ using a logarithm to the base 10 to normalize the data (Ali and Shook, 1980).

Predicted Transmitting Ability (PTA) data. The EBI is a breeding index, used to select genetically superior animals to increase profitability within Irish dairy herds (Veerkamp et al., 2002). The EBI and its sub-indices are described in detail by Berry et al. (2007). The EBI sub indices trait values for 'health' were extracted from the ICBF database for the year 2015, for all cows. The health sub index is made up of three traits: 'lameness', mastitis, and $\log _{10}$ SCC, expressed as predicted transmitting abilities (PTAs). The genetic PTA for 'lameness' is used in the cow-level analyses, and is a continuous variable. The higher the PTA for lameness, the more progeny that are expected to become lame during the lactation. Therefore, a PTA for 'lameness' less than 0 translates as a reduced risk for 'lameness', and a PTA greater than 0 translates as an increased risk for 'lameness'. An animal's PTA indicates the amount of a particular trait an animal is expected to pass on to its progeny, relative to the base population (Berry et al., (2007). The base population performance figures are 5,743 kg milk, $224 \mathrm{~kg}$ fat (3.9\%), $195 \mathrm{~kg}$ protein (3.39\%), a 400 day calving interval and $82.5 \%$ survival (Irish Cattle Breeding Statistics, 2018). The PTA for lameness was put into three groups; < $0,=0$, and $>0$.

Calving Month, Days in Milk, Cow Breed and Cow Parity. For the year 2015, calving date, days in milk (DIM), cow breed and cow parity records were extracted from the ICBF database. Days in milk refers to the number of days the cow has been producing milk on each day her mobility score and BCS were recorded, therefore each cow has two DIM records. Cows that had not yet calved on the day that mobility score and BCS were collected were recorded as 0 DIM. Days in milk was categorized into three groups; < 60 DIM, $60-120$ DIM, and $\geq 120$ DIM. Calving dates were grouped into calving months for the analyses, whereby 1,371 cows calved in January, 5,970 in February, 2,509 in March, and 1,219 in April 
or later. Analysed cows comprise 75\% Holstein, 13\% Jersey, and 9\% Friesian cattle, which is representative of the national population (Ring et al., 2018). Cow breed was put into the following groups for the analyses; Holstein-Friesian (HF), Holstein-Jersey (HJ), other Holstein-Friesian cross (HX) i.e. Holstein-Friesian crossed with any other breed that is not Jersey, and other Jersey-Cross (JX), i.e. Jersey crossed with any breed other than HolsteinFriesian. Parity ranged from 1 through 13, whereby parity 1 cows made up $30 \%$ of all the cows, parity 2 cows made up $20 \%$ of all the cows, and Parity $3+$ cows made up $50 \%$ of all the cows.

\section{Herd-level data collection and edits}

Herd-level data for this study were collected from a survey completed in 2015 by the farmers via Survey Monkey. Each farmer completed the survey throughout the calendar year 2015. The objective of the survey was to collect data on the overall health status (not just mobility related) of the herds (including some questions of farmers' perception of their herds' health status). The survey consisted of 38 questions collecting information including; herd identifiers, general farm characteristics, level of concentrate and mineral supplementation, number and type of animals purchased throughout the year 2015, biosecurity measures practiced on farm, milking routine, cow roadway condition, distances walked by the cows, claw trimming and foot bathing routine. Not all data from the survey was deemed biologically relevant for this analyses (e.g., certain biosecurity measures), therefore were not included. Non-binary responses by farmers were re-categorized into binary responses using authors' expertise and expertise of others (including experiences technicians) in the field for the purposes of this analysis in an attempt to have relatively even number of herds within each category and indeed to ensure categories made biological sense. Where it did not make biological sense to categorize to binomial responses and the number of herds in a category was less than five farms, the variable was dropped from any further analysis. These binary responses are outlined in Table 1, describing in detail exactly how the categories were created. Due to missing records, incomplete responses, or failure of farmers to complete the surveys, just 47 of the total 68 had herd-level data available to include in this analyses. 
40 | Chapter 3

Table 1. Herd-level factors and observed number of herds per factor level ( $\mathrm{n}=50$ farms)

\begin{tabular}{|c|c|c|c|c|}
\hline Factor $^{1}$ & Herd-Owner response & $\begin{array}{l}\text { Farms, } \\
\mathrm{n}^{2}\end{array}$ & Binary categories & $\begin{array}{l}\text { Farms, } \\
\mathrm{n}^{2}\end{array}$ \\
\hline \multirow[b]{2}{*}{ Grazing platform } & Single platform & 10 & Single platform & 10 \\
\hline & $\leq 3$ platforms & 32 & \multirow[t]{2}{*}{$\begin{array}{l}>1 \text { platform / use public } \\
\text { road }\end{array}$} & 40 \\
\hline \multirow{5}{*}{$\begin{array}{l}\text { Walking } \\
\text { distance }^{3}\end{array}$} & $>3$ platforms & 8 & & \\
\hline & $<0.4 \mathrm{~km}$ & 2 & \multirow{4}{*}{$\begin{array}{l}<0.8 \mathrm{~km} \\
\geq 0.8 \mathrm{~km}\end{array}$} & 16 \\
\hline & $0.4-0.79 \mathrm{~km}$ & 14 & & 33 \\
\hline & $0.8-1.59 \mathrm{~km}$ & 21 & & \\
\hline & $\geq 1.6 \mathrm{~km}$ & 12 & & \\
\hline \multirow[t]{2}{*}{$\begin{array}{l}\text { Collecting yard } \\
\text { procedure after } \\
\text { milking }\end{array}$} & $\begin{array}{l}\text { Not retained, allowed } \\
\text { walk freely back to } \\
\text { pasture }\end{array}$ & 38 & $\begin{array}{l}\text { Not retained, allowed walk } \\
\text { freely back to pasture }\end{array}$ & 38 \\
\hline & $\begin{array}{l}\text { Retained until all cows } \\
\text { are milked }\end{array}$ & 10 & $\begin{array}{l}\text { Retained until all cows are } \\
\text { milked }\end{array}$ & 10 \\
\hline \multirow{6}{*}{$\begin{array}{l}\text { Milking } \\
\text { duration }^{4}\end{array}$} & $\leq 60$ minutes & 4 & $<90$ minutes & 29 \\
\hline & $61-90$ minutes & 25 & \multirow[t]{4}{*}{$\geq 90$ minutes } & \multirow[t]{4}{*}{20} \\
\hline & $91-120$ minutes & 12 & & \\
\hline & $121-150$ minutes & 4 & & \\
\hline & $\leq 151$ minutes & 4 & & \\
\hline & $1=$ Smooth & 16 & Smooth (1) & 16 \\
\hline \multirow{4}{*}{$\begin{array}{l}\text { Cow path } \\
\text { roughness } \\
\text { (ranked 1-5) }\end{array}$} & $2=$ less smooth than 1 & 22 & \multirow{4}{*}{$\begin{array}{l}\text { Relatively not smooth - very } \\
\text { rough }(>1)\end{array}$} & \multirow{4}{*}{34} \\
\hline & $3=$ less smooth than 2 & 11 & & \\
\hline & $4=$ less smooth than 3 & 1 & & \\
\hline & $5=$ Very Rough & 0 & & \\
\hline \multirow{8}{*}{$\begin{array}{l}\text { Cow path } \\
\text { cleanliness } \\
(\text { ranked } 1-5)^{5}\end{array}$} & 0.75 & 1 & \multirow[t]{2}{*}{ Clean (1-1.5) } & \multirow[t]{4}{*}{27} \\
\hline & 1.00 & 6 & & \\
\hline & 1.25 & 13 & \multirow{6}{*}{$\begin{array}{l}\text { Relatively not clean - } \\
\text { significant mud and dung } \\
\text { build up }(>1.5)\end{array}$} & \\
\hline & 1.50 & 7 & & \\
\hline & 1.75 & 11 & & \multirow[t]{4}{*}{22} \\
\hline & 2.00 & 7 & & \\
\hline & 2.25 & 3 & & \\
\hline & 2.50 & 1 & & \\
\hline \multirow{2}{*}{$\begin{array}{l}\text { Cow path } \\
\text { maintenance }\end{array}$} & $\begin{array}{l}\text { Completed within the } \\
\text { past year }\end{array}$ & 20 & $\begin{array}{l}\text { Completed within the past } \\
\text { year }\end{array}$ & 20 \\
\hline & $\begin{array}{l}\text { Completed within the } \\
\text { past } 3 \text { years }\end{array}$ & 13 & $\begin{array}{l}\text { Completed more than } 1 \text { year } \\
\text { ago }\end{array}$ & 28 \\
\hline
\end{tabular}




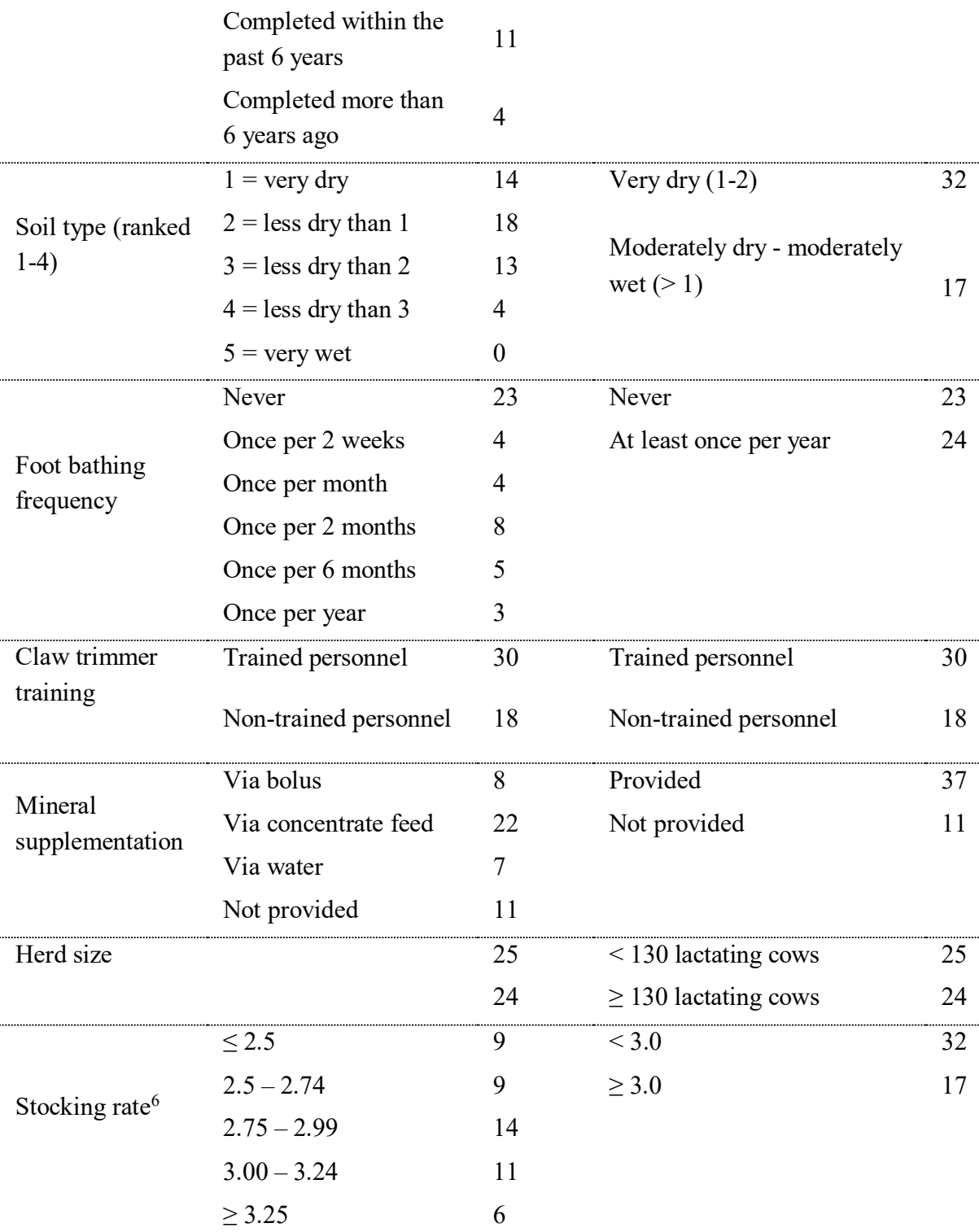

${ }^{1}$ All data presented is for the lactation during the calendar year 2015

${ }^{2}$ The number of farms does not always equal to 50 due to missing observations

${ }^{3}$ Refers to the distance cows have to walk to the furthest away grazing ground

${ }^{4}$ Refers to the average time from when the cows leave the paddock until they return to the paddock after milking

${ }^{5}$ Cow road cleanliness was scored on a five-point scale each season (spring, summer, autumn and winter). These scores were averaged across all seasons

${ }^{6}$ Livestock units per hectare on the milking platform 


\section{Statistical Analysis}

Descriptive statistics and modelling were performed using the R statistical software (RStudio Team, 2016), using binomial logistic regression models (function 'glmer' and 'glmmTMB').

Pre model building. Prior to multivariable model development, variables were tested for collinearity using Fishers-exact test, and variables found to be markedly correlated were not used in the model simultaneously. Correlated variables included; cow parity and FPCM, walking distance and herd size, milking duration and stocking rate, and grazing platform and stocking rate. Pairs of correlated variables were not tested simultaneously, rather each variable was tested for one at a time and the significant variable $(\mathrm{P}$ value $<0.05)$ was kept. Binomial logistic regression was used to model the nominal outcome variables, in which the log odds of the outcomes are modelled as a linear combination of the cow and herd-level variables. Binomial logistic regression was used to investigate the potential risk factors for imperfect, impaired and severely impaired (all forms of suboptimal mobility) mobility (mobility score $\geq 1$ ) together, which were compared to optimal mobility (mobility score 0 ). Binomial logistic regression was also used to investigate the potential risk factors for impaired and severely impaired forms of suboptimal mobility (mobility score $\geq 2$ ) compared to optimal and imperfect mobility (mobility score 0 and 1 ).

For the binomial logistic regression analyses the potential cow-level risk factors for suboptimal mobility included in the analyses were; BCS, FPCM, $\log _{10}$ SCC, the PTA for 'lameness', cow breed, calving month and DIM.

\section{Model building}

Step 1; all cow and herd-level variables were run together in one multilevel model, with repeated measures using the mobility score and BCS collected during the early scoring period. Biologically relevant interactions were also tested for using author's own expertise. The interactions tested included; walking distance and cow path roughness/maintenance/cleanliness, $\log _{10}$ SCC and cow path cleanliness, and soil type and mineral supplementation. A combined forward and backwards stepwise variable selection method was applied. The step function used selects the variables to be kept based on the AIC of the model. Step 2; step 1 was repeated by replacing the early lactation mobility score and BCS with the late lactation mobility score and BCS. Step 3; all selected variables from step 1 and 2 were inputted together with early and late lactation mobility score and BCS inputted as repeated measures in the model. Cow nested within herd was inputted in the final model as a random effect variable. Step 4; the model created in step 3 was then restricted to significant variables $(\mathrm{P}$ value $<0.05$ ) only and each removed variable was retested one at a time again in the model. Removed and retested variables that did not significantly affect the outcome of the model selected in step 3 were excluded from any further analyses. Variables that were removed and retested that were either significant or affected the significance of other variables already in the model were further investigated for their interaction with the other variables. 


\section{RESULTS}

The proportion of cows in each mobility score is previously reported by O'Connor, 2020 (accepted), whereby $35.7 \%$ of cows were scored as having some form of suboptimal mobility (mobility score $\geq 1$ ) during the early and $38.2 \%$ during the late scoring period. The proportion of mobility score $\geq 2$ at the cow-level was $4.2 \%$ during the early and $7.1 \%$ during the late scoring period, while the proportion of mobility score $=3$ was $0.7 \%$ during the early and $0.6 \%$ during the late scoring period.

The herd-level prevalence (average proportion of cows per herd) of suboptimal mobility (mobility score $\geq 1$ ) was $36.1 \%$ (standard deviation $(\mathrm{SD})=13.15$ ) during the early scoring period and $37.8 \%(\mathrm{SD}=7.84)$ during the late scoring period. The herd-level prevalence of cows with a mobility score $\geq 2$ at the herd-level was $11.0 \%(\mathrm{SD}=8.61)$ during the early scoring period and $5.9 \%(\mathrm{SD}=5.71)$ during the late scoring period, while the prevalence mobility score $=3$ was $1.3 \%(\mathrm{SD}=2.37)$ during the early scoring period and $0.5 \%(\mathrm{SD}=$ 1.17) during the late scoring period.

Results for the analysis of the cow and herd-level risk factors for suboptimal mobility are presented in Table 2 and Table 3.

Cow-level risk factors for mobility score $\geq 1$. Results for the analyses of the potential cow-level risk factors for all forms of suboptimal mobility (mobility score $\geq 1$ ) are presented in Table 2 . Having a $\mathrm{BCS}=3$ and $>3$ (compared to $\mathrm{BCS}<3$ ) was associated with a decreased risk of occurrence for having a mobility score $\geq 1$ compared to mobility score 0 . A FPCM yield between $6,000-7,100 \mathrm{~kg}$, and $>7,100 \mathrm{~kg}$ (compared to $<6,000 \mathrm{~kg}$ ) were found to be associated with an increased risk of occurrence for having a mobility score $\geq 1$. Elevated $\log _{10}$ SCC was also associated with an increased risk of occurrence of a cow being scored as mobility score $\geq 1$. Similarly, a PTA for 'lameness' $=0$ and $>0$ (compared to a PTA $<0$ ) increased the risk of occurrence of mobility score $\geq 1$ compared to mobility score 0 . Cow breeds; HJ and JX cows (compared to HF cows) were found to be associated with a decreased risk of occurrence of mobility score $\geq 1$, while there was no significant association between HFX cow breed and suboptimal mobility. Cows that calved in February, March, or April or later (compared to cows that calved in January) were associated with an increased risk of occurrence of mobility score $\geq 1$ versus mobility score 0 . Similarly, cows $>120$ DIM were also associated with an increased risk for the occurrence of mobility scores $\geq 1$ compared to mobility score 0 .

Herd-level risk factors for mobility score $\geq 1$. As outlined in Table 3, milking duration $\geq 90$ minutes was found to be a potential risk factor for the increased occurrence of mobility score $\geq 1$ compared to mobility score 0 . When routine claw trimming was undertaken by non-specifically trained personnel there was a decreased risk of occurrence of mobility score $\geq 1$. There tended to be an increased risk for the occurrence of mobility score $\geq 1$ for herds with at least two grazing platforms for the lactating herd, or herds that use public roads in order to travel between grazing paddocks and the milking parlour. 
44 | Chapter 3

Table 2. Results ${ }^{1}$ of the final binomial logistic regression model of the cow $(n=6,061)$ and herd $(n=$ 44) level risk factors associated with mobility $\operatorname{score}^{2} \geq 1$.

\begin{tabular}{|c|c|c|c|c|c|c|c|}
\hline Variable $^{3}$ & Category & $\begin{array}{l}\mathrm{n} \\
\text { cows }\end{array}$ & $\begin{array}{l}P \text { - } \\
\text { Value }\end{array}$ & $\begin{array}{l}\text { Odds } \\
\text { Ratio }\end{array}$ & SE & $\begin{array}{l}P \text {-Value } \\
\text { pairwise } \\
\text { comparison }\end{array}$ & $\begin{array}{l}95 \% \\
\mathrm{CI}\end{array}$ \\
\hline Intercept & & & & 0.03 & 1.54 & $<0.001$ & $\begin{array}{l}0.02- \\
0.06\end{array}$ \\
\hline \multirow[t]{3}{*}{$\mathrm{BCS}$} & $<3$ & 2,619 & 0.000 & 1.00 & & & \\
\hline & $=3$ & 2,124 & & 0.62 & 1.05 & $<0.001$ & $\begin{array}{l}0.57- \\
0.67\end{array}$ \\
\hline & $>3$ & 1,318 & & 0.54 & 1.06 & $<0.001$ & $\begin{array}{l}0.49- \\
0.60\end{array}$ \\
\hline \multirow[t]{3}{*}{ FPCM } & $<6,000$ & 1,880 & 0.000 & 1.00 & & & \\
\hline & $6,000-7,100$ & 2,010 & & 1.59 & 1.06 & $<0.001$ & $\begin{array}{l}1.45- \\
1.75\end{array}$ \\
\hline & $>7,100$ & 2,171 & & 2.4 & 1.07 & $<0.001$ & $\begin{array}{l}2.17- \\
2.67\end{array}$ \\
\hline $\log _{10} \mathrm{SCC}$ & & & 0.000 & 1.53 & 1.08 & $<0.001$ & $\begin{array}{l}1.34- \\
1.74\end{array}$ \\
\hline \multirow[t]{3}{*}{ PTA } & $<0$ & 3,967 & 0.000 & 1.00 & & & \\
\hline & $=0$ & 703 & & 1.18 & 1.07 & 0.015 & $\begin{array}{l}1.06- \\
1.33\end{array}$ \\
\hline & $>0$ & 1,391 & & 1.41 & 1.06 & $<0.001$ & $\begin{array}{l}1.28- \\
1.54\end{array}$ \\
\hline \multirow[t]{4}{*}{ Breed } & $\mathrm{HF}$ & 3,957 & 0.000 & 1.00 & & & \\
\hline & $\mathrm{HJ}$ & 1,207 & & 0.47 & 1.07 & $<0.001$ & $\begin{array}{l}0.42- \\
0.53\end{array}$ \\
\hline & HFX & 695 & & 1.11 & 1.07 & 0.138 & $\begin{array}{l}0.99- \\
1.25\end{array}$ \\
\hline & JX & 202 & & 0.37 & 1.16 & $<0.001$ & $\begin{array}{l}0.29- \\
0.47\end{array}$ \\
\hline \multirow{4}{*}{$\begin{array}{l}\text { Calving } \\
\text { Month }\end{array}$} & January & 744 & 0.000 & 1.00 & & & \\
\hline & February & 3,521 & & 1.30 & 1.08 & $<0.001$ & $\begin{array}{l}1.15- \\
1.48\end{array}$ \\
\hline & March & 1,263 & & 1.66 & 1.09 & $<0.001$ & $\begin{array}{l}1.44- \\
1.91\end{array}$ \\
\hline & April or later & 533 & & 1.40 & 1.11 & 0.001 & $\begin{array}{l}1.18- \\
1.66\end{array}$ \\
\hline DIM & $<60$ & 2,318 & 0.066 & 1.00 & & & \\
\hline
\end{tabular}


Risk factors \& Mobility scores | 45

\begin{tabular}{|c|c|c|c|c|c|c|c|}
\hline & $60-120$ & 1,391 & & 1.10 & 1.06 & 0.118 & $\begin{array}{l}1.00- \\
1.22\end{array}$ \\
\hline & $>120$ & 2,352 & & 1.12 & 1.05 & 0.028 & $\begin{array}{l}1.03- \\
1.22\end{array}$ \\
\hline \multirow{2}{*}{$\begin{array}{l}\text { Milking } \\
\text { duration }\end{array}$} & $<90$ minutes & 2,504 & 0.006 & 1.00 & & & \\
\hline & $\geq 90$ minutes & 3,557 & & 1.34 & 1.11 & 0.006 & $\begin{array}{l}1.13- \\
1.60\end{array}$ \\
\hline \multirow{2}{*}{$\begin{array}{l}\text { Claw trimmer } \\
\text { training }\end{array}$} & Trained personnel & 3,435 & 0.006 & 1.00 & & & \\
\hline & $\begin{array}{l}\text { Non-trained } \\
\text { personnel }\end{array}$ & 2,626 & & 0.74 & 1.11 & 0.006 & $\begin{array}{l}0.62- \\
0.89\end{array}$ \\
\hline \multirow{2}{*}{$\begin{array}{l}\text { Grazing } \\
\text { platform }\end{array}$} & Single platform & 914 & 0.089 & 1.00 & & & \\
\hline & $\begin{array}{l}>1 \text { platform / use } \\
\text { of public road }\end{array}$ & 5,147 & & 1.27 & 1.15 & 0.089 & $\begin{array}{l}1.01- \\
1.59\end{array}$ \\
\hline
\end{tabular}

BCS = body condition score; FPCM = fat and protein corrected milk; PTA = 'lameness' predicted transmitting ability; $\log _{10} \mathrm{SCC}=\log 10$ transformation of somatic cell count; HF = Holstein-Friesian; $\mathrm{HJ}=$ Holstein Jersey; HFX = Holstein-Friesian cross; JX = Jersey cross; CI = confidence interval.

$* * *, * *, *, \dagger$ odds ratio is significantly or tends to be different from $1(\mathrm{P}<0.001,0.01,0.05,0.10)$

${ }^{1}$ All data presented is for the lactation during the calendar year 2015

${ }^{2}$ Mobility score $0=$ optimal mobility; mobility score $1=$ imperfect mobility; mobility score $2=$ impaired mobility; mobility score 3 = severely impaired mobility.

${ }^{3}$ Cow nested within herd accounted for as a random variable

Cow-level risk factors for mobility score $\geq 2$. Similar to the risk factors at the cowlevel for mobility score $\geq 2$, a BCS $=3$ and $>3$ were associated with a decreased risk for the occurrence of mobility score $\geq 2$ compared to mobility score $<2$ (mobility score 0 and 1 ). Having a PTA for 'lameness' $=0$ was not significantly associated with an increased risk for mobility score $\geq 2$, while having a PTA for 'lameness' $>0$ was. Cows later in their lactation $(>120$ DIM) were also associated with an increased risk for mobility score $\geq 2$; however being $60-120$ DIM was not associated with an increased risk for mobility score $\geq 2$. Fat and protein corrected milk yield, calving month, $\log _{10} \mathrm{SCC}$, and breed were dropped from this model during the model building procedure as they were not significantly associated with a mobility score $\geq 2$.

Herd-level risk factors for mobility score $\geq 2$. Collecting yard procedure whereby herds are retained in the collecting yard until all cows are milked (rather than not being retained and allowed walk freely back to pasture) was significantly associated with an increased risk for the occurrence of mobility score $\geq 2$ compared to mobility score $<2$. Foot bathing frequency of at least once per year (compared to never) was also significantly associated with an increased risk for the occurrence of mobility $\geq 2$ at the herd-level. 
46 | Chapter 3

Table 3 Results $^{1}$ of the final binomial logistic regression model of the cow $(n=6,765)$ and herd $(n=$ 47) level risk factors associated with mobility $\operatorname{score}^{2} \geq 2$.

\begin{tabular}{|c|c|c|c|c|c|c|c|}
\hline Variable $^{3}$ & Category & $\begin{array}{l}\mathrm{n} \\
\text { cows }\end{array}$ & $\begin{array}{l}P- \\
\text { Value }\end{array}$ & $\begin{array}{l}\text { Odds } \\
\text { Ratio }\end{array}$ & $\mathrm{SE}$ & $\begin{array}{l}P \text {-Value } \\
\text { pairwise } \\
\text { comparison }\end{array}$ & $\begin{array}{l}95 \% \\
\text { CI }\end{array}$ \\
\hline Intercept & & & & 0.00 & 1.47 & $<0.000$ & $\begin{array}{l}0.00- \\
0.00\end{array}$ \\
\hline \multirow[t]{3}{*}{ BCS } & $<3$ & 2,928 & 0.000 & 1.00 & & & \\
\hline & $=3$ & 1,471 & & 0.37 & 1.27 & $<0.000$ & $\begin{array}{l}0.25- \\
0.55\end{array}$ \\
\hline & $>3$ & 6,765 & & 0.46 & 1.33 & 0.007 & $\begin{array}{l}0.29- \\
0.74\end{array}$ \\
\hline \multirow[t]{3}{*}{ PTA } & $<0$ & 4,414 & 0.014 & 1.00 & & & \\
\hline & $=0$ & 788 & & 1.57 & 1.49 & 0.257 & $\begin{array}{l}0.82- \\
3.03\end{array}$ \\
\hline & $>0$ & 1,563 & & 2.33 & 1.33 & 0.003 & $\begin{array}{l}1.46- \\
3.72\end{array}$ \\
\hline \multirow[t]{3}{*}{ DIM } & $<60$ & 2,543 & 0.000 & 1.00 & & & \\
\hline & $60-120$ & 1,571 & & 1.12 & 1.35 & 0.701 & $\begin{array}{l}0.69- \\
1.83\end{array}$ \\
\hline & $>120$ & 2,650 & & 12.75 & 1.27 & $<0.000$ & $\begin{array}{l}8.62- \\
18.84\end{array}$ \\
\hline \multirow[t]{2}{*}{$\begin{array}{l}\text { Collecting } \\
\text { yard } \\
\text { procedure }\end{array}$} & $\begin{array}{l}\text { Not retained, } \\
\text { allowed walk freely } \\
\text { back to pasture }\end{array}$ & 5,492 & 0.007 & 1.00 & & & \\
\hline & $\begin{array}{l}\text { Retained until all } \\
\text { cows are milked }\end{array}$ & 1,273 & & 2.26 & 1.38 & 0.011 & $\begin{array}{l}1.33- \\
3.84\end{array}$ \\
\hline \multirow[t]{2}{*}{$\begin{array}{l}\text { Foot bathing } \\
\text { frequency }\end{array}$} & $\begin{array}{l}\text { At least once per } \\
\text { year }\end{array}$ & 3,590 & 0.014 & 1.00 & & & \\
\hline & Never & 3,175 & & 0.53 & 1.32 & 0.019 & $\begin{array}{l}0.34- \\
0.83\end{array}$ \\
\hline
\end{tabular}

$\overline{\mathrm{BCS}}=$ body condition score; PTA = 'lameness' predicted transmitting ability; $\mathrm{CI}=$ confidence interval. $* * *, * *, *, \dagger$ odds ratio is significantly or tends to be different from $1(\mathrm{P}<0.001,0.01,0.05,0.10)$

${ }^{1}$ All data presented is for the lactation during the calendar year 2015

${ }^{2}$ Mobility score $0=$ optimal mobility; mobility score $1=$ imperfect mobility; mobility score $2=$ impaired mobility; mobility score 3 = severely impaired mobility.

${ }^{3}$ Cow nested within herd accounted for as a random variable 


\section{DISCUSSION}

The proportion of suboptimal mobility (a cow with a mobility score $>0$, using the UK AHDB 4-point scale) in the present study was $35.7 \%$ during the early scoring period and $38.2 \%$ during the late scoring period. Although this appears quite high it is important to note the scoring method used, whereby suboptimal mobility includes cows with mobility levels ranging from imperfect to severely impaired. As reported by O'Connor et al. (2020) In prep, cows with a mobility score 2 and 3 (impaired and severely impaired mobility) made up 4.2\% during the early and $7.1 \%$ during the late scoring period, while just $0.7 \%$ of the cows had a mobility score 3 (severely impaired mobility) during the early and $0.8 \%$ during the late scoring period. Somers et al. (2015) reported a 'lameness' prevalence of between $11.6 \%$ and $14.6 \%$ throughout the lactation in 10 pasture-based Irish dairy farms, whereby 'lameness' refers to a cow with a mobility score $\geq 3$ (described as moderately lame) using the 5-point scale described by Sprecher et al. (1997). Comparing the prevalence in our study to the study of Somers et al. (2015) (and indeed many other studies reporting the incidence of mobility issues) is fraught with difficulties due to the variation between mobility scoring scales used. However, if we assume a mobility score $\geq 3$ using the scoring method described by Sprecher et al. (1997) is comparable to a mobility score $\geq 2$ described in our study; the prevalence reported in our study ( $4.2 \%$ and for the early and $7.1 \%$ for the late scoring period) is substantially lower. The lower prevalence of a possibly comparable level of suboptimal mobility found in our study could be explained by differences in genetics, farm management practices and/or the comparison between the studies.

\section{Cow-level risk factors associated with suboptimal mobility}

Our study analysed BCS of each cow recorded at two time points (during early lactation and during late lactation) as repeated measures, as described in the materials and methods. It has been reported by Lim et al. (2015) that, as the level of BCS loss of cows increased between at least two recordings, that the probability of becoming 'lame' increases. Somers et al. (2019) reported on the effect of BCS at the time of calving on the risk for 'lameness', which refers to a cow with a locomotion score $\geq 3$ using a five point scale. Somers et al. (2019) found that BCS loss around the time of calving was associated with reduced 'lameness', while BCS loss after calving was associated with an increased risk for 'lameness'. In the current study each cows BCS, mobility score were recorded on the same day, therefore no cause, and effect between BCS and mobility score can be concluded, rather an association. The present study reports that cows with a BCS $\geq 3$ were at a lower risk of being identified as having all levels suboptimal mobility (mobility score $\geq 1$ ) compared to mobility score 0 and for having impaired and severely impaired mobility (mobility score $\geq 2$ ) compared to mobility score $<2$. This finding is in agreement with Solano et al. (2015) reporting that cows with low BCS had the highest 'lameness' prevalence (referring to a locomotion score $\geq 3$ using a five point scale). Green et al. (2014) also reported that cows with a BCS $<2.5$ were associated for an increased risk to be treated for 'lameness' (defined by the presence of certain 


\section{8 | Chapter 3}

claw disorders), which implies cows with less body condition have an increased risk to have mobility issues.

The present study also reports that milk yield (expressed as FPCM) $\geq 6,000 \mathrm{~kg}$ is a potential risk factor for having all forms of suboptimal mobility (mobility score $\geq 1$ compared to mobility score 0 ). This finding is in agreement with much of the research published over the past number of years (e.g., (Green et al., 2002; Bicalho et al., 2008; Archer et al., 2010)), reporting that various forms of 'lameness' or in this case; all forms of suboptimal mobility are indeed associated with higher milk yield (Huxley, 2013). The present study also found that FPCM yield was dropped during the model building process (results presented in Table. 3) because it was found not to be significantly associated with an increased risk for the occurrence of mobility scores $\geq 2$ compared to mobility score $<2$. Similar results are reported in this study for other cow-level risk factors including; $\log _{10} \mathrm{SCC}$, cow breed and calving month, whereby these risk factors appear to pose significant risk for increased mobility scores $\geq 1$ (compared to mobility score 0 ), but not significantly associated with an increased risk for mobility score $\geq 2$ (compared to mobility scores $<2$ ). We are not aware of any research that analysed cow and herd-level risk factors in a similar way as to how we have done in the current study. Therefore, we hypothesized that perhaps these cow-level risk factors mentioned, that are significant when analysing the risk for mobility scores $\geq 1$ compared to mobility score 0 , are not associated with a risk for mobility scores $\geq 2$, because the number of cows scored with a mobility score $\geq 2$ is relatively low compared to the number of cows with a mobility score $\geq 1$.

As mentioned, the current study also found that increased SCC is associated with mobility score $\geq 1$, whereby cows with relatively higher $\log _{10}$ SCC had an increased risk for the occurrence of mobility scores $\geq 1$ compared to mobility score 0 . This finding is in contradiction with the study by Archer et al. (2011) using the same mobility score method as used in the current study, which reported that cows with a mobility score $=2$ on some farms, and mobility score $=3$ on other farms, actually had a lower geometric mean $\log { }_{10}$ SCC compared to cows with a mobility score 0 or 1 . One of the main differences between the study of Archer et al. (2011) and the present study is the distribution of the number of cows per mobility score. Archer et al. (2011) reports that just $1.7 \%$ of all cows were scored as mobility score 0 , while in the present study $\sim 60 \%$ of all cows were scored as mobility score 0 during both the early and late scoring period. Finally, there is also a difference in the type of data analysed between the study of Archer et al. (2011) compared to the present study, whereby Archer et al. (2011) used repeated measures for SCC and mobility scores, whereas average lactational SCC data was analysed in the present study which may be a cause for contradicting results between both studies. Archer et al. (2011) goes on to discuss the findings of Cook et al. (2004) that lame cows may spend more time standing compared to non-lame cows, therefore reducing the exposure of teat ends of lame cows to pathogens residing in the bedding material of cubicles. However, in contradiction to this, it is also reported by Navarro et al. (2013) that 'lame' cows (defined as cows scored as locomotion score 3 using the 
Sprecher et al. 1997 scale) stood on average for shorter periods compared to 'non-lame' cows. The findings of Navarro et al. (2013) could imply that the teat end is exposed to more pathogens due to more time spent lying of lame cows. If it is true that lame cows do spend more time lying down then this could be an explanation for the results reported in the present study that elevated SCC associated with mobility scores $\geq 1$, due to the teat end being exposed to pathogens more often. However, it seems fair to say the casual relationship between time spent standing and suboptimal mobility is not yet completely understood.

The present study also examined the association between the potential risk factors; 'PTA for lameness' which is the genetic predictive transmitting ability for lameness, whereby the higher the PTA, the more progeny that are expected to become lame during the lactation. Therefore, a cow with a 'lameness' PTA $<1$ is less likely to have been visibly lame throughout the lactation, a PTA $=0$ is more likely to have been visibly lame throughout the lactation that a cow with a PTA $<1$, but less likely compared to a cow with a PTA $>1$ for 'lameness'. Therefore, the results of the present study found that when a cows PTA for lameness was $\geq 0$ (compared to $<0$ ) there was an increased risk for mobility scores $\geq 1$. For the analysis examining the risk factors for mobility score $\geq 2$ compared to mobility scores $<$ 2 , there was only an increased risk associated with a PTA $>0$. What is most interesting from our findings is that even with the inclusion of the genetic PTA values for "lameness" in our analysis in an effort to correct for a genetic predisposition for suboptimal mobility, the associated effect of cow breed on mobility prevailed.

The main breeds of the cows used in this study were Holstein (75\%), Jersey (13\%), and Friesian (9\%), which is representative of the national population (Ring et al., 2018). As reported in this study, the Jersey breed and Jersey cross breeds are less likely to be associated with mobility scores $\geq 1$, which is in agreement with earlier studies (Chesterton et al., 1989, Alban, 1995). Both studies reported that Jersey breed cows had a lower risk for 'lameness' compared to heavier breeds, which is comparable to the present study whereby Jersey breed cows (referring to Holstein Jersey and Jersey crossed with any other breed) were less likely to have suboptimal mobility compared to Holstein-Friesian breed cows, which are a heavier breed. There are also some suggestions that cows with less pigmented claws (mainly Friesian breeds) are more susceptible to claw problems (Toussaint Raven et al., 1985), which have been shown to be associated with suboptimal mobility (O'Connor et al., 2019). This is in agreement with the results of the present study whereby Holstein-Friesian breed are more at risk for having suboptimal mobility. Chesterton et al. (1989) suggests that this could be due to different growth and wear rates of hoof horn, while Webster (1987) states that black claws are harder than white claws. Although the results presented in the current study show that Jersey breed (including HJ and JX) are associated with a decreased risk for suboptimal mobility compared to Holstein-Friesian breed, we also tested the associated effect of breed by changing the reference value from Holstein-Friesian breed to Jersey breed. This resulted in the confirmation that Holstein-Friesian breed is a potential risk factor for the increased risk for suboptimal mobility compared to JX (Jersey crossed with any breed other than Holstein- 


\section{0 | Chapter 3}

Friesian). This increased risk for suboptimal mobility associated with the Holstein-Friesian breed could potentially be explained by their predisposition to having higher milk yield, which has been reported throughout the literature to be associated with mobility issues (O'Connor et al., 2019, Archer et al., 2010). However, given that FPCM was also included in this model, this predisposition for high yield associated with Holstein-Friesian breed should in theory be accounted for.

One of the key performance indicators in typical Irish spring calving, pasture-based dairy systems is cow fertility. Performance in terms of cow fertility is vital in order to ensure compact calving, which is a requirement to manage the interface between the cow and the pasture with an ultimate balance to maximize intake while taking cognisance of grass utilization (Dillon et al., 2005; Shalloo et al., 2014). Interestingly, the results of the present study indicate that calving in February or later (compared to calving in January) is a potential risk factor for mobility scores $\geq 1$. This could be due to cows with suboptimal mobility being associated with lower reproductive efficiency as reported by Somers et al., (2015). Another explanation for this, could be due to the fact that in typical Irish spring calving, pasture-based systems, cows remain indoors until they calve, therefore cows with later calving dates have to wait longer periods to access pasture, and pasture has been shown to be positive for mobility, and reduce the risk of suboptimal mobility (Chapinal et al., 2013). However, it is possible that cows could have had suboptimal mobility prior to housing, and could have recovered during the housing period, prior to calving and prior to when their mobility scorings took place, which is not accounted for in the model due to not having this data.

\section{Herd-level risk factors associated with suboptimal mobility}

Longer milking durations ( $\geq 90$ minutes) are reported in our study to be a risk factor for mobility scores $\geq 1$. Milking duration in this study refers to the time from when cows leave the paddock prior to milking until they return to the grazing paddock after milking as outline in Table 1. Longer milking time could potentially imply that cows are standing longer periods in the collecting yard before or after milking, or that cows are walking longer distances to and from pasture to be milked, or both. Walking distance and collecting yard procedure were other potential risk factors also analysed separately in these analyses; however, they were dropped during the model building process due to a lack of significance with suboptimal mobility. As all combinations of pairs of variables were tested for collinearity, distance walked and collecting yard procedure were not found be correlated with milking duration. Similarly, herds with more than one grazing platform/use of a public road i.e. with fragmented land implying cows must walk longer distances and potentially make use of public road, were found to be associated with an increased risk for the occurrence of mobility scores $\geq 1$. Similar to a longer milking duration, herds with more than one grazing platform/use of a public road could also imply that cows are walking longer distances between pasture and the milking parlor as well as increased time spent standing in the collecting yard before and after milking. There was however, an association between 
collecting yard procedure and the risk for mobility scores $\geq 2$, whereby herds that cows are retained in the collecting yard until all cows are milk was found to be a risk factor for an increased occurrence of mobility score $\geq 2$ compared to mobility scores $<2$.

Prior to the analyses we hypothesied that potential risk factors such as; walking distance, cow path roughness, cow path cleanliness, cow path maintnance would be associated with an increased for suboptimal mobility, however none of these mentioned variables were significant ansd were thus dropped during the model building procedure. Chesterton et al. (1989) reported on the association between road quality and mobility issues in pasture-based systems, and found a strong link between the average maintenance and condition of cow paths and the prevalence of suboptimal mobility, however cow path cleanliness, maintenance, and roughness (or their interaction with walking distance) were not significantly associated with suboptimal mobility in the present study and were therefore dropped in the model building process. It is possible that the reason for these variables not affecting the risk for suboptimal mobility could be explained by number of herds analysed in our study, which was less than the number analysed in the study of Chesterton et al. (1989). This could potentially be a limitation of the current study, as it was not possible to collect data from a greater number of farms due to the time constraints and availability of staff. Another possible reason for the cow path variables not being significant could also be due to a potential bias in the survey results collect for each herd, as they are self-reported by the farmers themselves.

Our study also found a decreased risk for mobility scores $\geq 1$ associated with herds wherein cows' claws were trimmed by non-trained personnel. Non-trained personnel refer to anyone (including the herds' person) who has not undergone any formal claw trimming training. On one hand, we hypothesized that herds wherein claw trimming was carried out by untrained personnel implied that it is most likely the herds' person undertaking the claw trimming of the herd. Therefore this could likely mean that claw trimming is being carried out at more regular intervals or more promptly when required, compared to herds wherein claw trimming is only carried out by trained personnel. On the other hand, our finding that herds wherein =claws were trimmed by non-trained personnel is associated with a decreased risk for suboptimal mobility could also imply that trained personnel are only called in to complete claw trimming when there is a relatively large number of cows with suboptimal mobility. Therefore, when cows have imperfect mobility, the untrained personnel is sufficient, however when cows have impaired and severely impaired mobility, it is likely a trained professional is required. Similarly, as presented in Table 3, farms that do not use a footbath are associated with a decreased risk of occurrence of mobility scores $\geq 2$ compared to mobility scores $<2$. In other words, our study reports that the use of footbaths (ranging from once per month to once per year) is associated with an increase in the herd-level prevalence of suboptimal mobility in this study. Similar findings have been reported throughout the literature, whereby the use of footbaths was associated with higher 'locomotion scores' which one of the possible explanations provided is that the use of footbaths may be indicative of elevated levels of 


\section{2 | Chapter 3}

infectious type disorders (which are associated with suboptimal mobility) (Chesterton et al., 1989; Amory et al., 2006). However, the level of infectious type disorders in our data and indeed Irish pasture-based systems is quite low (O'Connor et al., 2019). Amory et al. (2006) also argues that the benefit of footbath use is dependent on their correct use, i.e. it is possible that footbaths were used incorrectly. Incorrect usage of footbaths ranged from not changing the footbath solution as frequently as recommended, which can result in contaminated footbaths, or using footbaths in which the solution is either too diluted or concentrated. There is a perception among Irish farmers that the use of footbaths is associated with harder hooves, which is unproven as far as the authors are aware. Based on this perception, we hypothesize in our study that the association between the lack of foot bath use and decreased herd-level suboptimal mobility could be explained due to the assumption that when cases of suboptimal mobility arise within a herd, foot baths may be implemented in an effort to harden hooves to reduce the prevalence of non-infectious type disorders associated with suboptimal mobility. Again, besides a short communication by Doherty et al. (2014) and the study of Chesterton et al. (1989), no other studies investigated the use of foot bathing frequency in pasture-based dairy farms to the best of our knowledge.

\section{CONCLUSIONS}

From the findings in this study, we conclude that there are both cow-level and herd-level risk factors for suboptimal mobility in pasture-based dairy production systems. Cow-level risk factors associated with all forms of suboptimal mobility (mobility scores $\geq 1$ ) include low BCS, higher yield (in terms of FPCM), elevated $\log _{10}$ SCC, stage of lactation, and a genetic predicted transmitting ability for 'lameness' and Holstein-Friesian breed. While cow-level risk factors for mobility score $\geq 2$ include BCS, stage of lactation, and a genetic predicted transmitting ability for 'lameness'. Therefore, there is potential to manage the prevalence of suboptimal at the cow-level through improved breeding strategies. Herd-level risk factors for mobility scores $\geq 1$ include longer milking times, the use of trained personnel for on farm claw trimming and fragmented grazing platforms, herd-level risk factors for mobility scores $\geq 2$ include the use of footbaths, as well as cows being held in the collecting yard after milking. Therefore, reducing the time spent milking and the amount of time a cow spends in the collecting yard could potentially reduce the prevalence of suboptimal mobility at the herdlevel.

\section{ACKNOWLEDGEMENTS}

Funding from the Irish Department of Agriculture, Food and the Marine STIMULUS research grant Healthy Genes is greatly appreciated, as well as a research grant from Science Foundation Ireland and the Department of Agriculture, Food and Marine on behalf of the Government of Ireland under the Grant 16/RC/3835 (VistaMilk). The authors also wish to acknowledge Céline Schlaepfer and all participating farmers and recorders for data recording 
Risk factors \& Mobility scores $\mid 53$

and collection, as well as the Walsh Fellowship. We also would like to thank Jim Grant of Teagasc, for his statistical advice. 


\title{
Chapter 4
}

\section{Associating mobility scores with production and reproductive performance in pasture-based dairy cows}

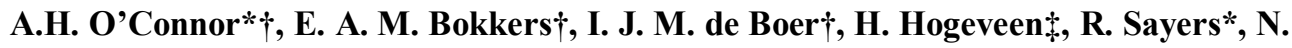 \\ Byrne*, E. Ruelle*, and L. Shalloo* \\ * Teagasc, Animal and Grassland Research and Innovation Centre, Moorepark, Fermoy, Co. \\ Cork, Ireland \\ $\dagger$ Animal Production Systems group, Department of Animal Sciences, Wageningen \\ University \& Research, the Netherlands \\ \$ Business Economics group, Department of Social Sciences, Wageningen University \& \\ Research, the Netherlands
}

Journal of Dairy Science (2020) In Press. 


\title{
56 | Chapter 4
}

\begin{abstract}
Lameness in dairy cows can have significant impacts on cow welfare, farm profitability and the environment. To determine the economic and environmental consequences of lameness, we first need to quantify its effect on performance. The objective of this study therefore, was to determine the associations of various production and reproductive performance measurements (including milk, fat and protein yield, somatic cell count, calving interval, cow death, or cow slaughter), and mobility scores in spring calving, pasture-based dairy cows. We collected; mobility scores $(0=$ good, $1=$ imperfect, $2=$ impaired, and $3=$ severely impaired mobility), body condition scores, and production data for 11,116 cows from 68 pasture-based dairy herds. Linear mixed modelling was used to determine the associations between specific mobility scores and milk, fat and protein yield, somatic cell count and calving interval. Binomial logistic regression was used to determine the association between mobility score and cow death, or slaughter. Significant yield losses of up to $1.4 \%$ of the average yield were associated with mobility score 2 and yield losses of up to $4.7 \%$ were associated with mobility score 3 during the early scoring period. Elevated somatic cell count was associated with all levels of suboptimal mobility during the late scoring period. Cows with a mobility score 2 during the early scoring period were associated with longer calving interval length, while cows with a mobility score 3 during the late scoring period were associated with longer calving interval length. Cows with a mobility score $\geq 1$ were more likely to be culled during both scoring periods. Our study, therefore, shows an association between specific mobility scores and production and reproductive performance in spring calving, pasture-based dairy cows scored during the summer grazing period.
\end{abstract}

Keywords: lameness, milk production, culling, reproduction, locomotion 


\section{INTRODUCTION}

Lameness has been identified as the third most important health-related economic loss, after fertility and mastitis (Bruijnis et al., 2010, Alawneh et al., 2011, Huxley, 2013). Lameness also has serious negative consequences on animal welfare (Leach et al., 2012, Navarro et al., 2013) and the environment, for example; increased greenhouse gas emissions (Mostert et al., 2018), acidification, eutrophication and fossil fuel depletion (Chen et al., 2016). Lameness has the potential to reduce the overall lifetime performance of dairy cows due to milk production loss and culling (Huxley, 2013), as well as having the potential to further impact on sustainability by increasing the total greenhouse gas emissions per unit of milk produced (Mostert et al., 2018). Lame cows are also more at risk for developing future mobility issues (Green et al., 2002, Hirst et al., 2002). Hence, lameness can be considered to be among the most significant disease challenges in current dairy production systems (Huxley, 2012).

In the majority of the north-west European pasture-based systems, cows are housed during the winter months but managed at pasture for the remainder of the year. Specifically in Ireland, the majority of milk production systems operate a spring calving, pasture-based grazing system. In such a system, feed demand and supply are synchronized by both calving pattern and stocking rate, with the vast majority of the feed consumed through grazing (Shalloo et al., 2014). In studies that examine mobility in these types of systems, it is generally the higher risk winter period that is prioritised. However, during the summer grazing period cows are exposed to a number potential risks, such as walking long distances between the milking parlour and pasture each day on varying types of roadway surfaces. In contrast, during the winter period, risk factors are similar to those of cows managed in nonpasture-based systems and mostly include risk factors such as availability of cubicle spaces (Fregonesi et al., 2007), shed flooring type and exposure of claws to slurry (Cook et al., 2004, Alvergnas et al., 2019). Risk factors from both types of systems contribute to the development of claw disorders, of which up to $90 \%$ are found in the hind limbs (Somers and O’Grady, 2015).

Clinical lameness in systems other than spring calving, pasture-based systems has been shown to be negatively associated with milk yield (Green et al., 2002), reproductive performance, additional labor, and treatment costs (Enting et al., 1997). Amory et al. (2008) reports substantial yield losses for up to five months prior to farmer's diagnosis of a claw disorder. This delay in diagnosis and subsequent treatment may result in cows having mobility problems for longer periods of time, which could potentially increase their stress levels due to the pain associated with lameness (O'Callaghan, 2002, Leach et al., 2012).

The consequences of lameness, especially more severe types of lameness have been well researched for a number of management systems, such as year round housing (Bicalho et al., 2008) and non-seasonal calving pasture-based systems (Archer et al., 2010). However, there have been relatively fewer studies examining the effect of less severe or mild types of lameness in spring calving, pasture-based systems, like those in Ireland. In our study, we use the phrase 'optimal mobility' (mobility score 0) and 'suboptimal mobility' (mobility score $\geq$ 


\section{8 | Chapter 4}

1), referring to the UK Agriculture and Horticulture Development Board four point scale. 'Therefore, the aim of this study was to determine the associations between mobility scores and production and reproductive performance in spring calving, pasture-based dairy cows.

\section{MATERIALS AND METHODS}

\section{Cow Data}

Using an existing database, herds were selected for inclusion based on the following criteria; 1) maximum of $100 \mathrm{~km}$ from Teagasc, Moorepark in Fermoy (Co. Cork, Ireland), 2) must have been registered to the Irish Cattle Breeding Federation (ICBF) milk recording system, 3) herd owners must have been willing to have their herd gnomically tested, and 4) must have been operating a spring-calving pasture-based system. The Irish pasture-based system refers to a system in which cows are turned out to pasture post calving during the spring, once ground conditions allow and there is feed available. Spring calving is the norm in such Irish pasture-based systems, whereby over $70 \%$ of such cows calve between January and March (Irish Cattle Breeding Statistics, 2018) and remain outside grazing for the summer and autumn months, and are partially/fully housed during the winter months (December to January). In this system, once cows calve they return to pasture with supplementary feed offered post calving to individual cows as required. The system focus is to manage the interface between the cow and the pasture, with an ultimate focus of maximizing grass intake (managed through pre-grazing herbage mass and post grazing residuals) as well as grass utilization (Dillon et al., 2005).

Sixty-eight pasture-based dairy herds (11,116 cows) fitted the criteria and were included in the analysis. The average herd size was 163 (standard deviation $=110$ ) cows, ranging from 40 to 640 cows per herd. The main breed of the cows was Holstein, Jersey, and Friesian making up $75 \%, 13 \%$, and $9 \%$ respectively, which is representative of the national population (Ring et al., 2018). Parity ranged from 1 through 13 , whereby parity 1 cows made up $30 \%$ of all the cows, parity 2 cows made up $20 \%$ of all the cows, and Parity $3+$ cows made up $50 \%$ of all the cows. The mean calving date for the cows in this study was the $18^{\text {th }}$ February 2015 $\left(\right.$ median $=23^{\text {rd }}$ February), ranging from $2^{\text {nd }}$ January through $23^{\text {rd }}$ May 2015, of which 1,404 cows calved in January, 6,047 cows calved in February, 2,503 cows calved in March, 929 cows calved in April, and the remaining 206 cows calved in May.

BCS and Mobility Score. Figure 1 presents the distribution of both the early and late scoring period mobility score and BCS for all cows analysed. Each herd was visited twice by two trained technicians from Teagasc, Moorepark in 2015 (the same two technicians visited all farms). Both technicians were experienced herds personnel with experience using both the scoring methods used in this study, as described below. The first visit (early scoring period) was conducted in March through May for each herd. The average date for the first visit was $5^{\text {th }}$ April 2015 (ranging from $2^{\text {nd }}$ March through $13^{\text {th }}$ May 2015). During the first visit, the average day in milk (DIM) for the lactating cows was 40, with a standard deviation of 31 , ranging from 70 days pre calving to 111 days post calving. The second visit (late 
scoring period) was conducted in June through November for each herd. The average date for the second visit was $3^{\text {rd }}$ August 2015 (ranging from $2^{\text {nd }}$ June through $26^{\text {th }}$ November 2015). During the second visit, the average DIM was 160, with a standard deviation of 49 , ranging from 23 through 300 days post calving. Cows were treated during a third herd visit (by one commercial company (Farm Relief Services, Roscrea, Co. Tipperary, Ireland), if required. Treatment refers to the recommended actions as per the UK AHDB mobility scoring method, which recommends routing (preventative) trimming or treatment when/if required and cows that were treated between the first and second visits were not included in the analyses, i.e. cows that were treated after the first mobility scoring visit but before the second mobility scoring visit were not included. Body condition of each cow was scored as they walked through a chute, using both visual and tactile appraisal on a scale of 1 to 5 with 0.25 increments, as described by Edmonson et al. (1989). Cows were mobility scored on exit from the parlour on a concrete surface. Mobility of each cow was scored using the UK Agriculture and Horticulture Development Board four-point scale (https://dairy.ahdb.org.uk/technicalinformation/animal-health-welfare/lameness/husbandry-prevention/mobilityscoring/\#.WXnhULuFOr8; accessed December 16, 2017), using the following definitions.

- A score of 0 describes a cow with good mobility that walks with even weight bearing and rhythm on all four feet, with a flat back. Long and fluid strides are possible.

- A score 1 describes a cow with imperfect mobility (any mobility score $>0$ is defined as suboptimal mobility) with uneven steps or shortened strides affecting one or more limbs and it may not be immediately identifiable.

- A score 2 describes a cow with impaired mobility, which is a cow with uneven weight bearing on one or more limbs that is immediately identifiable and/or shortened strides, usually associated with an arched back.

- A score of 3 describes a cow with severely impaired mobility; a cow with this score is unable to walk as fast as the rest of the 'healthy' herd due to more severely impaired symptoms compared to score 2 .

Milk Production Data and Somatic Cell Count. Milk and production data were extracted retrospectively from the ICBF database for the complete lactation of cows that entered the study in spring 2015. Milk data included; 305-day yield in kilograms (kg) for milk, fat, and protein, and production data included; stage of lactation during each scoring period, i.e. day in milk (DIM) and the average somatic cell count for the entire lactation. The output variable for both SCC models (for the early and late scoring period separately) was $\log 10$ SCC, which is a $\log 10$ transformation applied to normalize the SCC data (Ali and Shook, 1980).

Economic Breeding Index (EBI) data. The EBI is a breeding index, used to identify genetically superior animals to increase profitability within Irish dairy herds (Veerkamp et al., 2002). The EBI and its sub-indices are described in detail by Berry et al. (2007). The EBI sub-indices trait values for production, fertility and health were extracted from the ICBF database for the year 2015 for all cows, in order to correct for a genetic predisposition for 


\section{0 | Chapter 4}

certain traits. The production sub-index is made up of three traits representing the milk $\mathrm{kg}$, fat $\mathrm{kg}$ and protein $\mathrm{kg}$. The fertility sub-index is made up of two traits: calving interval and survival. The health sub-index is made up of three traits: lameness, mastitis, and SCC. An animal's predicted transmitting ability (PTA) indicates the amount of a particular trait an animal is expected to pass on to its progeny, relative to the base population. The base population refers to cows born in 2005, and then calved and were milk recorded in 2007 . The base population performance figures are $5,743 \mathrm{~kg}$ milk, $224 \mathrm{~kg}$ fat (3.9\%), $195 \mathrm{~kg}$ protein (3.39\%), a 400-day calving interval and $82.5 \%$ survival.

Cow Death and Cow Slaughter Data. Cow death date refers to the date on which a cow died on farm (including cows euthanized on farm) and cow slaughter date refers to the date on which a cow exited the herd specifically to be slaughtered. These data were available and extracted from the ICBF database for all the animals in the dataset.

Calving Interval. Calving interval data were extracted from the ICBF database for all the animals in the dataset. Calving interval in our study is calculated using each cows calving date in 2015 and in 2016, thus parity 1 cows (in 2015) become parity 2 cows in 2016 (and so on) and are used as the reference value in the statistical models.

\section{Data Edits}

Cows were only included in each of the analysis if all predictor variables were available and recorded correctly to the best of our knowledge. Supplemental Figures S1, S2, S3, and S4 (https: / / doi .org/ $10.3168 /$ jds .2019 -17103) describe the edits made for the milk, fat, and protein analysis; the SCC analysis; the calving interval analysis; and the cow death and cow slaughter analyses, respectively. 


\section{Statistical Analysis}

Descriptive statistics and modelling were performed using the R statistical software (RStudio Team, 2016), using linear mixed-effects models (function 'Imer') and binomial logistic regression models (function 'glm').

\section{Analysis for Milk, Fat, and Protein Production, Somatic Cell Count Performance,}

and Calving Interval length. A linear mixed model analysis was used to model the relationship between specific mobility scores and milk, fat, and protein production, SCC, and calving interval length:

$Y_{i j k l m}=\beta_{0}+M_{k} O S_{k}+B C S_{l}+P A R_{m}+\beta_{1} \times P T A_{i j}+\beta_{2} \times D I M_{i j}+\beta_{3} \times$ $S C C_{i j}+$ Farm $_{j}+\varepsilon_{i j k l m}$

Where $Y_{\mathrm{ijk} k \mathrm{~m}}$ corresponds to the 305-d milk, fat, or protein for cow i, of farm $\mathrm{j}$, with mobility score $\mathrm{k}, \mathrm{BCS}_{\mathrm{l}}$, and parity $\mathrm{m} . \mathrm{MOS}_{\mathrm{k}}$ is the corresponding early or late scoring period mobility score for ${ }_{\mathrm{ijk} k \mathrm{~m}}, \mathrm{BCS}_{1}$ is the corresponding early or late scoring period $\mathrm{BCS}$ for ${ }_{\mathrm{ijk} k \mathrm{~m}}, \mathrm{PAR}_{\mathrm{m}}$ is the corresponding parity for ${ }_{\mathrm{ijklm}}, \mathrm{PTA}_{\mathrm{ij}}$ is the corresponding PTA for milk $\mathrm{kg}$, fat $\mathrm{kg}$ or protein $\mathrm{kg}$ for cow $\mathrm{i}$ of farm $\mathrm{j}$. DIM $\mathrm{Dij}_{\mathrm{j}}$ is the corresponding DIM for cow $\mathrm{i}$ of farm $\mathrm{j}$, and $\mathrm{SCC}_{\mathrm{ij}}$ is the corresponding $\log _{10}$ transformation of SCC for cow $\mathrm{i}$ of farm $\mathrm{j}$. The parameters $\beta_{0}, \beta_{1}, \beta_{2}$, and $\beta_{3}$ are the regression coefficients and $\varepsilon_{\mathrm{ijklm}}$ the error term. When $\mathrm{Y}_{\mathrm{ijklm}}$ corresponds to the $\log _{10} \mathrm{SCC}$, PTA $\mathrm{i}_{\mathrm{ij}}$ is the corresponding PTA for SCC, while all other fixed variables remain the same as for when $\mathrm{Y}_{\mathrm{i}}$ corresponds to the 305-day milk, fat or protein for ${ }_{\mathrm{ijklm}}$, except for $\mathrm{SCC}_{\mathrm{ij}}$ which is replaced with $\mathrm{MKG}_{\mathrm{ij}}$, which is the corresponding 305-day milk yield in kilograms for ${ }_{\mathrm{j} j \mathrm{jlm}}$. Farm was also included in each model as a random effect. Random error terms $\varepsilon_{\mathrm{ijklm}}$ and random farm effects Farm $_{\mathrm{j}}$ are assumed to be independently normally distributed around 0 with variances $\sigma^{2}$ and $\sigma^{2 / f}$ respectively. Only significant variables were kept in all the models, except for BCS, which was forced into all models regardless of its statistical significance, due to its proven strong association with suboptimal mobility (O’Connor et al. 2019).

Six models were run in total to determine the association between milk, fat and protein production performance and mobility scores; three using early scoring period mobility score and BCS and the remaining three for late scoring period mobility score and BCS. Body condition score was inputted as a categorical variable with three classes: $\mathrm{BCS}<3.00, \mathrm{BCS}=$ 3.00 , and $\mathrm{BCS}>3.00$; i.e., less than the median, the median, and greater than the median $\mathrm{BCS}$, respectively. Two models were run in total to determine the associations between SCC and mobility scores, one using early scoring period mobility score and BCS and one with late scoring period mobility score and BCS. Similarly, two models were run in total to determine the association between calving interval length and mobility scores, one for early scoring period mobility score and BCS, and one for late scoring period mobility score and BCS. The distribution of standard residuals of the model was plotted and assessed to check the model fitting. 


\section{2 | Chapter 4}

Analysis for Cow Death or Slaughter. Binomial logistic regression was used to model nominal outcome variables, in which the log odds of the outcomes are modeled as a linear combination of the predictor variables. The model was run four times (two times using the early scoring period mobility score and BCS, and two times using the late scoring period mobility score and BCS) with the outcome variables cow death or cow slaughter (categorical variables, coded as cow did not die $=0$ and cow died $=1$, and cow not slaughtered $=0$ and cow slaughtered $=1$ ). The associations between the predictor variables (early or late scoring period mobility score, early or late scoring period BCS, cow parity, DIM, health, and calving interval length PTAs) on cow death or slaughter were assessed individually. Farm was also included in each model as fixed predictor variable because the model was unable to converge with farm as a random variable. 


\section{RESULTS}

\section{Mobility Score and Milk, Fat, and Protein Production Performance}

Model results from the linear mixed models analysing the association between 305-day milk, fat, and protein yield and the early or late scoring period mobility and BCS are reported in Table 1. Early scoring period mobility score 1 (imperfect mobility) tended to be associated with increased 305-day milk and protein yield, while late scoring period mobility score 1 was associated with an increased 305-day milk, fat and protein yield (1\% higher 305-day milk yield compared to the average yield) when compared to the reference value, mobility score 0 (good i.e. optimal mobility). Early scoring period mobility 2 (impaired mobility) was associated with a decreased 305-day milk and protein yield (102 kg reduced 305-day milk yield), while late scoring period mobility score 2 had no significant association with 305-day milk, fat, or protein yield. Both early and late scoring period mobility score 3 (severely impaired mobility) were associated with decreased 305-day milk yield (299 kg reduction of milk in the early scoring period and $356 \mathrm{~kg}$ reduction of milk in the late scoring period) and decreased 305-day protein yield (10 kg reduction in the early scoring period and $15 \mathrm{~kg}$ reduction in the late scoring period). Late scoring period mobility score 3 was associated with decreased fat yield (13 $\mathrm{kg}$ reduction), while the early scoring period mobility score 3 was not associated with fat yield.

As reported in Table 1, early scoring period BCS $>3$ (compared to $\mathrm{BCS}<3$ ) tended to be associated with decreased milk yield and was associated with protein yield, but had no significant associations with fat yield. Late scoring period $\mathrm{BCS}=3$ also had no significant association with performance, while late scoring period $\mathrm{BCS}>3$ was significantly negatively associated with milk, fat, and protein yield. Higher parity cows were associated with higher milk, fat, and protein 305-day yield. The PTAs for milk, fat, and protein, as well as stage of lactation during each scoring period (DIM) also had significant positive associations with milk, fat, and protein yield, while as $\log _{10}$ SCC increased milk, fat, and protein yield decreased in both scoring periods. 
64 | Chapter 4

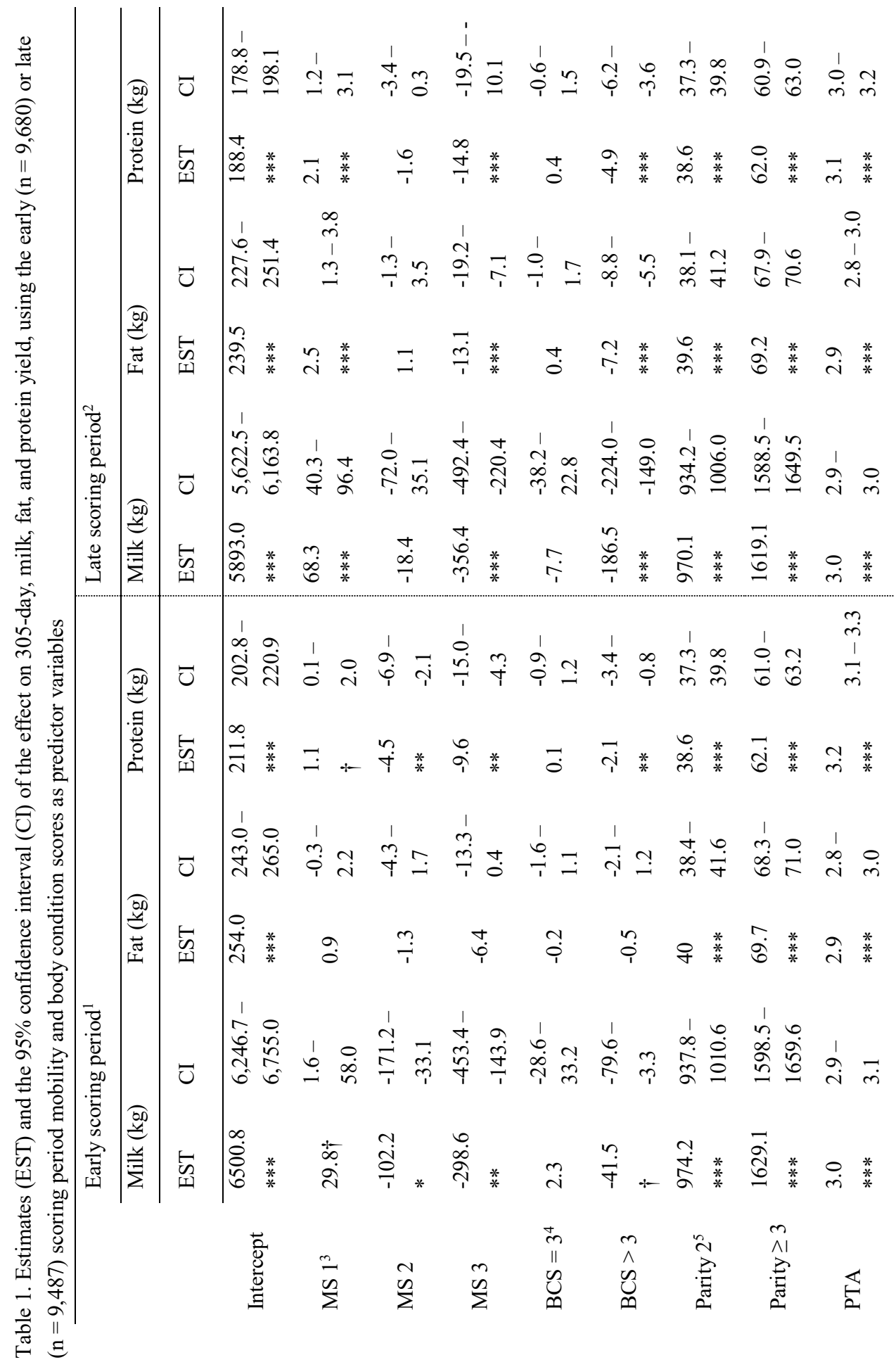


Production \& Mobility scores | 65

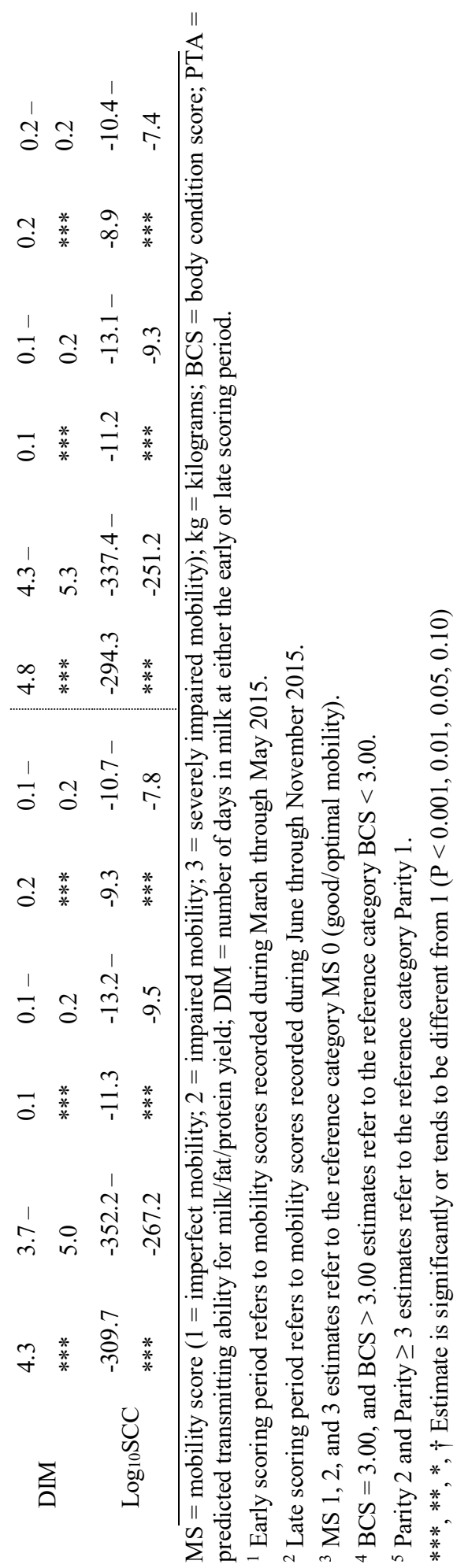


66 | Chapter 4

\section{Mobility Score and Somatic Cell Count Performance}

Model results from the linear mixed models analysing the effect of early and late scoring period mobility score on the $\log$ SCC are reported in Table 2 (estimate of coefficients on the transformed SCC scale) and Table 3 (estimated marginal means on the untransformed SCC scale). Elevated SCC was associated with all levels of suboptimal mobility (mobility score 1,2 , and 3 ) in the late scoring period, while mobility score 1 (imperfect mobility) and mobility score 2 (impaired mobility) were associated with elevated SCC in the early scoring period. Both early and late scoring period BCS had no associations with SCC. Parity 2, and parity $>3$ cows were significantly associated with elevated SCC compared to the reference category, parity 1 cows, during both scoring periods' analyses. The PTA for SCC was associated with increased SCC during both scoring periods, while stage of lactation was only associated with SCC during the late scoring period and as 305-day milk yield increased SCC decreased during both scoring periods 
Table 2. Estimates and the $95 \%$ confidence interval (CI) of the effect of mobility score on log somatic cell count (SCC), using the early $(n=9,716)$ or late $(n=9,575)$ scoring period mobility and body condition scores as predictor variables

\begin{tabular}{|c|c|c|c|c|}
\hline & \multicolumn{4}{|c|}{ Log Somatic Cell Count } \\
\hline & \multicolumn{2}{|c|}{ Early scoring period $^{1}$} & \multicolumn{2}{|c|}{ Late scoring period $^{2}$} \\
\hline & Estimate & $\mathrm{CI}$ & Estimate & $\mathrm{CI}$ \\
\hline Intercept & $5.123 * * *$ & $5.082-5.164$ & $5.140 * * *$ & $5.093-5.188$ \\
\hline MS $1^{3}$ & $0.030 * * *$ & $0.020-0.041$ & $0.029 * * *$ & $0.018-0.039$ \\
\hline MS 2 & $0.057 * * *$ & $0.031-0.083$ & $0.047 * * *$ & $0.027-0.067$ \\
\hline MS 3 & $0.062 \dagger$ & $0.003-0.121$ & $0.098 * *$ & $0.046-0.150$ \\
\hline $\mathrm{BCS}=3^{4}$ & 0.002 & $-0.009-0.014$ & 0.002 & $-0.009-0.014$ \\
\hline $\mathrm{BCS}>3$ & 0.001 & $-0.014-0.015$ & 0.012 & $-0.002-0.026$ \\
\hline Parity $2^{5}$ & $-0.030 * * *$ & $-0.045--0.016$ & $-0.034 * * *$ & $-0.048--0.019$ \\
\hline Parity $\geq 3$ & $0.096 * * *$ & $0.082-0.110$ & $0.092 * * *$ & $0.078-0.106$ \\
\hline PTA & $1.242 * * *$ & $1.174-1.311$ & $1.205^{* * *}$ & $1.136-1.273$ \\
\hline DIM & $-0.000 \dagger$ & $-0.001-0.000$ & $-0.000 *$ & $-0.000--0.000$ \\
\hline Milk (kg) & $-0.000 * * *$ & $-0.000--0.000$ & $-0.000 * * *$ & $-0.000--0.000$ \\
\hline
\end{tabular}

MS = mobility score ( 1 = imperfect mobility; 2 = impaired mobility; 3 = severely impaired mobility); $\mathrm{BCS}=$ body condition score; PTA = predicted transmitting ability for somatic cell count; DIM = number of days in milk at either the early or late scoring period.

${ }^{1}$ Early scoring period refers to mobility scores recorded during March through May 2015.

${ }^{2}$ Late scoring period refers to mobility scores recorded during June through November 2015.

${ }^{3} \mathrm{MS} \mathrm{1,2}$, and 3 estimates refer to the reference category MS 0 (good/optimal mobility).

${ }^{4} \mathrm{BCS}=3.00$, and $\mathrm{BCS}>3.00$ estimates refer to the reference category $\mathrm{BCS}<3.00$.

${ }^{5}$ Parity 2 and Parity $\geq 3$ estimates refer to the reference category Parity 1.

$* * *, * *, *, \uparrow$ Estimate is significantly or tends to be different from $1(\mathrm{P}<0.001,0.01,0.05,0.10)$.

Table 3. Estimated marginal means (EMM) and the standard error (SE) based on the log somatic cell count model (Table 2$)$, using the early $(n=9,716)$ or late $(n=9,575)$ scoring period mobility and body condition scores as predictor variables

\begin{tabular}{|c|c|c|c|c|}
\hline & \multicolumn{4}{|c|}{ Antilog of log Somatic Cell Count Model } \\
\hline & \multicolumn{2}{|c|}{ Early Scoring Period $^{1}$} & \multicolumn{2}{|c|}{ Late Scoring Period $^{2}$} \\
\hline & EMM & $\mathrm{SE}$ & EMM & SE \\
\hline MS 0 & 84,947 & 3,057 & 85,616 & 2,824 \\
\hline MS 1 & 91,080 & 3,382 & 91,491 & 3,130 \\
\hline MS 2 & 96,894 & 4,857 & 95,398 & 3,990 \\
\hline MS 3 & 98,030 & 8,794 & 107,375 & 8,495 \\
\hline
\end{tabular}

${ }^{1}$ Early scoring period refers to mobility scores recorded during March through May 2015.

${ }^{2}$ Late scoring period refers to mobility scores recorded during June through November 2015.

MS = mobility score $(0=$ good/optimal mobility; 1 = imperfect mobility; 2 = impaired mobility; 3 = severely impaired mobility) 


\section{Calving Interval}

Model results from the linear mixed models analysing the effect of early and late scoring period mobility score on calving interval length (in days) are reported in Table 4. Both early and late scoring period mobility score 1 (imperfect mobility) had no significant association with calving interval length. However, early scoring period mobility score 2 (impaired mobility) was associated with an increase in calving interval length by 3.5 days; while late scoring period mobility score 2 had no association with calving interval length. Early scoring period mobility score 3 (severely impaired mobility) had no association with calving interval length, while late scoring period mobility score 3 was significantly associated with an increase in calving interval length by just over 6 days. Both early and late scoring period BCS $>3$ were associated with a decreased calving interval length, while $\mathrm{BCS}=3$ had no associated with calving interval length compared to the reference category, BCS $<3$. Parity 2 cows (parity 2 in 2015/parity 3 in 2016) were associated with a shorter calving interval during the early scoring period analysis, while parity $\geq 3$ had a tendency for an increased calving interval length when compared to parity 1 (parity 1 in 2015/parity 2 in 2016) cows. As the PTA for calving interval length increased (becomes less negative), calving interval length increased.

Table 4. Estimates and the $95 \%$ confidence interval (CI) of the effect of mobility score on calving interval, using the early $(n=8,599)$ or late $(n=8,500)$ scoring period mobility and body condition scores as predictor variables

\begin{tabular}{|c|c|c|c|c|}
\hline & \multicolumn{4}{|c|}{ Calving Interval } \\
\hline & \multicolumn{2}{|c|}{ Early scoring period $^{1}$} & \multicolumn{2}{|c|}{ Late scoring period $^{2}$} \\
\hline & Estimate & $\mathrm{CI}$ & Estimate & $\mathrm{CI}$ \\
\hline Intercept & $347.55 * * *$ & $344.29-350.79$ & $279.17 * * *$ & $273.55-284.75$ \\
\hline MS $1^{3}$ & 0.70 & $-0.27-1.68$ & 0.82 & $-0.15-1.80$ \\
\hline MS 2 & $3.67^{*}$ & $1.21-6.13$ & 1.34 & $-0.61-3.28$ \\
\hline MS 3 & 5.68 & $-0.07-11.44$ & $6.08 *$ & $1.05-11.1$ \\
\hline $\mathrm{BCS}=3^{4}$ & -0.78 & $-1.84-0.27$ & -0.46 & $-1.53-0.61$ \\
\hline $\mathrm{BCS}>3$ & $-1.77^{*}$ & $-3.12--0.43$ & $-2.12 * *$ & $-3.43--0.82$ \\
\hline Parity $2^{5}$ & $-1.62 *$ & $-2.87--0.37$ & -1.14 & $-2.38-0.10$ \\
\hline Parity $\geq 3$ & 0.84 & $-0.21-1.88$ & $1.19 \dagger$ & $0.14-2.24$ \\
\hline PTA & $0.49 * * *$ & $0.26-0.72$ & $0.49 * * *$ & $0.25-0.73$ \\
\hline DIM & $0.59 * * *$ & $0.57-0.61$ & $0.61 * * *$ & $0.59-0.63$ \\
\hline
\end{tabular}

MS = mobility score ( 1 = imperfect mobility; 2 = impaired mobility; 3 = severely impaired mobility); $\mathrm{BCS}=$ body condition score; PTA = predicted transmitting ability for calving interval length; DIM = number of days in milk at either the early or late scoring period.

${ }^{1}$ Early scoring period refers to mobility scores recorded during March through May 2015.

${ }^{2}$ Late scoring period refers to mobility scores recorded during June through November 2015.

${ }^{3}$ MS 1, 2, and 3 estimates refer to the reference category MS 0 (good/optimal mobility). 
${ }^{4} \mathrm{BCS}=3.00$, and $\mathrm{BCS}>3.00$ estimates refer to the reference category $\mathrm{BCS}<3.00$.

${ }^{5}$ Parity 2 and Parity $\geq 3$ estimates refer to the reference category Parity 1.

$* * *, * *, *, \dagger$ Estimate is significantly or tends to be different from 1

\section{Cow Death and Cow Slaughter}

Model results from the binomial logistic regression models analysing the association between early and late scoring period mobility score on cow deaths and slaughters are reported in Table 5. All levels of suboptimal mobility (mobility score 1, 2, and 3) during both scoring periods had no significant association with cow deaths. However, all levels of suboptimal mobility during both scoring periods were associated with an increased log odds for a cow to be slaughtered, compared to the reference category of mobility score 0 (good i.e. optimal mobility). Thus, as mobility score increased, so too did a cows likelihood of being slaughtered. Early and late scoring period $\mathrm{BCS}=3$ and $\mathrm{BCS}>3$ was associated with a decreased $\log$ odds for cow deaths, while early scoring period BCS had no association with cow slaughters, and $\mathrm{BCS}=3$ and $\mathrm{BCS}>3$ during the late scoring period was associated with a decreased log odds for a cow to be slaughtered compared to $\mathrm{BCS}<3$. Higher parity cows (parity $\geq 2$ ) also had increased log odds for slaughter during both scoring periods, while only parity $\geq 4$ cows had increased log odds for death during both scoring periods. As the PTA for lameness and calving interval increased so too did the log odds for being slaughtered during both scoring periods, while the PTA for mortality was not significantly associated with cow deaths or cow slaughters. As stated in the materials and methods section, farm was also included in each model as fixed predictor variable, because the model was unable to converge with farm as a random variable. As a result, a small number of farms were significant in both models for cow deaths and cow slaughters, but due to the large number of farms involved in this study the results are not reported in Table 5. 
70 | Chapter 4

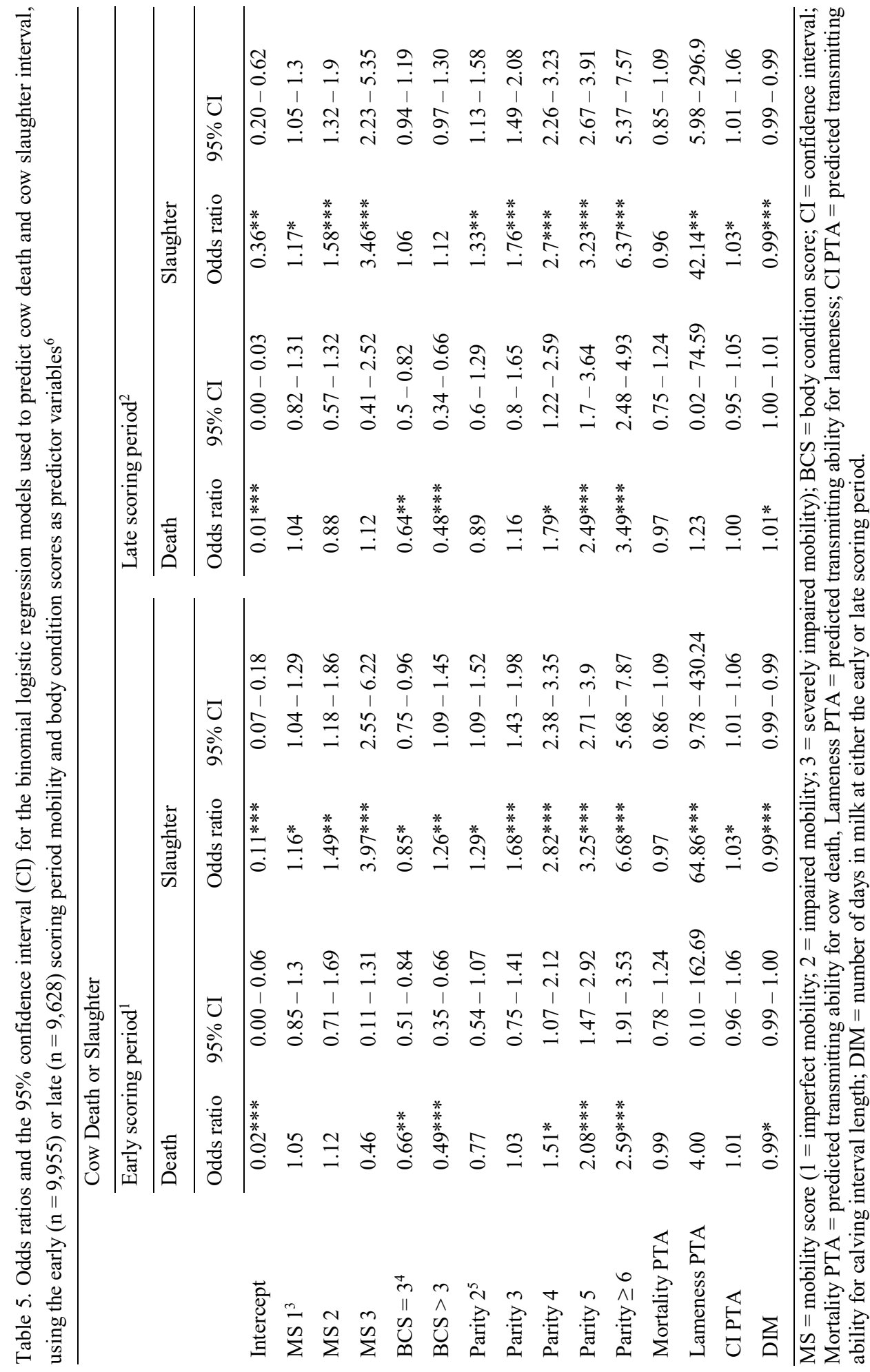


Production impacts \& Mobility scores $\mid 71$

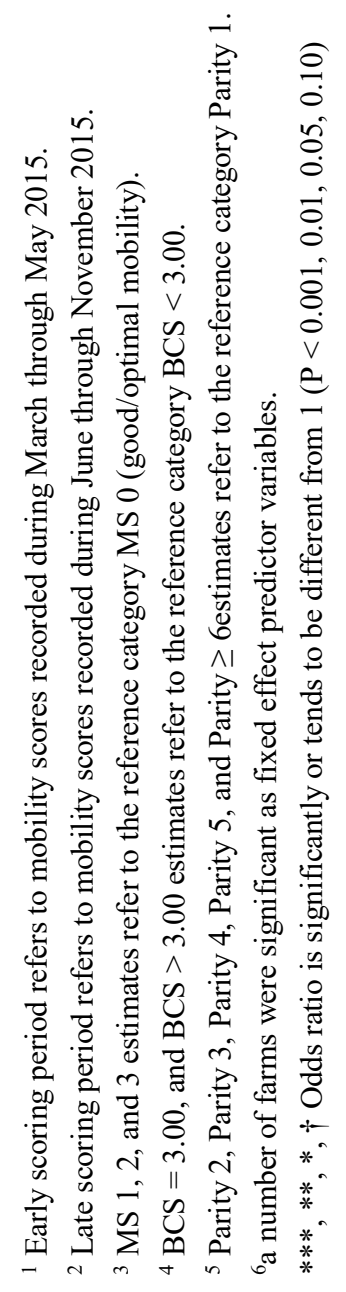




\section{2 | Chapter 4}

\section{DISCUSSION}

\section{Milk, Fat, and Protein Production Performance}

This analysis has identified an association between mobility score 2 (impaired mobility), mobility score 3 (severely impaired mobility), and reduced milk and protein 305-day yields during the early scoring period, and an association between mobility score 3 and reduced milk, fat, and protein yields during the late scoring period, compared to cows with mobility score 0 (optimal mobility) in a spring calving, pasture-based system. However, there was no significant association between milk, fat, or protein yield, and mobility score 2 during the late scoring period, which could suggest that a cow with a mobility score 2 during the late scoring period (later in the lactation) has less potential to impact on the yield for the lactation compared to a cow with a mobility score 2 during the early scoring period (earlier in the lactation). Yield losses, specifically fat and protein yield losses are of particular importance in milk production systems in Ireland as this is the basis for how farmers are paid for their milk (Geary et al., 2010); however, literature on the association between suboptimal mobility and fat and protein yield are less available. Many studies have reported on production losses (specifically milk yield) associated with 'lame' cows, but focused on confinement type systems (Bicalho et al., 2008); wherein cows are housed all of the time, year-round calving, pasture-based systems (Archer et al., 2010); wherein calving pattern is not synchronized with feed demand, with cow grazing occurring when possible, and autumn calving, pasture-based systems (Green et al., 2002); wherein cows calving during the autumn months, with cows grazing occurring when possible. The comparison of the yield losses associated with impaired and severely impaired mobility in our study to the yield losses reported in other studies, requires consideration of the methods of data collection and the way in which lameness is defined. Firstly, the methods of data collection can vary from potential lame cows being pre-selected by farmers followed by diagnosis by a veterinarian (Green et al., (2002), to the method of data collection implemented in the present study whereby all cows were mobility scored without any pre selection. Secondly, defining or classifying lameness can also vary significantly between studies. For example, using the 5-point scale developed by Sprecher et al. (1997), a cow is defined as 'lame' when she had a score $\geq 3$, however, using the same scoring method Olechnowichz and Jaskowski (2015) define a cow as 'lame' when she had a score $\geq 2$, and Kovács et al. (2015) only referred to a cow as 'lame' when her score was $\geq 4$

Hence in our study, we only refer to varying levels of suboptimal mobility (mobility score 1, 2, and 3) and optimal mobility (mobility score 0 ) as defined by the UK Agriculture and Horticulture Development Board four point scale (https://dairy.ahdb.org.uk/technicalinformation/animal-health-welfare/lameness/husbandry-prevention/mobilityscoring/\#.WXnhULuFOr8; accessed December 16, 2017).

In our study, milk yield losses of about $350 \mathrm{~kg}$ for a 305 -day lactation was associated with cows with severely impaired mobility (mobility score 3 ) during the late scoring period. This result is comparable to the results of Archer et al. (2010), reporting milk yield losses of up to 
$350 \mathrm{~kg}$ for 305-day lactation associated with severely lame cows, using the same mobility scoring method. The study of Hernandez et al. (2002), however, reports much greater yield losses, with lame cows producing about $850 \mathrm{~kg}$ less milk compared to non-lame cows when referring to the mean yield. The relatively greater yield loss reported by Hernandez et al. (2002) could most likely be due to differences in production systems and that cows were milked three times per day, whereas cows in the present study were milked twice per day. Comparable results between our study and the study of Archer et al. (2010) were evident despite the slightly higher average milk yields in the study of Archer et al. (2010). Archer et al. (2010) reported that 'severely lame' cows (equivalent to severely impaired cows in the present study) failed to achieve their potential 305-day milk yield, but that progressive yield losses did not occur until 4 months after lameness was detected. This implies that the use of test day yield depending on the milk recording system and frequency and a lameness event relative to a milk recording event can result in suboptimal mobility having a poor association with test day milk yield. Daily milk yield allows for more prompt identification of yield losses, however this type of data is rarely collected on commercial farms, therefore depending on the level of milk recording i.e. every four/eight/twelve weeks, the lameness event and its effects may be more difficult to pick up. In research settings wherein data is collected daily or for a full lactation setting, both the direct and indirect effects are captured across the lactation. However, it could also be a limitation of the present study having analysed the effect of mobility score on an entire lactation using just two mobility scores per cow, whereby other events between both scoring periods could have been missed in the analysis. The reasoning for using just two mobility scores used in the present study was simply due to the large number of farms included in this study and the time availability of the technicians which resulted in two measurements of both mobility score and BCS collected for each cow. Figure 1 (a) and 1 (b) illustrate the distribution of each mobility score for both scoring periods. 
(a)

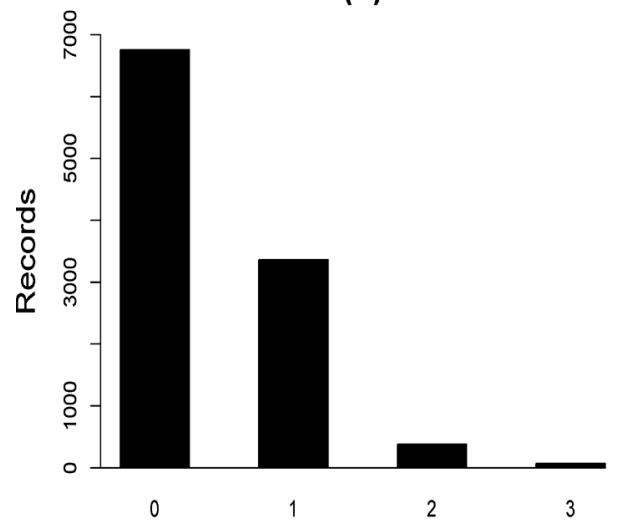

Early Scoring Period Mobility Score

(c)

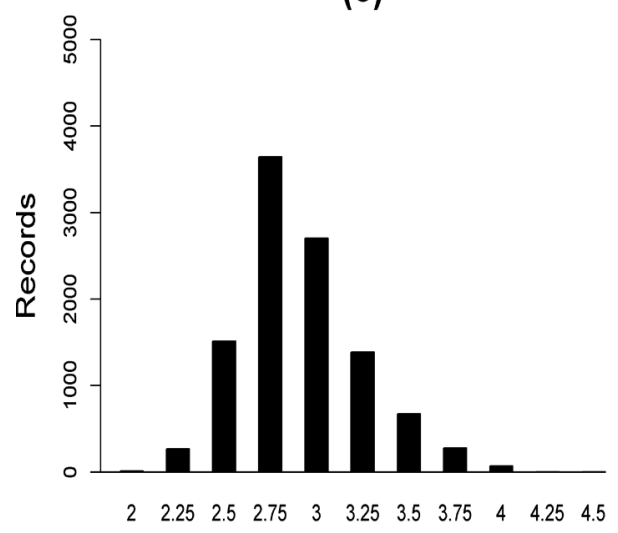

Early Scoring Period Body Condition Score (b)

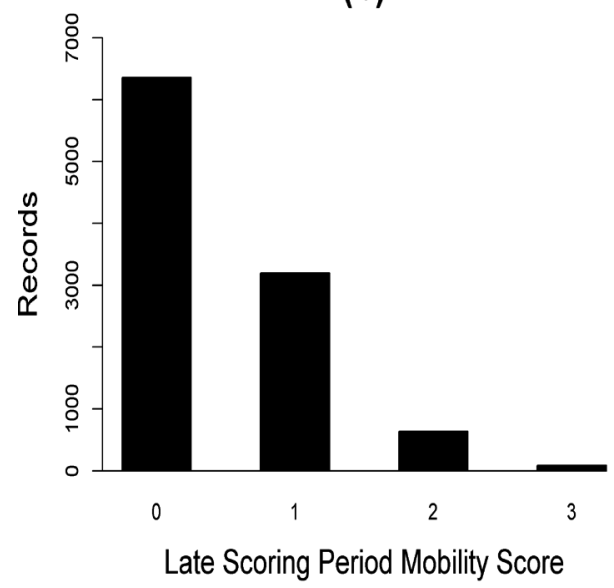

(d)

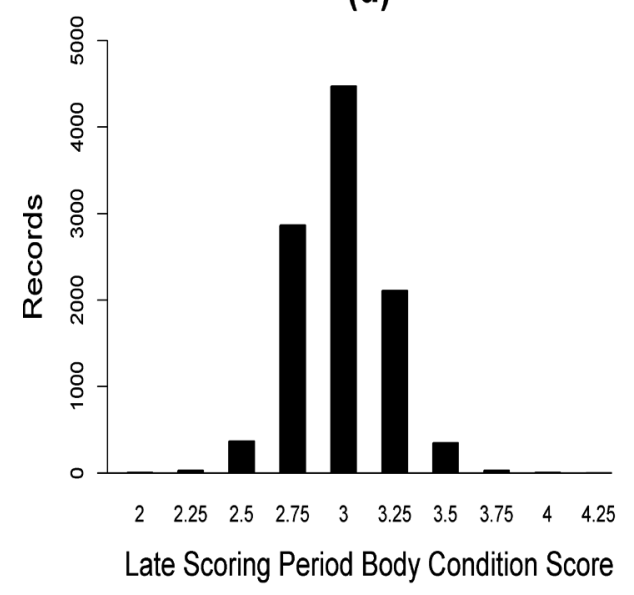

Figure 1. Distribution of (a) early and (b) late scoring period mobility score, and (c) early and (d) late scoring period body condition score

Early scoring period refers to mobility scores recorded during March through May 2015.

Late scoring period refers to mobility scores recorded during June through November 2015. 
In our study there was a tendency for increased milk and protein yield associated with cows scored as mobility score 1 during the early scoring period and significantly increased milk, fat, and protein yield in cows scored as mobility score 1 during the late scoring period. Mobility score 1 (imperfect mobility), is a mild deviation from optimal gait, thus we hypothesised that cows scored as mobility score 1 in our study could be comparable to what is often not included in the 'lame' category throughout the literature, because mobility score 1 cows have imperfect mobility, thus are more difficult to identify by the untrained eye. Higher yielding cows being associated with lameness have been reported on throughout the literature (Green et al., 2002: Amory et al., 2008; Archer et al., 2010). The increase in yield reported in the present study associated with mobility score 1 is relatively small throughout the entire lactation in comparison to the reported increase reported by for example Green et al. (2002). Green et al. (2002) found that 'lame' cows were associated with a higher milk yield by up to $342 \mathrm{~kg}$ over a 305-day lactation, while in the present study, mobility score 1 cows were associated with a higher milk yield by just $68 \mathrm{~kg}$ over a 305 -day lactation $(\sim 1 \%$ increase in yield throughout the lactation). The mean 305-day yield in the present study $(6,400 \mathrm{~kg})$ is similar to that reported by Green et al. (2002). However, a key difference (other than type of system) is the use of repeated measures and specific test day record yields as the outcome variables by Green et al. (2002), while in the present study the average lactation yield was used as the outcome variable. The increase in yield reported by Green et al. (2002) is much greater compared to the reported yield in the present study. This difference could be explained by the difference in the type of data collected and analysed in both studies, or could be due to the inclusion of a correction for a genetic predisposition for higher yields, by including the each cows PTAs for milk, fat, and protein in our analysis, that was not included in the study of Green et al. (2002).

Regardless, the results of our study showing that early scoring period mobility score 2 is negatively associated with yield, highlights the importance of regular mobility scoring on farm by trained professionals. Routine mobility scoring of entire herds, however, is quite labor intensive, thus there is a need for automated sensor technology in order to facilitate the identification of problem cows (specifically mobility score 1 cows that may progress to mobility score 2 or 3 ) at an earlier stage (Schlageter-Tello et al., 2018). Perhaps if farmers had regular updates of each cows mobility score, it would be easier to identify mobility score 1 cows before they possibly progress to a more severe state of suboptimal mobility, which would also facilitate earlier treatment (Leach et al., 2012) and reduce the potential yield losses from occurring.

\section{Somatic Cell Count}

This study reports on elevated SCC on the $\log 10$ scale associated with suboptimal mobility (mobility score 1, 2, and 3) during both scoring periods, except for a tendency for elevated SCC for mobility score 3 cows during the early scoring period. The tendency reported in Table 2 could be explained by the relatively lower number of cows scored as mobility score 


\section{6 | Chapter 4}

3 in the present study and the large variation in SCC among this group. As reported in the untransformed SCC scale in Table 3, however, cows with suboptimal mobility have higher SCC compared to cows with optimal mobility during both the early and late scoring periods. A biological explanation for the association between suboptimal mobility and elevated SCC could potentially be explained using the findings of Navarro et al. (2013) and Walker et al. (2008). Navarro et al. (2013) reported that 'lame' cows (defined as cows scored as locomotion score 3 using the Sprecher et al., 1997 scale) stood on average for shorter periods compared to 'non-lame' cows. The implied increased lying time potentially increases the risk of exposure to pathogens at the teat end. The study of Walker et al. (2008) confirms that lame cows do spend more time lying down. Another possible explanation for the association between elevated SCC and suboptimal mobility reported in the present study could be due to an immune response of cows with suboptimal mobility. O'Driscoll et al. (2015) identified a higher neutrophil percentage in 'lame' cows compared with 'sound' cows, and 'lame' cows tended to have a higher neutrophil: lymphocyte ratio compared with 'sound' cows. In the study of O'Driscoll et al. (2015), a 'lame' cow was referred to as a cow with an obvious impairment of one or more limbs specifically due to sole ulcers, which have been shown to be associated with suboptimal mobility by O'Connor et al. (2019). The higher neutrophil: lymphocyte percentage found by O'Driscoll et al. (2015) associated with 'lame' cows has been previously described in animals experiencing stress (Fell et al., 1999) and in cows with an increased genetic susceptibility for disease (Kulberg et al., 2002).

\section{Calving Interval}

It has been demonstrated in a review paper by Huxley (2013) that lameness negatively influences a wide range of measures of reproductive performance. To the best of our knowledge, the present study is the first to identify an increased calving interval length associated with specific mobility scores. Our study reports on the association between mobility score 2 during the early scoring period, and mobility score 3 during the late scoring period, with an increased calving interval length. Cows with a mobility score 3 during the early scoring period, however, were not significantly associated with an increased calving interval length, which could be a result of the relatively lower number of mobility score 3 cows. Similarly, cows with a mobility score 2 during the late scoring period were also not significantly associated with an increased calving interval, which could be explained by the fact that cows with a mobility score 2 during the late scoring period may have had optimal mobility during the early scoring period when they became pregnant. The findings of other studies compliment ours by reporting on longer calving intervals associated with the presence of sole ulcers (Hultgren et al., 2004), heel-horn erosions and sole hemorrhages (Sogstad et al., 2006), which are all types of claw disorders shown to be associated with suboptimal mobility (O'Connor et al., 2019). Other factors linked to calving interval length have also been reported throughout the literature, with Sprecher et al. (1997) and Hernandez et al. (2001) reporting an increased number of days from calving to first service and from calving 
to conception for 'lame' cows. The aim in spring calving, pasture-based systems, is to synchronise grass growth with nutrient requirements, thus calving pattern is used to synchronize feed supply and feed demand of the herd with the seasonal pattern of grass growth (Shalloo et al., 2014). Therefore, in such systems the calving pattern and the length of the calving interval is a key indicator of efficiency at the farm level and deviations from the seasonal pattern can result in various types of losses.

\section{Cow Death and Slaughter}

The effect of lameness on culling has been reported frequently throughout the literature, with the majority of published work reporting an association between lameness and increased risk to be culled. Booth et al. (2004) reports on the association between lameness and culling where culling refers to both cow deaths on farm and cow slaughters, while McConnel et al. (2008) reports on the association between lameness and cow mortality (cow deaths on farm). Sprecher et al. (1997) reports an association between lameness and 'culling'. In the present study we analysed cow deaths on farm and cow slaughters separately. We found no association between mobility score and cow deaths, which we expected because it is assumed that cows would be culled (sold) prior to succumbing to a severe enough state of lameness that they could die on farm. However, we identified an increased risk to be slaughtered associated with cows with suboptimal mobility (mobility score 1, 2 and 3 ) compared to cows with optimal mobility (mobility score 0 ). From this finding, we hypothesize that if there were a substantial proportion of cows with suboptimal mobility within a herd, this could potentially be associated with increased herd-level culling. Increased herd-level culling implies a requirement for an increase in replacement heifers in the herd or lower rates of expansion if this is what was happening on farm. Higher culling rates in herds would result in a younger age profile than is optimum and thus less potential for voluntary culling. The possibility of increased culling of cows within a herd due to suboptimal mobility also has the potential to reduce overall herd yield, due to milk yield being dependent on parity, whereby first parity cows produce less milk than mature cows (Hutchinson et al., 2013). However, it is important to note that the decision to cull a cow is a complex one in which many more factors are considered, factors including yield, gestation status, and even SCC levels of which were not analysed for their association with culling in this study.

\section{CONCLUSIONS}

Our study shows that suboptimal mobility in spring calving, pasture-based systems has negative associations with production (milk, fat and protein yield, and SCC), and reproductive performance (calving interval length), as well as being associated with a higher risk for premature culling. The results of the current study are in agreement and comparable with other dairy management systems, such as confinement type systems and year round calving, pasture-based systems. Spring calving pasture-based systems are based on low inputs and low outputs where cost control is paramount to the success of the system, therefore 


\section{8 | Chapter 4}

preventable losses associated with suboptimal mobility have significant economic impacts, despite the prevalence of suboptimal mobility in such systems being relatively lower.

\section{ACKNOWLEDGEMENTS}

Funding from the Irish Department of Agriculture, Food and the Marine STIMULUS research grant Healthy Genes is greatly appreciated, as well as a research grant from Science Foundation Ireland and the Department of Agriculture, Food and Marine on behalf of the Government of Ireland under the Grant 16/RC/3835 (VistaMilk). The authors also wish to acknowledge the co-operation of all participating farmers and recorders for data recording and collection, as well as the Walsh Fellowship. 


\section{Supplementary material}

Supplemental Figure S1. Flowchart illustrating deletions from the original data set for milk, fat, and protein 305-d yield analysis using early/late scoring period mobility score and BCS as predictor variables. Early scoring period refers to mobility scores recorded during March through May 2015. Late scoring period refers to mobility scores recorded during June through November 2015. Incomplete records refer to all predictor variables used in the milk, fat, and protein analysis, including early/late scoring period mobility score and BCS.

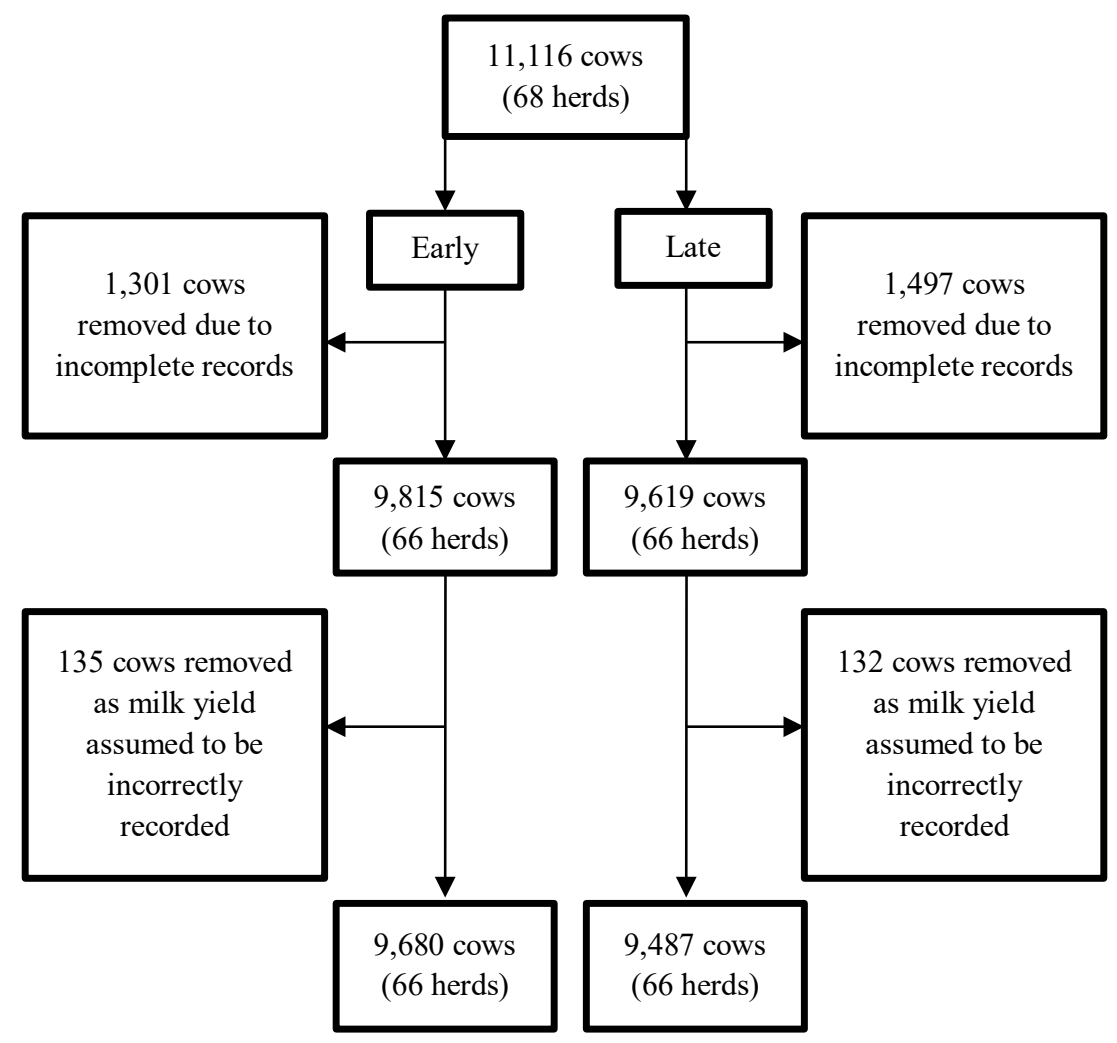




\section{0 | Chapter 4}

Supplemental Figure S2. Flowchart illustrating deletions from the original data set for SCC analysis using early/late scoring period mobility score and BCS as predictor variables. Early scoring period refers to mobility scores recorded during March through May 2015. Late scoring period refers to mobility scores recorded during June through November 2015. Incomplete records refer to all predictor variables used in SCC analysis, including early/late scoring period mobility score and BCS.

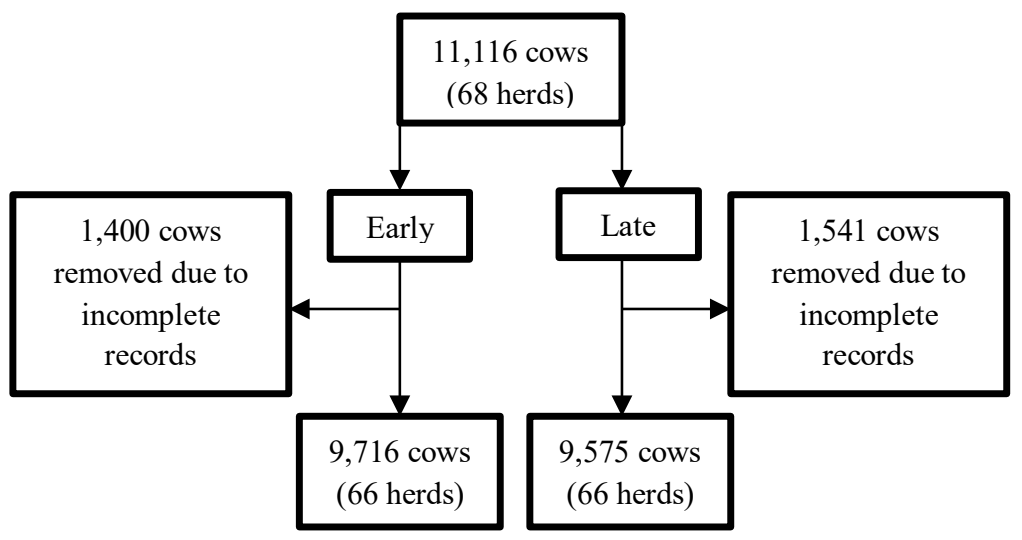


Supplemental Figure S3. Flowchart illustrating deletions from the original data set for the calving interval length analysis, using early/late scoring period mobility score and BCS as predictor variables. Early scoring period refers to mobility scores recorded during March through May 2015. Late scoring period refers to mobility scores recorded during June through November 2015. Incomplete records refer to all predictor variables used in the calving interval length analysis, including early/late scoring period mobility score and BCS.

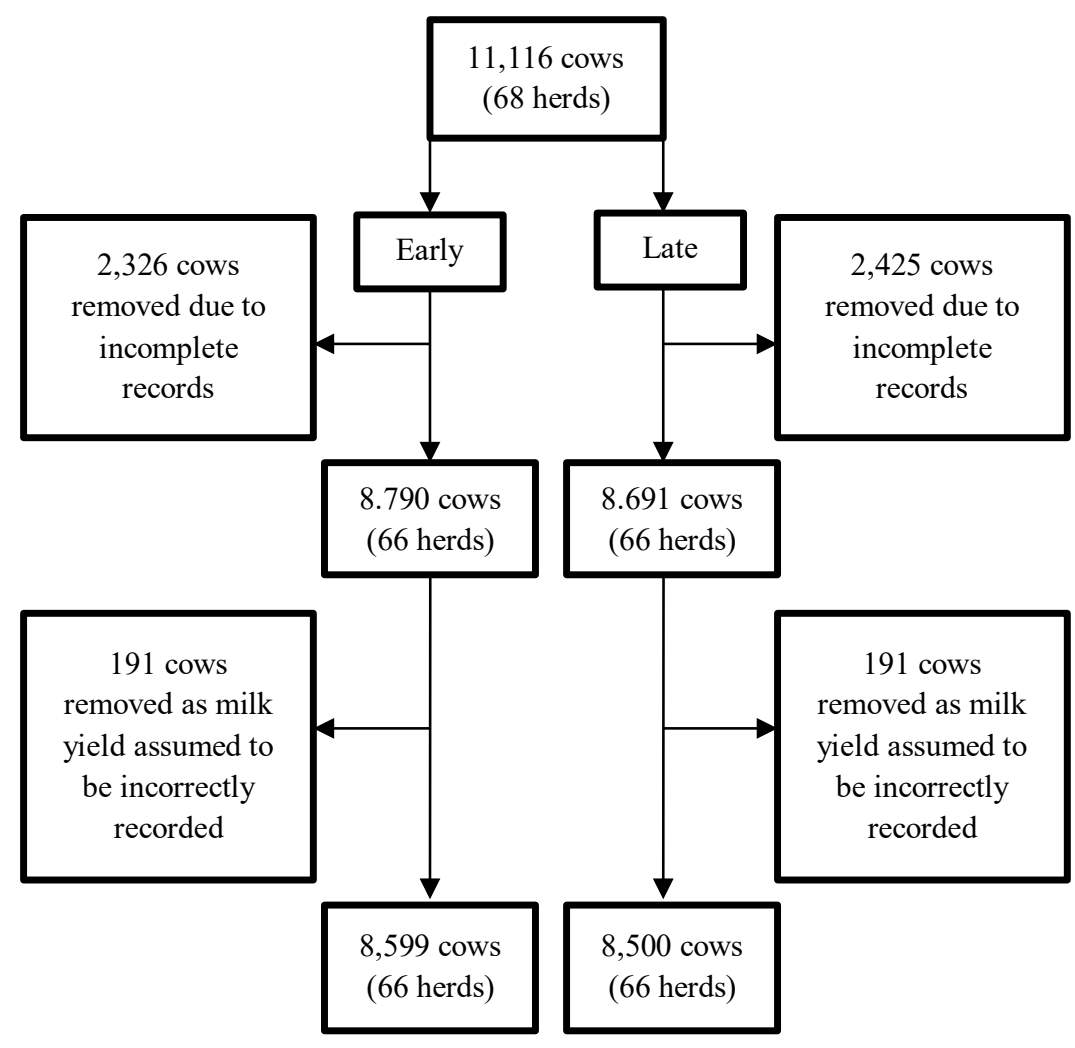




\section{2 | Chapter 4}

Supplemental Figure S4. Flowchart illustrating deletions from the original data set for cow death and cow slaughter analysis, using early/late scoring period mobility score and BCS as predictor variables. Early scoring period refers to mobility scores recorded during March through May 2015. Late scoring period refers to mobility scores recorded during June through November 2015. Incomplete records refer to all predictor variables used in the cow death and cow slaughter analysis, including early/late scoring period mobility score and $\mathrm{BCS}$.

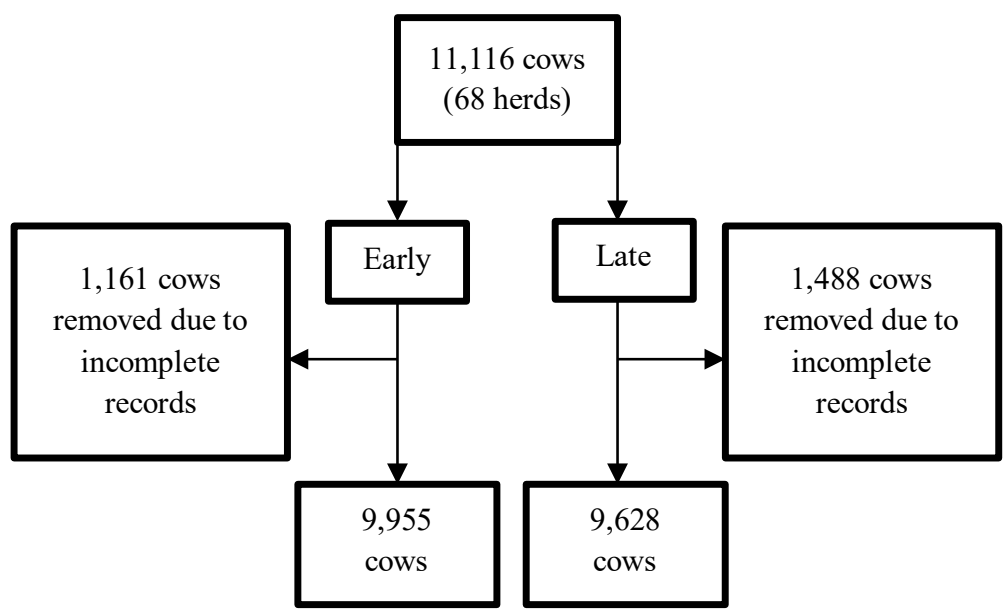




\section{Chapter 5}

The economic impact of suboptimal mobility in dairy cows under spring calving, pasture-based management

A. H. O'Connor* $\uparrow$, L. Shalloo*, E. A. M. Bokkers $\dagger$, I. J. M. de Boer $\dagger$, H. Hogeveen $\uparrow$, R. Sayers*, N. Byrne*, and E. Ruelle*

* Teagasc, Animal and Grassland Research and Innovation Centre, Moorepark, Fermoy, Co. Cork, Ireland

$\dagger$ Animal Production Systems group, Department of Animal Sciences, Wageningen University \& Research, the Netherlands

† Business Economics group, Department of Social Sciences, Wageningen University \& Research, the Netherlands 


\section{4 | Chapter 5}

\section{ABSTRACT}

It is well accepted throughout the literature that severe forms of suboptimal mobility are associated with substantial production losses and economic consequences. While recently, it was reported that milder forms of suboptimal mobility in seasonal calving, pasture-based dairy cows are also associated with yield losses, elevated somatic cell count, increased calving interval length, and an increased risk to be culled. Therefore, the overall aim of the current study was to determine the economic consequences, specifically on farm net profit, associated with varying prevalence of suboptimal mobility within spring calving, pasturebased dairy herds. A new sub model predicting suboptimal mobility was developed and integrated within the Pastured Based Herd dynamic model (PBHDM). The model predicts claw disorders initially and then the mobility score of each individual cow in the herd. The model simulates the operation of a spring calving, pasture-based dairy farm with a daily time step including a mobility score for each cow on each day. The impact of a cow having suboptimal mobility was also simulated, whereby a cow with a mobility score $>0$ has an increased risk to be culled and cows with a mobility score $>1$ has a reduced milk yield. The sub model predicted claw disorders and mobility scores within reasonable accuracy relative to the actual dataset. The impact on profitability is simulated based on production and reproductive effects of individual animals as well as the associated treatment costs. Four scenarios were evaluated based on varying values for a genetic predisposition for lameness (good, average, poor and very poor mobility herds). The good mobility herd ( $95 \%$ of the herd had optimal mobility (mobility score 0 )) can achieve $€ 16,500$ more overall farm net profit compared to a very poor mobility herd $(90 \%$ of the herd had suboptimal mobility (mobility score $>0)$ ). The substantial decrease ( $18 \%$ compared to the good mobility herd) in farm net profit is due to reduced milk yield, increased culling, and treatment costs for mobility issues. We conclude that as the prevalence of cows with suboptimal mobility scores (even mild suboptimal mobility scores) increases within a herd, the overall farm next profit decreases. Keywords: lameness, dairy cattle, dynamic model, grass-based ruminant systems 


\section{INTRODUCTION}

Lameness is described as one of the most important disease challenges of dairy cows (Huxley, 2012) with a prevalence ranging from $0 \%$ to $45 \%$ (Cramer et al., 2008). Lameness is one form of suboptimal mobility, whereby in this study, suboptimal mobility refers to any deviation from normal or 'optimal' mobility of a dairy cow. Consequently, suboptimal mobility is a broader term than lameness whereby throughout the literature lameness usually refers to just moderate to severe forms of suboptimal mobility. Using the UK Agriculture and Horticultural Development Board (AHDB) mobility scoring scale, optimal mobility refers to a cows with a mobility score 0 , while suboptimal mobility refers to any mobility score $>0$. A mobility score 1 describes a cow with imperfect mobility, a mobility score of 2 describes a cow with impaired mobility, and mobility score 3 describes a cow with severely impaired mobility.

Suboptimal mobility can have significant impacts on the welfare of dairy cows, due to the associated pain (O Callaghan et al., 2002, Flower and Weary, 2009). Severe forms of suboptimal mobility have also been shown to be associated with significant production loss (Green et al., 2002, Bicalho et al., 2008). Also, in pasture-based systems, suboptimal mobility has been shown to be associated with production losses, as well as elevated somatic cell count, increased risk for culling and prolonged calving interval length (O'Connor et al., (2020) In prep. Although there is a perception that within pasture-based herds, lameness is less of a problem compared to cows in year round confinement type systems (Olmos et al., 2009), suboptimal mobility prevalence of up to $38 \%$ was previously reported in a pasture based setting (O'Connor et al., 2019). The belief in a lower risk for suboptimal mobility in pasture-based systems in combination with those systems having a high focus on low inputs is a reason that prevention of suboptimal mobility does not have a high priority in these systems. Insights into the avoidable potential losses resulting from suboptimal mobility are paramount to the success of campaigns to improve the mobility of dairy cows in pasturebased systems.

Previously throughout the literature studies have reported on the economic consequences related to lameness or specific claw disorders causing lameness (Bruijnis et al., 2010, Ettema et al., 2010). Ettema et al. (2010) estimated the economic loss associated with lameness to be up to $€ 192$ per cow per year, while Bruijnis et al. (2010) estimated the cost of specific claw disorders to be $€ 53$ per cow. Other earlier studies including that of Enting et al. (1997) and Kossaibati and Esslemont (1997) reported on the economic losses at the cow level, defining lameness as a binary trait. Because these previous studies only looked at lameness, being the more extreme forms of suboptimal mobility, they might have underestimated the total costs of suboptimal mobility. Therefore the economic impact of varying prevalence' of specific levels of suboptimal mobility (and not just the binary variable "lameness") asks for further study.

For the majority of the north-west European pasture-based systems, cows are housed during the winter months but managed at pasture for the remainder of the year. Ireland enjoys a 


\section{6 | Chapter 5}

favourable climate for grass production and therefore, the majority of dairy herds are managed under a spring calving, pasture-based seasonal system. In such a system, over $70 \%$ of cows calve between February and March (Irish Cattle Breeding Statistics, 2018). The compact calving season is favoured in such a system in an effort to maximise milk produced from grazed grass by managing the interface between peak milk production and peak grass production (Dillon et al., 2005). Dairy cows in typical Irish spring calving, pasture-based systems are exposed to different risk factors compared to cows managed in confinement type systems (O'Connor., et al. in review), and hence we hypothesized that the economic consequences of suboptimal mobility may also differ between management systems. Therefore, the objective of the current study was to estimate the economic consequence of varying prevalence of different levels of suboptimal mobility specifically within spring calving, pasture-based dairy herds. To do this, four different scenarios were analysed, whereby cows within each scenario had specific levels of a genetic predicted transmitting ability to have 'lameness'.

\section{MATERIALS AND METHODS}

To simulate physical and financial performance of spring calving, pasture-based, production systems, two models were combined and utilised: The Pasture Based Herd Dynamic Milk model (PBHDM) (Ruelle et al., 2015) and the Moorepark Dairy Systems Model (MDSM) (Shalloo et al., 2004). In order to simulate the production impacts of suboptimal mobility on cow performance, a specific mobility sub-model was developed within the PBHDM to simulate mobility scores for each cow within the herd. The definitions of each mobility score predicted by the sub model are based on the UK Agriculture and Horticulture Development Board four-point scale (https://dairy.ahdb.org.uk/technical-information/animal-healthwelfare/lameness/husbandry-prevention/mobility-scoring/\#.WXnhULuFOr8; accessed December 16, 2017):

- A score of 0 describes a cow with good mobility that walks with even weight bearing and rhythm on all four feet, with a flat back. Long and fluid strides are possible.

- A score 1 describes a cow with imperfect mobility with uneven steps or shortened strides affecting one or more limbs and it may not be immediately identifiable.

- A score 2 describes a cow with impaired mobility, which is a cow with uneven weight bearing on one or more limbs that is immediately identifiable and/or shortened strides, usually associated with an arched back.

- A score of 3 describes a cow with severely impaired mobility; a cow with this score is unable to walk as fast as the rest of the 'healthy' herd due to more severely impaired symptoms compared to score 2 . 


\section{Description of the models}

The Pastured Based Herd dynamic model (PBHDM) was developed and described in detail by Ruelle et al. (2015;2016). The PBHDM is a dynamic, stochastic model developed in $\mathrm{C}++$. The PBHDM simulates the performance of individual dairy animals from birth to death, with a daily time step. The model allows for the events of dairy animals to be simulated under different management regimes (mainly through different feeding) of groups of animals. The groups included are calves (up to 90 days), three groups of heifers ( 3 months through 12 months, 13 through 24 months, and greater than 24 months), lactating cows (the focus of this study), and the dry cows. For the lactating cows, the PBHDM simulates the production of milk, fat and protein yield whereby the simulation of milk production per day is calculated based on the interaction between the energy and protein intake of the cow, body condition score (BCS) change and each individual animal milk yield. The BCS of each cow is also calculated using a daily time step. The model simulates each animal's intake at grazing which is dependent on various animal characteristics, but also takes into consideration supplementation, grass availability and quality. The grass growth in the model is predicted using the MoSt GG model (Ruelle et al., 2018). The MoSt GG model simulates grass growth with a daily time step taking into account soil water and soil nitrogen dynamics.

The Moorepark Dairy Systems Model (MDSM; (Shalloo et al., 2004)) is a stochastic budgetary simulation model. The objective of the MDSM is to simulate pasture-based milk production systems across a range of economic indicators, including profit, when changes are made to the farm being simulated. An example of a study wherein the MDSM has been previously utilised is to estimate the effect of mastitis on the profitability of Irish dairy farms (Geary et al., 2012). The model integrates animal inventory and valuation, milk supply, feed requirements, land and labor utilization with economic analysis (Shalloo et al., 2004).Variables costs accounted for in the MDSM include; fertilizer, contractor charges, veterinarian, artificial insemination, silage and reseeding, Fixed costs are also included such as; machinery maintenance and running costs, farm maintenance, car, telephone, electricity, and insurance. The MDSM was updated with current price levels. The MDSM was fully incorporated into the PBHDM in 2019. 


\section{Mobility sub model}

The sub model for mobility (developed within the PBHDM) and its impact on performance consists of four steps, which are outlined briefly in the flow diagram (Figure 1) below and described in more detail later in the materials and methods.

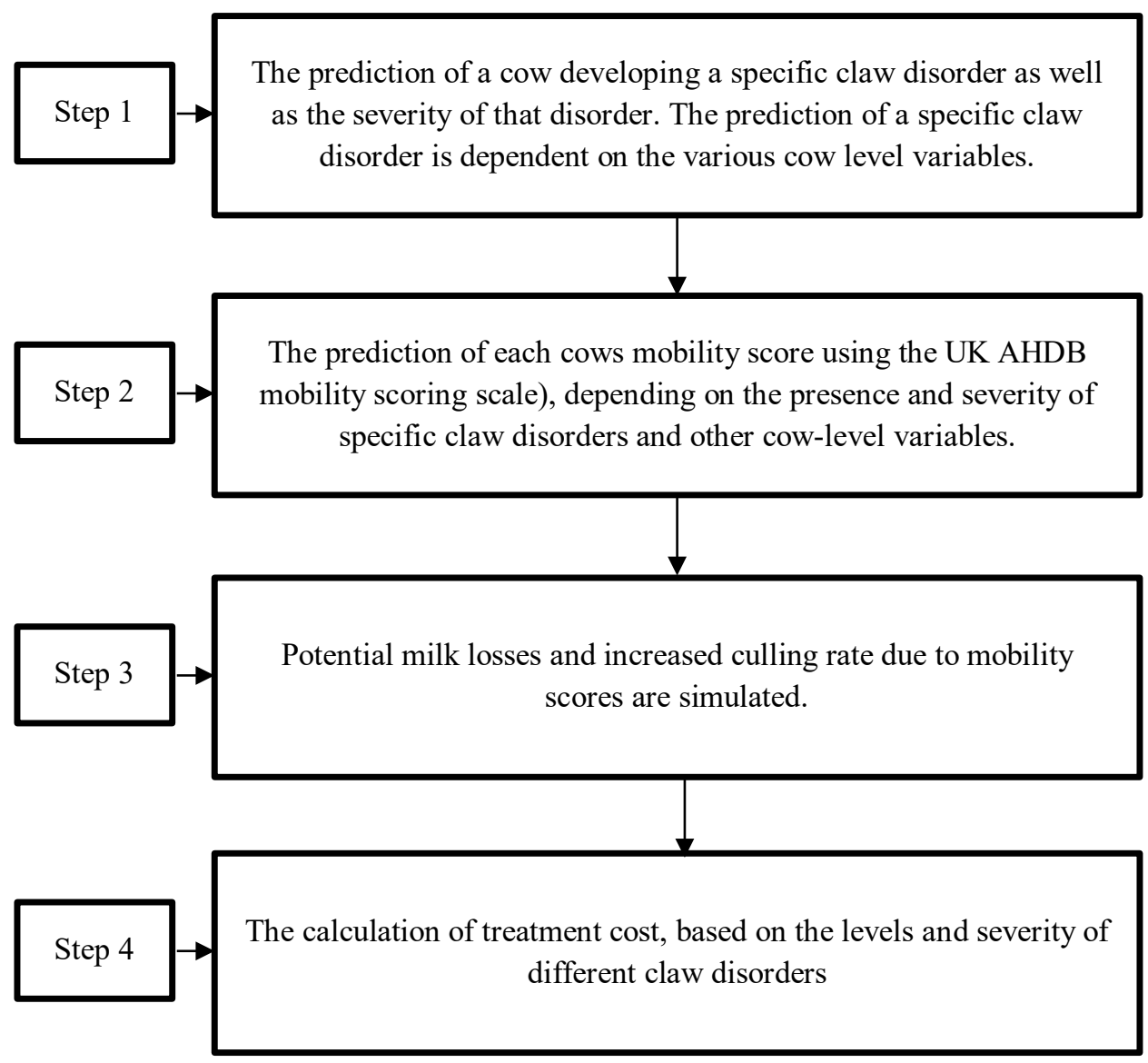

Figure 2 Flow diagram of the mobility sub model developed in the current study

Step 1: Claw disorders. Five specific claw disorders and their severities were simulated (Table 1). The probability for developing a claw disorder is dependent on BCS, cow parity, as well as the PTA for lameness, and the PTA for milk yield. The probabilities were determined from a logistic regression model (Table 2) based on a study involving about 7,000 cows as described in detail by O'Connor et al. (2019). Every cow in this study had their hind hooves lifted to be inspected for the presence and severity of claw disorders, as well as their mobility score and BCS recorded. That study generated a set of cow level variables related to the different claw disorders. The claw disorders were simulated separately, i.e. a cow could have more than one claw disorder at a time, but not more than one severity of a 
specific claw disorder at the same time. Hence, it was not possible for example, to simulate a cow with an overgrown claw 2 and an overgrown claw 3 at the same time.

The probability to develop claw disorders is completed with a daily time step and depends on the stage of lactation. Therefore in this model, the probability to develop a claw disorder has been limited to a period of time in the lactation depending on the claw disorder (up to 45 days in milk for an overgrown claw and sole hemorrhage (based on the findings of Charfeddine and Pérez-Cabal (2017) related to thickness of the fat pad in the digital cushion), up to 120 days in milk for white line disease, up to 150 days in milk for a sole ulcer (based on the findings of Amory et al. (2008)), and up to 60 days in milk for digital dermatitis (based on Mostert et al. (2018) adapted from Amory et al. (2008)). During the specific periods as described above, the probability for a cow to develop a claw disorder on a given day originates from the regression model presented in Table 2 (annual probability for the cow to develop a claw disorder is divided by the number of days the cow can develop the claw disorder). Each day a cow has a certain probability to develop a specific severity of each claw disorder, which was calculated as follows;

$$
P_{\text {claw disorder }}=\frac{\frac{R}{1+R}}{\text { ndays }}
$$

With $\mathrm{R}$ as the exponential of the regression for the corresponding claw disorder (overgrown claw / sole haemorrhage / white line disease / sole ulcer / digital dermatitis) as outlined in Table 1, and ndays as the number of days a cow can develop that claw disorder as described above.

When a cow develops a specific claw disorder, the model randomly simulates the severity based on the study of O'Connor et al. (2019) (Table 3), and the length of time the cow will have the developed claw disorder was simulated based on the reports of Bruijnis et al. (2010) and is outlined in Table 4. 


\section{$90 \mid$ Chapter 5}

Table 1 Descriptions of claw disorders and their severities simulated

\begin{tabular}{llll}
\hline Claw disorder & Severity score & 3 \\
\hline Overgrown Claw & 1 & 2 & 3 \\
White line disease & 1 & 2 & 3 \\
Sole hemorrhage & 1 & 2 & - \\
Sole ulcer & Present & - & - \\
Digital dermatitis $^{1}$ & Present & - &
\end{tabular}

Severity score 1 = mild form of the disorder; severity score 2 = moderate form of the disorder; severity score 3 = severe form of the disorder.

${ }^{1}$ Sole ulcer and digital dermatitis were recorded as binary variables as either present or not present in the hind hooves.

Table 2 Coefficients for simulating the development of claw disorders in the hind hooves based on the findings of O'Connor et al. (2019)

\begin{tabular}{|c|c|c|c|c|c|}
\hline & $\begin{array}{l}\text { Overgrown } \\
\text { claw }\end{array}$ & Sole hemorrhage & $\begin{array}{ll}\text { White line } \\
\text { disease }\end{array}$ & Sole ulcer & $\begin{array}{l}\text { Digital } \\
\text { dermatitis }\end{array}$ \\
\hline Intercept & -0.62 & -0.30 & -0.63 & -4.97 & -3.79 \\
\hline $\mathrm{BCS}<3.00$ & Reference & & & & \\
\hline $\mathrm{BCS}=3.00$ & 0.10 & 0.21 & 0.10 & -0.01 & 0.06 \\
\hline $\mathrm{BCS}<3.00$ & 0.31 & 0.42 & 0.15 & -0.04 & -0.16 \\
\hline Parity 1 & Reference & & & & \\
\hline Parity 2 & 0.73 & 0.08 & 0.37 & -0.72 & -0.05 \\
\hline Parity $3+$ & 0.83 & 0.19 & 0.96 & 1.09 & 0.42 \\
\hline PTA lame $^{1}$ & 3.26 & 5.11 & 7.79 & 17.00 & 3.12 \\
\hline PTA milk ${ }^{2}$ & +0.00 & +0.00 & +0.00 & +0.00 & +0.00 \\
\hline
\end{tabular}

${ }^{1}$ Predicted transmitting ability for lameness

${ }^{2}$ Predicted transmitting ability for milk production

$\mathrm{BCS}=$ body condition score 
Table 3 Percentage of chance for cows have a specific severity of each claw disorder based on the findings of O'Connor et al. (2019)

\begin{tabular}{lll}
\hline Claw Disorder $^{1}$ & Severity $^{2}$ & $\%{\text { of } \text { cows }^{3}}^{2}$ \\
\hline Overgrown claw & 1 & 68 \\
& 2 & 26 \\
Sole hemorrhage & 3 & 6 \\
& 1 & 62 \\
White line disease & 2 & 25 \\
& 3 & 12 \\
& 1 & 65 \\
& 2 & 19 \\
& 3 & 15
\end{tabular}

${ }^{1}$ Sole ulcer and digital dermatitis not included as these disorders were scored as present or not present and not severity scored.

${ }^{2} 1$ = mild; 2 = moderate; 3 = severe

${ }^{3} \mathrm{n}=6,927$

Table 4 Length of time (days) a cow has a claw disorder prior to treatment

\begin{tabular}{llll}
\hline & \multicolumn{3}{l}{ No. days present before treated by a vet } \\
\hline Overgrown claw 3 $^{1}$ & 88.45 & 2.9 & adapted from (Bruijnis et al., 2010) \\
Sole hemorrhage $3^{2}$ & 103.09 & 3.38 & (Bruijnis et al., 2010) \\
White line $3^{2}$ & 88.45 & 2.9 & (Bruijnis et al., 2010) \\
Sole ulcer & 76.25 & 2.5 & (Bruijnis et al., 2010) \\
Digital dermatitis & 107.97 & 3.54 & (Bruijnis et al., 2010) \\
\hline
\end{tabular}

${ }^{1}$ Overgrown claw 3 refers to a severe form of an overgrown claw

${ }^{2}$ Sole hemorrhage 3 refers to a severe form of a sole hemorrhage

${ }^{3}$ White line 3 refers to a severe form of a white line

*All claw disorders with a severity score 1 and 2 (mild and moderate claw disorders) are treated at the end of the lactation by a professional hoof trimmer

Step 2: Mobility scoring prediction. The mobility score of each cow is simulated daily depending on the specific claw disorder and severity that the cow has on that day (as simulated during the previous step), the prediction of the mobility scores is based on the study of O'Connor et al. (2019) using the UK AHDB four point mobility scoring scale as described above.

The coefficients of the regression used to predict mobility scores in the study of O'Connor et al. (2019) were used in the model presented in the current paper to predict the mobility score 


\section{2 | Chapter 5}

of each cow on a daily basis (Table 5). The calculation for the probability to have a certain mobility score is as follows;

$$
\begin{aligned}
& P_{M S 0}=\frac{1}{1+R_{1}+R_{2}+R_{3}} \times 100 \\
& P_{M S 1}=\frac{R_{1}}{1+R_{1}+R_{2}+R_{3}} \times 100 \\
& P_{M S 2}=\frac{R_{2}}{1+R_{1}+R_{2}+R_{3}} \times 100 \\
& P_{M S 3}=\frac{R_{3}}{1+R_{1}+R_{2}+R_{3}} \times 100
\end{aligned}
$$

With $R$ as the exponential of the regression for the mobility score $0 / 1 / 2 / 3$ as outlined in Table 5 . 
Table 5 Coefficients for predicting mobility score, based on the findings of O'Connor et al. (2019)

\begin{tabular}{|c|c|c|c|c|}
\hline & Category & Mobility score 1 & Mobility score 2 & Mobility score 3 \\
\hline Intercept & & -1.32 & -3.70 & -5.56 \\
\hline \multirow[t]{3}{*}{ Overgrown claw } & 1 & 0.22 & -0.18 & -0.33 \\
\hline & 2 & 0.40 & 0.77 & 0.37 \\
\hline & 3 & 1.13 & 2.46 & 3.16 \\
\hline \multirow[t]{3}{*}{ Sole hemorrhage } & 1 & 0.19 & -0.16 & -0.20 \\
\hline & 2 & 0.27 & 0.19 & 0.24 \\
\hline & 3 & 0.37 & 0.73 & 0.06 \\
\hline \multirow[t]{3}{*}{ White line disease } & 1 & 0.11 & 0.33 & -0.53 \\
\hline & 2 & 0.22 & 0.62 & -0.04 \\
\hline & 3 & 0.33 & 1.48 & 1.34 \\
\hline Sole ulcer & Present & 0.57 & 1.96 & 2.65 \\
\hline Digital dermatitis & Present & 0.65 & 1.90 & 3.31 \\
\hline \multirow[t]{3}{*}{$\mathrm{BCS}$} & $<3.00$ & Reference & & \\
\hline & $=3.00$ & -0.33 & -0.70 & -1.17 \\
\hline & $>3.00$ & -0.50 & -1.13 & -2.38 \\
\hline \multirow[t]{3}{*}{ Parity } & $=1$ & Reference & & \\
\hline & $=2$ & 0.36 & 0.64 & 0.72 \\
\hline & $\geq 3$ & 0.92 & 1.63 & 1.80 \\
\hline PTA lame $^{1}$ & & 6.03 & 12.20 & 18.91 \\
\hline PTA milk $^{2}$ & & 0.00 & 0.00 & 0.00 \\
\hline
\end{tabular}

$\mathrm{BCS}=$ body condition score

${ }^{1}$ Predicted transmitting ability for lameness

${ }^{2}$ Predicted transmitting ability for milk production

Step 3 Milk losses and culling. Milk production per cow is also simulated using a daily time step. Milk loss due to suboptimal mobility was estimated based on the results reported by (O'Connor et al., (2020) In prep., whereby mobility score 1 had no significant effect on milk yield, while mobility score 2 was associated with a milk yield loss of up to 1.6 $\%$ (depending on the duration the cow had that mobility score) compared to the average yield corrected for a 305 day lactation, and mobility score 3 was associated with a milk yield loss of up to $6 \%$ compared to the average yield corrected for a 305 day lactation. Therefore, in the current study all cows simulated to be mobility score 2 and 3 only experiences milk yield losses. Milk yield losses were modelled based on the hypothesis of milk losses happening for an average length of three months after the development of a specific claw disorder, which was based on the length of time a cow is likely to have a claw disorder (Bruijnis et al., 2010). 


\section{4 | Chapter 5}

This resulted in a daily milk yield loss of $6 \%$ for each day at mobility score 2 and $16 \%$ for each day at mobility score 3 .

For cows simulated to have suboptimal mobility (mobility score $\geq 1$ ) at any time throughout the lactation, there is an increased risk to be culled based on the results of a previous study by (O'Connor et al., (2020) In prep. The increased risk was calculated by multiplying the voluntary culling risk (circa 10\%) by the odds ratios reported by O'Connor et al. (2020) In prep. Therefore, a cow with a mobility score 0 had a $9 \%$ chance to be culled (base chance for every cow regardless of mobility score), a cow with a mobility score 1 had a $11 \%$ chance to be culled, a cow with a mobility score 2 had a $13 \%$ chance to be culled, and a cow with a mobility score 3 had a $37 \%$ chance to be culled.

Step 4 Treatment. In the model presented in the current study, veterinary treatment was applied for all claw disorders with a severity $=3$, and for cows simulated to have sole ulcers and digital dermatitis. Veterinary treatment was not applied for other claw disorders with a severity $<3$ as it was assumed these disorders were not severe enough to justify veterinary assistance and is generally addressed by the farmer. Therefore a herd health approach was applied wherein veterinary assistance was applied once per month on farm as required i.e. each month if at least one cow was simulated to have a claw disorder severity = 3 , then the vet was called to treat that animal or number of animals if there were more than 1. The average veterinary call out charge and the cost per cow to treat claw disorders is outlined in Table 6 (Irish Farmers Association (IFA), 2020). It was assumed that veterinary assistance would only be acquired during daytime hours, as it is highly unlikely that a farmer would call a vet for suboptimal mobility related issues outside of normal working hours. Similar to the study of Bruijnis et al. (2010) it was also assumed that treatment occurred once for per claw disorder. The only exception to this assumption was for all cases of sole ulcers and digital dermatitis, which required two visits and is described in Table 6. Finally, on a date around the time of the end of the current lactation and the grazing period, a professional hoof trimmer visit was applied to the farm. During this visit, only cows with a suboptimal mobility were treated i.e. only cows with a mobility score $\geq 1$ were treated. Therefore if no cows on the farm had a mobility score $\geq 1$ the professional hoof trimmer was not needed. The average call out charge for the professional hoof trimmer is $€ 60.00$ which is the current industry standard in Ireland. The cost per cow after the call charge is $€ 9.00$ per cow. 
Table 6 Calculation of cost of veterinary treatment for claw disorders ${ }^{1}$

\begin{tabular}{lll}
\hline Claw Disorder & Category & Cost $(€)$ \\
\hline Overgrown claw & 1 & 0 \\
& 2 & 0 \\
Sole hemorrhage & $3^{2}$ & $26.08^{3}$ \\
& 1 & 0 \\
White line disease & 2 & 0 \\
& $3^{2}$ & $26.08^{3}$ \\
Sole ulcer & 1 & 0 \\
Digital dermatitis & 2 & 0 \\
\hline
\end{tabular}

${ }^{1}$ Call out charge for a vet estimated to be $€ 52.50$ divided by total number of cows requiring treatment (average cost in Ireland) (Irish Farmers Association (IFA), 2020).

${ }^{2}$ Only claw disorders simulated to be severity level 3 and all cases of sole ulcer and digital dermatitis required veterinary treatment.

${ }^{3}$ Veterinary cost of $€ 104.30$ per hour and 15 minutes required to treat a claw disorder was assumed

${ }^{4}$ Sole ulcer and digital dermatitis required two visits by a vet; visit 1 wherein a shoe at an additional cost of $€ 8$ was applied to a case of sole ulcer / bandage at an additional cost of $€ 3$ was applied to a case of digital dermatitis, visit 2 wherein shoe / bandage was removed.

\section{Genetic inputs and the Economic Breeding Index}

The Economic Breeding Index (EBI) was launched in Ireland in 2001 to identify genetically superior animals to increase profitability within Irish dairy herds (Veerkamp et al., 2002). The EBI and its sub-indices are described in detail by Berry et al. (2007). The EBI is expressed as the expected profit $(€)$ per lactation of the progeny of the specific animal, and the genetic merit values of the component traits are expressed as predicted transmitting abilities (PTAs). In 2020, seven sub-indices are included in the EBI: production (33\% contribution to the overall EBI value; PTAMY milk yield, PTAPROT protein yield, PTAFAT fat yield), fertility (contribution of 33\%; PTACALV calving interval (in days), PTASURV survival), calving (contribution of $10 \%$ ), beef (contribution of $8 \%$ ), maintenance (contribution 8\%), management (contribution 4\%), health (contribution 4\%; PTALAME lameness, PTAMAST mastitis, PTASCC somatic cell count). The PBHDM model has been linked directly with the milk and fertility sub-indices (Ruelle et al., 2018) through the relevant PTAs. 
96 | Chapter 5

\section{Scenario analysis}

The four simulations were run simulating four different levels of suboptimal mobility based on varying levels of a genetic predisposition for lameness (PTALAME) and were as follows;

1) Good mobility herd - refers to a herd wherein all cows had the lowest likelihood to have suboptimal mobility scores, as simulated by differences in the PTA for lameness (PTALAME $=-0.1$ ). The PTA for lameness used as an input in this scenario corresponds to the highest PTA value present in the actual dataset (Table 7).

2) Average mobility herd - refers to a herd wherein all cows had a neutral likelihood to have suboptimal mobility or optimal mobility scores, as simulated by differences in the PTA for lameness (PTALAME $=0.0$ ). The PTA value used as an input in this scenario corresponds to the median PTA value in the actual dataset (Table 7).

3) Poor mobility herd - refers to a herd wherein all cows had a higher likelihood to have suboptimal mobility scores, as simulated by differences in the PTA for lameness (PTALAME $=+0.1$ ). The PTA value used as an input in this scenario corresponds to the lowest PTA value in the actual dataset (Table 7).

4) Very poor mobility herd - refers to a herd wherein all cows had the highest likelihood to have suboptimal mobility scores, as simulated by differences in the PTA for lameness $($ PTALAME $=+0.2)$. This PTA value is higher than any of the cows in the actual dataset (Table 7).

Within each scenario the prevalence of mobility scores was determined by choosing the worst mobility score for each cow throughout the lactation i.e. not the average. A base milk price 29 cent per litre was implemented within each scenario.

\section{RESULTS AND DISCUSSION \\ Claw disorders and mobility scores}

The simulated prevalence of claw disorders within a herd in each scenario is outlined in Table 8. The good mobility herd consistently had a higher proportion of cows with mild and moderate type claw disorders compared to severe type claw disorders, while the opposite is true for the poor mobility herd. This is in agreement with the actual dataset whereby for example in the simulated good mobility herd about $41 \%, 16 \%$, and $9 \%$ of cows had a mild, moderate or severe type white line claw disorder, respectively, while in the actual dataset about $39 \%, 11 \%$, and $6 \%$ of cows had a mild, moderate, or severe type white line claw disorder, respectively. The simulated scenarios tend to result in a slightly higher proportion of cows with moderate and severe type claw disorders, however overall the direction of the severity of disorders is in the correct way and are within reasonable accuracy with the actual dataset.

Three of the four scenarios (good, average and poor mobility herds) are representative of the actual dataset and the prevalence of suboptimal mobility in the actual dataset. For the simulated good mobility herd scenario, on average less than $5 \%$ of cows have mobility score 
0 , and no cows have a mobility score 2 or 3 , while within the top 5 farms in the actual data set $19.5 \%$ of cows have mobility score $1,3.2 \%$ have mobility score 2 and no cows have a mobility score 3 . For the simulated average mobility herd scenario $31 \%$ of cows have mobility score $1,3 \%$ of cows have mobility score 2 and no cows have mobility score 3 , which corresponds well to the actual data set, wherein the median 5 farms (with regards mobility health) is made of $30.2 \%$ mobility score 1 cows, $4.8 \%$ mobility score 2 cows and $1.1 \%$ mobility score 3 cows. For the simulated poor mobility herd scenario it was predicted that $57 \%$ of cows had a mobility score $1,13 \%$ of cows had a mobility score 2 , and $5 \%$ of cows had a mobility score 3. Compared to the worst 5 farms (with regard to mobility health) wherein $29.9 \%$ of cows had a mobility score $1,18 \%$ of cows had a mobility score 2 , and $3.5 \%$ had a mobility score 3 .Finally, the very poor mobility herd scenario was simulated to have a prevalence of $98 \%$ of cows with suboptimal mobility (41\% mobility score $1,30 \%$ mobility score 2 , and $27 \%$ mobility score 3 ), which is worse than any of the herds in the actual dataset. The rationale behind running this scenario was to simulate a 'worst case' scenario for comparison. Both the prevalence' reported by O'Connor et al. (2019) and Fabian et al. (2014) is lower than what is reported in confinement type systems, with Cook et al. (2016) reporting a mean prevalence of clinical lameness among herds to be $13.2 \%$ and Husfeldt and Endres (2012) reporting a mean prevalence of lameness to be $17.1 \%$ among the herds in that study. If the cases of lameness as described by Husfeldt and Endres (2012) are comparable to cows with a mobility score 2 and 3 in the current study, the proportion of impaired and severely impaired mobility in the poor mobility herd could be comparable to confinement type systems.

Previously Bruijnis et al. (2010) developed a model to predict specific claw disorders (as either subclinical or clinical) with a monthly time step within typical Dutch dairy systems. The model developed by Bruijnis et al. (2010) successfully predicted a prevalence of disorders corresponding to such systems. However the model did not in turn predict mobility scores, which was the desired outcome of the present study, whereby based on a prediction for cows to have specific severities of claw disorders (regardless of being clinical or not) were used to predict mobility scores. Similar to Bruijnis et al. (2010), Mostert et al. (2018) also developed a model to predict specific claw disorders. The main difference between the model developed by Mostert et al. (2018) and the model developed in the current study is that claw disorders in the current study can be developed for a defined period of time, whereas claw disorders can only strictly be developed on just one specific day in lactation in the model developed by Mostert et al. (2018). Therefore the model developed in the current study is more flexible and potentially more representative of the actual data. However, the model in the current study simulated the length of time for a cow to have a claw disorder based on the findings of Bruijnis et al. (2010), which was representative of a typical Dutch dairy production system. Therefore, the number of days a typical cow in a spring calving, pasturebased system could potentially differ to what is reported by Bruijnis et al. (2010), however we did not have sufficient data to simulate this. 
98 | Chapter 5

Table 7 Prevalence of mobility score within each scenario

\begin{tabular}{llllll}
\hline Simulation & $\begin{array}{l}\text { Input } \\
\text { PTA } \\
\text { lame }\end{array}$ & $\begin{array}{l}\text { Mobility } \\
\text { score 0 }\end{array}$ & $\begin{array}{l}\text { Mobility } \\
\text { score 1 }\end{array}$ & $\begin{array}{l}\text { Mobility } \\
\text { score 2 }\end{array}$ & $\begin{array}{l}\text { Mobility } \\
\text { score 3 }\end{array}$ \\
\hline Good mobility herd & -0.1 & 95 & 4 & 0 & 0 \\
Average mobility herd & 0 & 66 & 31 & 3 & 0 \\
Poor mobility herd & +0.1 & 25 & 57 & 13 & 5 \\
Very poor mobility herd & +0.2 & 1 & 41 & 30 & 27 \\
\hline
\end{tabular}

${ }^{1}$ Predicted transmitting ability for lameness 
Economics \& Mobility scores | 99

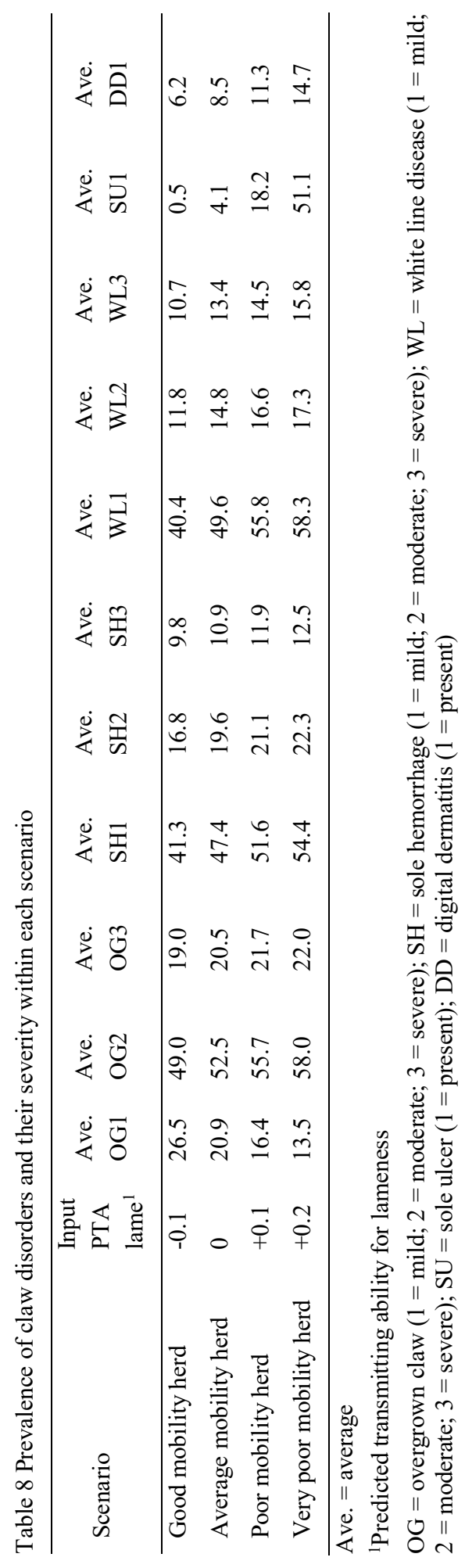




\section{Milk yield and culling}

The simulated milk yield affects associated with each level of suboptimal mobility are based on the results of O'Connor et al. (2020) In prep., which is in agreement with the findings of other studies in various type of production systems (Green et al., 2002, Bicalho et al., 2008, Charfeddine and Pérez-Cabal, 2017). Cows with a mobility score $>1$ had a reduced milk yield; while cows with mobility score 0 and 1 did not have any milk yield effect. As outlined in Table 9, on average cows within the good mobility herd scenario produced about $60 \mathrm{~kg}$ more milk throughout the lactation compared to the poor mobility herd, while cows in the very poor mobility herd produced about $270 \mathrm{~kg}$ less milk throughout the lactation compared to cows in the good mobility herd. As expected, the greatest difference in potential yield and actual simulated yield per herd is evident in the very poor herd with a difference of about $14,800 \mathrm{~kg}(2 \%)$ per year compared to the good mobility herd (Table 10). Here the potential milk yield refers to the milk yield that cow would ideally produce if she did not have suboptimal mobility (does not account for other ailments potentially affecting milk yield) and the actual milk yield refers to the yield she actually produced throughout the lactation.

Voluntary culling (culling for any reason other than reproductive reasons) was predicted to be the lowest ( $9 \%$ ) for the good mobility herd, followed by the average mobility herd (10\%), the poor mobility herd (11\%) and finally the very poor mobility herd (15\%) (Table 9). An important note here is that although the voluntary culling appears to be quite low, this is just voluntary culling and not the overall culling rate, which is presented in Table 9 as the overall replacement rate per scenario. This increased voluntary culling across scenarios due to suboptimal mobility is also a contributing factor for the lower average milk yield on a per cow basis within each scenario, due to a higher replacement rate and therefore a higher proportion of parity 1 cows within the herd. As presented in Table 10, the average milk yield per cow for the lactation is also examined on a per mobility score basis for each scenario. This yield is also compared to the potential yield of that cow if she had optimal mobility for the entire lactation i.e. cows are compared to themselves. For the good mobility herd scenario, a cow with a mobility score 3 was simulated to have between 0 and $1 \%$ milk yield loss over the entire lactation, however for the very poor mobility herd, a cow with a mobility score 3 was simulated to have a reduced milk yield throughout the lactation of up to $5.7 \%$, which is comparable to the results of O'Connor et al. (2020) In prep., wherein milk yield losses of up to $4.7 \%$ for the full lactation were associated with cows with a mobility score 3 . The varying milk yield losses between scenarios from cows simulated to have the same mobility score is due to the fact that the prevalence of mobility scores was determined by choosing the worst mobility score for each cow throughout the lactation i.e. not the average.

It is also comparable to the study of Archer et al. (2010) wherein cows managed under a year-round calving, pasture-based systems with severe mobility issues experienced milk yield losses of up to $4.8 \%$ throughout the lactation. This greater milk yield loss reported in the current study associated with mobility score 3 cows in the very poor mobility herd compared to mobility score 3 cows in the good mobility herd is explained by a longer duration 
during which the cows in the very poor mobility herd were likely to have had suboptimal mobility. The mobility score 3 cows in the very poor mobility herds were potentially mobility score 2 prior to progressing to mobility score 3 , therefore would have experienced milk yield losses while being mobility score 2 also.

Table 9 Milk production and culling \% within each scenario

\begin{tabular}{llll}
\hline & Ave. vol. culling & Ave. replacement rate & Ave. milk per cow $(\mathrm{kg})^{3}$ \\
\hline Good mobility herd & 9 & 23 & 6,788 \\
Average mobility herd & 10 & 23 & 6,774 \\
Poor mobility herd & 11 & 24 & 6,722 \\
Very poor mobility herd & 15 & 27 & 6,510 \\
\hline
\end{tabular}

${ }^{1}$ Average voluntary culling

${ }^{2}$ Average replacement rate

${ }^{3}$ Average total milk production per cow per lactation 
102 | Chapter 5

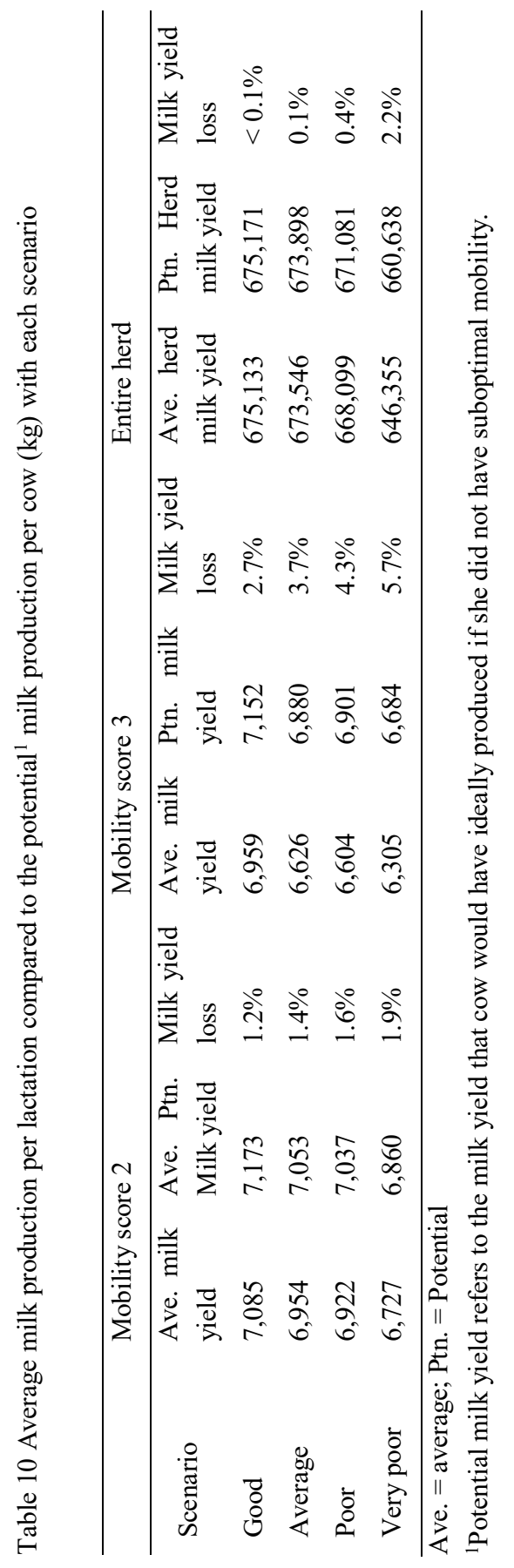




\section{Costs and Profitability}

The aspects of farm net profit that change due to milk receipts and treatment costs are outlined in Table 11, the greatest profit was achieved in a good mobility herd (€91,202). The increase in the prevalence of suboptimal mobility resulted in a reduction in farm profit of about $2 \%$ for an average mobility herd, $5 \%$ for a poor mobility herd, and $18 \%$ for a very poor mobility herd in comparison with the good mobility herd. When comparing the simulation run 50 times over a 16-year period, the standard deviation was $9 \%, 10 \%, 10 \%$, and $14 \%$ of the net farm profit for the good, average, poor and very poor mobility herd respectively. A higher proportion of suboptimal mobility scores within the very poor mobility herd were associated with increased uncertainty. The average treatment cost for claw disorders and cows with a mobility score $\geq 1$ was the lowest for the good mobility herd costing $€ 1,288$ per year. An average mobility herd endured a $36 \%$ increase in treatment costs for claw disorders and suboptimal mobility (compared to the treatment cost in the good mobility herd), having an average treatment cost of $€ 1,750$, while a poor mobility herd endured a $130 \%$ increase in treatment costs (compared to the good mobility herd), with a treatment cost of $€ 2,931$, and a very poor mobility herd had the highest treatment cost of $€ 4,665$ per year or $260 \%$ greater than the average treatment cost for the good mobility herd.

Table 11 Treatment costs per mobility score and per scenario, milk receipts and overall farm net profit.

\begin{tabular}{|c|c|c|c|c|c|c|c|}
\hline & \multicolumn{7}{|c|}{ Ave. treatment costs $(€)$} \\
\hline & $\begin{array}{l}\text { Mobilit } \\
\text { y score } \\
0 \text { cows }\end{array}$ & $\begin{array}{l}\text { Mobility } \\
\text { score } 1 \\
\text { cows }\end{array}$ & $\begin{array}{l}\text { Mobilit } \\
\text { y score } \\
2 \text { cows }\end{array}$ & $\begin{array}{l}\text { Mobility } \\
\text { score } 3 \\
\text { cows }\end{array}$ & $\begin{array}{l}\text { Ave. } \\
\text { treatme } \\
\text { nt cost }\end{array}$ & $\begin{array}{l}\text { Ave. } \\
\text { milk } \\
\text { receipts }\end{array}$ & $\begin{array}{l}\text { Ave. } \\
\text { farm net } \\
\text { profit }\end{array}$ \\
\hline $\begin{array}{l}\text { Good mobility } \\
\text { herd }\end{array}$ & 1,027 & 220 & 39 & 1 & 1,288 & 214,583 & 91,202 \\
\hline $\begin{array}{l}\text { Average } \\
\text { mobility herd }\end{array}$ & 565 & 940 & 212 & 33 & 1,750 & 214,155 & 89,722 \\
\hline $\begin{array}{l}\text { Poor mobility } \\
\text { herd }\end{array}$ & 131 & 1,512 & 938 & 350 & 2,931 & 212,681 & 86,212 \\
\hline $\begin{array}{l}\text { Very poor } \\
\text { mobility herd }\end{array}$ & 1 & 860 & 1,915 & 1,890 & 4,665 & 206,473 & 74,649 \\
\hline
\end{tabular}

Treatment costs calculated in the present study refer to the costs associated with a veterinary or professional hoof trimmer time and equipment. In this study routine claw trimming treatment costs ranged from about $€ 1,200$ for a herd that is considered to be a good herd mobility up to $€ 4,600$ for a herd that is considered to be a very poor mobility herd (Table 11). During the first visit, it was assumed a shoe or bandage is applied to treat either a sole ulcer or digital dermatitis and thus a second visit is simulated for the shoe or bandage to be removed. However, in reality it could be that a number of these shoes and bandages would fall off with time or the farmer themselves would remove them, thus not requiring a second 


\section{4 | Chapter 5}

visit, but we did not have data to estimate this. Other studies including the study of Bruijnis et al. (2010) and Charfeddine and Pérez-Cabal (2017) also estimated the economic losses associated with specific claw disorders; however, both studies specifically focused on estimating the cost associated with individual claw disorders on a per case basis. Bruijnis et al. (2010) estimated the treatment costs of both subclinical and clinical claw disorders (in a default herd of 65 cows managed under typical Dutch year round calving, pasture-based system) and found that clinical cases of claw disorders (including a varying of types of claw disorders) were associated with treatment costs of up to $€ 289$ for the herd per year. This estimation accounts for veterinarian treatment, professional hoof trimmer trimming and additional treatment i.e. antibiotics. The treatment costs for the good mobility herd scenario in the current study are much greater than those reported by Bruijnis et al. (2010). This could most likely be explained by the fact that routine preventative treatment occurs in the present study, resulting in mobility score 1 cows have a treatment cost, while fewer treatments are applied in the study by Bruijnis et al. (2010).

Average total milk receipts for each scenario are also outlined in Table 11. Milk receipts in the current study do not account for discarded milk due to antibiotic treatment of cows with severe suboptimal mobility, as we did not have data to estimate this. The good mobility herds had the greatest milk receipts, followed by the average, poor and very poor mobility herd scenarios. In Table 12 the economic losses due to milk yield loses, increased culling, treatment costs and overall farm net profit loss for the average, poor and very poor mobility herd scenarios are compared to the good mobility herd. The greatest farm net profit loss (compared to the good mobility herd) was evident in the very poor mobility herd scenario of about $€ 16,500$. Of this milk yield loss made up 49\%, increased culling made up $31 \%$, and treatment costs made up the remaining $20 \%$ of total farm net profit loss. For the poor mobility herd scenario (which is representative of the worst 5 farms in the actual dataset) the overall farm net profit was almost $€ 5,000$ less than what was achieved in the good mobility herd. Milk yield losses made up $€ 1,900$ of this farm net profit loss. In comparison, Bruijnis et al. (2010) estimated a total cost of about $€ 2,200$ due to milk yield losses (including discarded milk due to antibiotic treatment for severe mobility issues) associated with subclinical and clinical claw disorders in a typical Dutch dairy production herd, wherein the total costs were estimated to be about $€ 4,900$. 


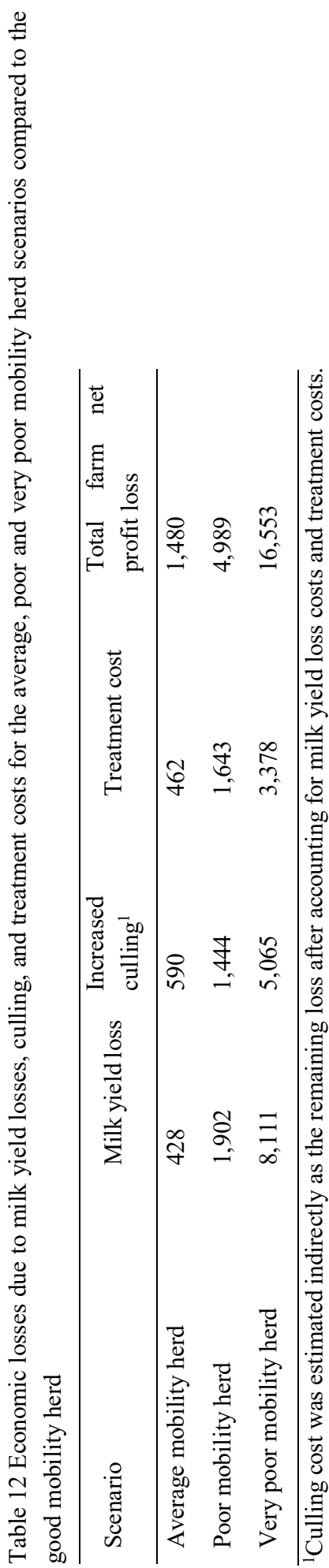




\section{Sensitivity Analysis}

Sensitivity analysis concerning milk price was completed by testing both a lower base milk price ( 26 cent per litre) and higher base milk rice (32 cent per litre) relative to the base milk price implemented for the four scenarios (29 cent per litre). For the good mobility herd scenario, the overall farm net profit was $€ 69,050$ with the 26 cent per litre base milk price, $€ 91,200$ with the 29 cent per litre base milk price (Table 11), and $€ 113,289$ with the 32 cent per litre base milk price This showed that a higher base milk price (32 cent per litre) resulted in an increased overall farm net profit but this was coupled with a relatively greater economic loss due to higher mobility scores. For the average mobility herd scenario the overall farm net profit was $€ 67,600$ with the 26 cent per litre based milk price, $€ 89,700$ with the 29 cent per litre base milk price (Table 11), and $€ 111,700$ with the 32 cent per litre base milk price. Similarly, this showed that a higher base milk price (32 cent per litre) achieved a higher overall farm net profit, but again this was coupled with a relatively higher economic loss due to lower milk yield as a result of suboptimal mobility. However, across all scenarios when a higher base milk price ( 32 cent per litre) is implemented, the proportion of economic losses as a result of a lower milk yield is less important relative to the overall farm net profit.

\section{CONCLUSIONS}

The mobility score prediction sub-model developed in this study was effective for predicting realistic prevalence' of mobility scores for typical spring calving, pasture-based systems. From this study, we conclude that as the prevalence of cows with suboptimal mobility scores (even mild suboptimal mobility scores) increases within a herd, the overall farm next profit decreases. This decrease is due to increased involuntary culling, reduced milk yield, and treatment costs for cows within the herd with suboptimal mobility. Therefore, we hypothesize that the earlier detection and treatment of cows with mild suboptimal mobility could potentially have positive implications for over farm net profit. Moreover, the earlier detection and treatment of cows with suboptimal mobility will have positive outcome for animal welfare and environmental impacts.

\section{ACKNOWLEDGEMENTS}

Funding from the Irish Department of Agriculture, Food and the Marine STIMULUS research grant Healthy Genes is greatly appreciated, as well as a research grant from Science Foundation Ireland and the Department of Agriculture, Food and Marine on behalf of the Government of Ireland under the Grant 16/RC/3835 (VistaMilk). The authors also wish to acknowledge the co-operation of all participating farmers and recorders for data recording and collection, as well as the Walsh Fellowship. 
Chapter 6

General Discussion 


\section{8 | Chapter 6}

\section{INTRODUCTION}

Lameness is one of the major problems associated with dairy production, affecting all three pillars of sustainability; lameness is associated with negative animal welfare impacts (Rushen, 2001, O'Callaghan, 2002, Mee and Boyle, 2020), substantial economic losses (Bruijnis et al., 2010), and environmental consequences, including increased emissions of greenhouse gases (Mostert et al., 2018), acidifying gases or eutrophying substances (Chen et al., 2016). Literature shows that there is quite some room to improve the prevalence of lameness, and hence the sustainability performance, on dairy farms. Lameness, however, is a binary characteristic whereby a cow is either lame or not lame. Thus when talking about lameness, the prevalence of cows with mild deviations to optimal gait and its impact are ignored. Up to now, there is little knowledge on the prevalence of imperfect mobility, the associated potential risk factors, causes, and indeed the impacts of the milder types of suboptimal mobility. Therefore, the main aim of this thesis is to understand suboptimal mobility in spring calving, pasture-based dairy systems, with a focus on risk factors, production performance and the economic consequences. Prior to determining the association between cow characteristics and potential risk factors of suboptimal mobility, the varying levels suboptimal mobility were defined in Chapter 1 .

Once a sound definition of suboptimal mobility was formulated, various cow level traits were examined for their association with specific levels of suboptimal mobility (Chapter 2). Next, a risk factor analyses was conducted to determine the potential risk factors at both the cow and herd-level for specific levels of suboptimal mobility (Chapter 3). Following on from this, analyses were completed to determine the production impacts associated with specific levels of suboptimal mobility (Chapter 4). Production impacts included; milk, fat and protein yield, and somatic cell count, calving interval length, and the culling and mortality risk. Finally, a sub-model was developed within a preexisting model in order to predict mobility scores in a typical spring calving, pasture-based dairy herd. This model was then used to determine the associated economic impact of varying prevalence of specific levels of suboptimal mobility within a spring calving, pasture-based dairy herd (Chapter 5). In this chapter, I will first discuss the causes and risk factors of suboptimal mobility in spring calving, pasture-based dairy systems: Second, I will discuss the impacts of suboptimal mobility for production and economic performance in spring calving, pasture-based dairy systems. Finally, practical implications and the main conclusions of this thesis are given.

\section{Suboptimal mobility in pasture-based dairy systems: causes and risk factors}

Throughout this thesis, the term suboptimal mobility is referred to rather than the binary term lameness, whereby suboptimal mobility accounts for cows with just mild deviations to optimal mobility all the way to potentially an inability to walk. We anticipated, therefore, that the prevalence of suboptimal mobility reported on in this way would potentially be higher than what has been reported on lameness so far throughout the literature). It was also anticipated that when examining such mild deviations to optimal mobility, that there could 
potentially be specific cow traits associated with these milder types of mobility issues, which has been somewhat ignored throughout the literature so far. As well as it was anticipated, that there could be potential risk factors for suboptimal mobility, unique to a spring calving, pasture-based system.

In order to examine my research questions, I used a pre-existing database, which brings with it both advantages and certain limitations. Advantages of using an existing dataset obviously include increased efficiency of data use; however, limitations that arose include the timeline over which some variables were recorded. That is why I was only able to reports on associations, and not on causalities.

In order to understand the specific levels of suboptimal mobility in pasture-based dairy cows, the type of claw disorders present and the severities were vital pieces of information. In pasture-based systems, the non-infectious type claw disorders are by far the most prevalent (Chapter 2). This finding is in agreement with some other research (Lawrence et al., 2011). Approximately $85 \%$ of all cows in our dataset had some form of non-infectious claw disorder (a severity score $>0$ for an overgrown claw, sole hemorrhage, white line disease, or sole ulcer), while just $2.8 \%$ of cows had some form of digital dermatitis (an infectious type claw disorder; Chapter 2). This finding was higher than anticipated, but should be interpreted with caution. The dataset utilized in this thesis consisted of a vast amount of information, including claw health data for approximately 7,000 cows. Claw health data were collected by lifting the hind hooves of each cow, regardless of their mobility score. Once the presence of a claw disorder was confirmed, this claw disorder was then severity scored on a three point scale, from mild to severe (applicable for overgrown claw, white line disease, and sole hemorrhage, while sole ulcer and digital dermatitis was just recorded as absent of present). This protocol resulted in a large number of cows being recorded as having a mild form of a claw disorder. This was an important insight to report on and one that is less reported on throughout the literature so far, whereby usually the focus has been on cows with obvious mobility issues or claw disorders not specifically severity scored (Fjeldaas et al., 2011). Other studies, therefore, potentially missed mild type claw disorders, except possibly by Manske et al. (2002) and O'Callaghan (2002), wherein both studies reported the presence of claw disorders in 'nonlame' cows. However it is not clear from their studies whether or not the 'non-lame' category described includes cows with an imperfect mobility (mild deviation of suboptimal mobility). In Chapter 2, it was concluded than even mild forms of claw disorders, including overgrown claw, white line disease and sole hemorrhage, were found to be associated with an increased risk for a cow to have imperfect mobility (mobility score 1) compared to having optimal mobility (mobility score 0 ). Similar to this, Chapter 2 also showed that both moderate and severe forms of the same claw disorders were associated with an increased risk for a cow to have impaired and severely impaired mobility (mobility score 2 and 3). Therefore, Chapter 2 confirmed a direct association between the severity of claw disorders and the level of suboptimal mobility. This conclusion prompted anticipations that perhaps potential risk 


\section{0 | Chapter 6}

factors already shown to be associated with an increased risk for severe mobility issues could potentially be associated with less severe forms of suboptimal mobility.

In Chapter 2 of this thesis it was discussed that non-infectious claw disorders are the most prevalent in pasture-based production systems. These finding are in accordance with those found by Somers and O'Grady (2015). However, the opposite of this seems to be true for confinement type systems or systems wherein less time is spent at grass. Somers et al. (2003), for example, reported that infectious type claw disorders, such as digital dermatitis, was by far the most prevalent for cows on slatted concrete flooring type. Perhaps an explanation for a higher prevalence of infectious type of claw disorders in non-grazing type systems could be due to the increased exposure cow's claws to slurry on concrete flooring types, (Cook et al., 2004), or variations of bedding types used in free stalls (Weary and Taszkun, 2000), or indeed overstocking, leading to reduced lying time (Winckler et al., 2015). Chapter 3 of this thesis examines the potential risk factors for suboptimal mobility specific to a seasonal calving, pasture-based systems. Generally throughout the literature, studies which have examined mobility issues in pasture-based systems seem to focus on the prevalence and associations of severe mobility issues (Ranjbar et al., 2016) and often during the higher risk winter housing period (Navarro et al., 2013, De Vries et al., 2015). However, it is during the spring and summer grazing period when cows are exposed to a number of potential risks unique to a pasture-based system. One such potential risk is walking long distances between the milking parlor and pasture each day on varying types of roadway surfaces (Chesterton, 2015). In contrast, during the winter period in spring calving, pasture-based systems when cows are fully or partially housed (generally when cows are no longer lactating); the potential risk factors are more similar to those of cows managed in non-pasture-based systems. Potential risk during this time include factors such as availability of cubicle spaces (Fregonesi et al., 2007), shed flooring type and as described above the exposure of claws to slurry (Cook et al., 2004, Alvergnas et al., 2019). On the one hand, however, the time during which cows in such pasture-based systems are housed is much shorter than the time spent indoors by cows in confinement type systems. It, therefore, could be that there is less time during which pasture-based cows can develop claw disorders while indoors. On the other hand, it could be that farmers are less willing to invest in suitable housing facilities due to the short time pasture-based cows spend there.

Few studies have focused on the potential risk factors specifically during the grazing period in pasture-based systems. Chesterton et al. (1989) reported associations between less frequent maintenance of cow roadways, and abrasive material on cow roadways with increased mobility issues at the herd level (Chesterton, 2015). Somers et al. (2019) determined specific cow-level risk factors such as higher parity and low body condition score (BCS) associated with severe mobility issues, while Bran et al. (2018) examined separately cow and herd-level risk factors for their associations with severe mobility issues. Unlike previous studies, in Chapter 3 of this thesis, a combined cow and herd-level multilevel model with repeated cowlevel variables was completed in order to capture the unique herd-level factors of a spring 
calving, pasture-based systems and cow-level factors together. The results of Chapter 3 show that potential risk factors at cow level for all forms of suboptimal mobility include: low body condition score (BCS), higher yield (in terms of fat and protein corrected milk (FPCM)), elevated somatic cell score (SCS), stage of lactation, genetics for 'lameness' and cow breed. All of which are comparable to the potential risk factors for severe types mobility issues in production systems other than pasture-based systems. For example Solano et al. (2015) also reported a higher prevalence of moderate to severe type mobility issues for under-conditioned cows, and several studies have shown the potential risk for mobility issues associated with higher yielding cows (Green et al., 2002, Bicalho et al., 2008, Archer et al., 2010). From this, it seems the cow-level risk factors associated with suboptimal mobility between types of production systems are comparable. This finding potentially places more importance on the herd-level risk factors rather than the cow itself in spring calving, pasture-based systems, which may have been missed if a separate cow and herd-level analysis was completed in Chapter 3. This is touched upon in the study of Vermunt and Parkinson (2002) wherein the multifactorial nature of mobility issues is discussed. With the causes of suboptimal mobility and indeed claw disorders being described as multifactorial, it seems short-sighted to assume common risk factors for suboptimal mobility for cows managed in very different production systems. Thus our method of completing a combined cow and herd-level model was indeed an effective choice for capturing the associated effects of the herd-level potential risk factors.

At the herd level Chapter 3 reported an increased risk for a higher prevalence of all forms of suboptimal mobility (mobility scores $\geq 1$ ) for herds wherein the average time spent completing milking (the time from when cows leave the paddock to be milked until the time they return to the paddock after milking) was more than 90 minutes compared to herds wherein the completion of milking took less than 90 minutes. Similarly, there was a higher risk for all levels of suboptimal mobility prevalence at the herd level for herds that comprised of more than one grazing platform compared to herds operating on just one grazing platform (Chapter 3). Having more than one grazing platform (fragmented land) indicates that cows in these herds may have to walk longer distances to the milking parlour from pasture each day, perhaps by use of varying quality of cow roadways or even by use of public roads in certain circumstances. Herds grazing on fragmented land may also spend more time waiting in the collecting yard before and after milking so as the entire herd can walk back to pasture together rather than walking back to pasture straight away after milking. Although this somewhat clarified the idea that indeed there are potential herd-level risk factors associated with mild forms of suboptimal mobility, the results of chapter 3 also found that the risk factors for moderate and severe types of suboptimal did not match those for mild suboptimal mobility. For example, Chapter 3 reports that the practice of foot bathing was associated with an increased prevalence of impaired and severely impaired mobility (mobility score 2 and 3 ), but not for an increased prevalence of mobility score $>0$ together. This result can in theory be interpreted in two ways. First, herds wherein foot bathing is implemented already had substantial mobility problems prior to implementing foot bathing and therefore it is likely these herds had a greater number of cows with mobility score $>1$ compared to herds which 


\section{2 | Chapter 6}

did not implement foot bathing. Second, foot bathing is a potential risk factor for suboptimal mobility, which is unlikely but should be kept in mind. To find the rationale behind this further research is required.

Cow roadway quality is a potential risk factor unique to spring calving, pasture-based systems, however there is very limited data and research available on its impacts on the prevalence of suboptimal mobility. An earlier study by Chesterton et al. (1989) found an association between cow roadway maintenance frequency and mobility issues in pasturebased systems, and reported a strong link between the less frequent maintenance and condition of cow roadways and the prevalence of suboptimal mobility. In the survey completed by farmers for this thesis, farmers were asked to score the roughness and cleanliness of the paths on a scale, as well as answer how often (if ever) cow path maintenance occurred on farm. However, none of these cow path variables were significantly associated with suboptimal mobility in the study (Chapter 3) and were therefore dropped in the model building process. A possible explanation for these variables not affecting the risk for suboptimal mobility could be the variations in management practices over time, i.e. in the study of Chesterton et al. (1989) the data were collected between 1985 and 1987, whereas in the study outlined in Chapter 3 of this thesis, the data were collected in one calendar year, 2015 and it is possible that some management practices may have changed with time when comparing both studies. Another possible reason for the cow path variables not being significant in Chapter 3 of this thesis could also be due to a potential bias in the survey results collected for each herd, as they are self-reported by the farmers. This type of data collection is fraught with difficulties, including the timing during which farmers provide the information can vary between farms, therefore causing seasonal differences in for example cow roadway quality. It could also be that farmer's interpretation of certain management practices on their farm is not the same as another farmer's interpretation (for example cow roadway cleanliness). Another possible limitation of such data is that parameters are not distinctive enough whereby data on the average distance walked daily by cows might have been more interesting that the longest distance from the milking parlours to the further grazing paddock for example.

In conclusion so far throughout the literature it is widely accepted that claw disorders are associated with more severe forms of suboptimal mobility, with the focus of previous studies been on the associations between severe type claw disorders and severe suboptimal mobility. However, one of the key findings from Chapter 2 is that not only are severe types of claw disorders associated with suboptimal mobility, but that even mild types of non-infectious claw disorders (overgrown claw, sole hemorrhage, and white line disease) are associated with imperfect mobility. Similarly, Chapter 3 of this thesis shows that various cow-level potential risk factors, such as higher milk yield, low body condition score and elevated somatic cell count are associated with all levels of suboptimal mobility. Although these potential risk factors are comparable to what is reported throughout the literature to be associated with severe mobility issues in a variety of type of production systems. This was the first time they 
were shown to be associated with mild forms of suboptimal mobility, specifically in spring calving, pasture-based systems.

\section{Production impacts and economic consequences of suboptimal mobility}

The production impacts and economic consequences of suboptimal mobility have been well reported on, particularly for more severe types of suboptimal mobility and in a number of different kinds of management systems. Some of the research prior to this thesis has included examining the impact of mobility issues on milk production in year round housing systems (Bicalho et al., 2008) and non-seasonal calving, pasture-based systems (Archer et al., 2010). While some studies including that of Bruijnis et al. (2010) estimated the economic costs associated with specific claw disorders in a year round calving, pasture-based system. In Chapter 4 and 5 the production impacts and economic consequences of less severe or mild types of suboptimal mobility in spring calving, pasture-based systems were studied.

Given the current practices on Irish dairy farms, where spring calving, pasture based systems are practiced, it is unlikely that cows with imperfect mobility would be selected for treatment, most likely due to the cost of professional hoof trimmer visits. However the findings of Leach et al. (2012) show that the earlier treatment of cows with mobility issues reduces the prevalence of severe mobility issues. To compliment this, the findings of Chapter 5 of this thesis, reports that a high prevalence of cows within a herd even with imperfect mobility (mobility score 1) negatively impacts farm net profit. Therefore, the cost benefit of identifying and treating cows with mild forms of suboptimal mobility could potentially outweigh the economic cost associated with professional hoof trimmers. For example, for an average mobility herd (simulated to have a prevalence of mobility score 1 cows of about $31 \%$ ) compared to a good mobility herd (simulated to have a $4 \%$ prevalence of suboptimal mobility), the difference in farm net profit is about $€ 1400$ less per year for the average mobility herd. It is therefore possible that the economic benefit to treating cows with imperfect mobility outweighs the economic cost.

In Chapter 5, prior to calculating the economic consequences associated with suboptimal mobility, first the sub model as developed to predict the mobility score of each cow. Mobility score predictions were based on the outputs of Chapter 2 of this thesis, and the prevalence of mobility scores predicted were reasonably accurate compared to the prevalence of mobility scores in the actual data set used throughout this thesis. Chapter 5 also simulated milk yield losses and the culling risk associated with each cows mobility score which was based on the outputs of Chapter 4 of this thesis.

In Chapter 4 it was concluded that cows with imperfect mobility were not significantly associated with any yield losses early in their lactation, but rather appeared to be associated with a slightly higher milk yield. However, it is likely that this higher milk yield reported in Chapter 4 associated with cows with imperfect mobility is indeed in agreement with the findings of Chapter 3 wherein higher yielding cows have a greater risk for having suboptimal mobility compared to their lower yielding herd mates. There are studies in agreement that 


\section{4 | Chapter 6}

higher yielding cows are associated with mobility issues (Green et al., 2002, Amory et al., 2008, Archer et al., 2010) however the yield effect reported in the present study associated with imperfect mobility is relatively small in comparison, and this is discussed in detail in Chapter 3 of this thesis. The temporal associations between yield and suboptimal mobility is still not definitively known and more research is required in this area in order to determine for example the cost-benefit of breeding for better mobility over increased yield.

Throughout Chapters 3, 4, and 5 of this thesis, the genetics for visible mobility issues are used, and we concluded that indeed cows with a higher predicted transmitting ability (PTA) for visible mobility issues are associated with an increased risk to have claw disorders and in turn suboptimal mobility. Therefore, it is anticipated that increased selection of animals with a lower PTA for visible mobility issues will reduce the overall prevalence of mobility issues within such spring calving, pasture-based dairy herds. The PTA for visible mobility issues was primarily used to predict claw disorders and mobility scores in the mobility score sub model developed in Chapter 5, however the PTA was also used as an input to create four different scenarios resulting in varying prevalence' of suboptimal mobility with each herd. This allowed for the comparison of farm profit between scenarios as a result of different mobility scores. The farm profits estimated in Chapter 5 were dependent on the prevalence of each mobility score within a herd, and this in turn affected milk yield, culling rate, and treatment costs associated with specific levels of suboptimal mobility.

In chapter 4 it was concluded that cows with impaired and severely impaired mobility (mobility score 2 and 3 ) were associated with significant lower yields, resulting in a milk yield loss of $100 \mathrm{~kg}$ for cows with impaired mobility (mobility score 2) and up to $350 \mathrm{~kg}$ for cows with severely impaired mobility (mobility score 3 ) compared to cows with optimal mobility, corrected for a 305 day lactation. This is comparable to the results of Archer et al. (2010), reporting milk yield losses of up to $350 \mathrm{~kg}$ for 305-day lactation associated with severely lame cows, using the same mobility scoring method. Possible explanations for the negative impact on yield associated with this level of suboptimal mobility could be partly due to the pain incurred by the cow (O'Callaghan, 2002) and a lower ability to graze or even a lower ability to compete for feed, and therefore more energy reserved for maintenance could be used for milk production, leading to a low body condition score. Low body condition score was shown in Chapter 3 to be associated with all levels of suboptimal mobility.

Another production type indicator reported in Chapter 4 to be negatively associated with suboptimal mobility was somatic cell count. The rationale behind examining this association was prompted by the findings of Navarro et al. (2013) and Walker et al. (2008). The study of Navarro et al. (2013) found that cows with severe suboptimal mobility stood on average for shorter periods compared to 'non-lame' cows, while the study of Walker et al. (2008) reported that cows with severe suboptimal mobility do indeed spend more time lying down. Therefore it could be that when cows with suboptimal mobility lay down for longer periods, there is an increased risk of exposure to pathogens at the teat end, which may result in elevated somatic cell count. It could also be that cows with mobility issues have a higher 
immune response (O'Driscoll et al., 2015) which could potentially be a reason for an elevated somatic cell count.

Similar to the negative impact on yield and somatic cell count associated with suboptimal mobility, Chapter 4 also concluded that cows with all levels of suboptimal mobility have an increased risk to be culled, and this increased risk was utilized to predict culling due to mobility issues in Chapter 5. This complements the results of Chapters 2 and 3 wherein high parity cows were shown to be a potential risk factor for suboptimal mobility. Majority of the research so far agrees that severe forms of suboptimal mobility are associated with an increased risk to be culled (Sprecher et al., 1997, Booth et al., 2004). However, this thesis has now shown that cows with imperfect mobility have a greater risk to be culled compared to herd mates with optimal mobility. This was a key input when developing the mobility score sub-model in Chapter 5 of this thesis. In Chapter 5, for example, it was shown that a poor mobility herd with a higher prevalence of suboptimal mobility $(75 \%$ of the herd with a mobility score $\geq 1$ ) was simulated to have an average voluntary culling rate of $11 \%$ and an average replacement rate $24 \%$, compared to a simulated good mobility herd with an average voluntary culling rate of $9 \%$ and a replacement rate of $23 \%$. Cows could be culled if not in gestation or due to other issues including suboptimal mobility. This increased replacement rate simulated in the poor mobility herd is of a consequence of increased involuntary culling possibly due to suboptimal mobility. This increased proportion of parity 1 cows within the poor mobility herd, also has the potential to decrease the milk produced overall at the herd level, which is also reported in Chapter 5 of this thesis.

Chapter 4 also investigated the impact of cow death (the death of a cow on farm) and found no association between this and suboptimal mobility which is not in agreement with some published work by for example McConnel et al. (2008), who reported higher levels of cow mortality on farms with a high proportion of moderate to severe suboptimal mobility. An explanation for the contradictory results from the current thesis to that of McConnel et al. (2008) could potentially be explained by the type of production system, which was confinement based in the study of McConnel et al. (2008). Due to the nature of Irish pasturebased systems, wherein cows must walk to and from pasture each day to be milked, it is also assumed that cows would be culled prior to succumbing to such a severe state of suboptimal mobility which was shown in this study, as they would not be able to keep up with the momentum of the system.

In conclusion, the production losses reported on in this thesis in Chapter 4 are representative of cows in spring calving, pasture-based systems, and the sub model developed in Chapter 5 effectively simulated realistic mobility score prevalence with such herds, while estimating how these affected the overall farm net profit.

\section{Practical implications}

Based on the findings presented in this thesis, it is evident that there is a high prevalence of mild type claw disorders within typical spring calving, pasture-based dairy herds, a 


\section{6 | Chapter 6}

prevalence that was overlooked up until now. Since the removal of milk quotas in 2015, the Irish dairy production has been undergoing expansion in herd sizes and overall output. Coupled with this the consumer is also increasingly aware of welfare standards on farm (Weary and von Keyserlingk, 2017). Given that suboptimal mobility is known to be negatively associated with dairy cow welfare, the prevalence of claw disorders within the herds' studied in this thesis was alarming (even though majority were mild cases) and definitely prompts room for improvement. However, knowing the prevalence of claw disorders is less doable for farmers compared to knowing the prevalence of mobility scores and indeed how associated these mild type claw disorders are to mobility scores. Farmers are more likely to conduct routine mobility scoring of their herd rather than routine claw inspections of entire herds. This is due to the cost associated with professional hoof trimmers to routinely inspect entire herds. Therefore this thesis has provided evidence showing that mobility score 1 cows (with imperfect mobility) could potentially have mild types of claw disorders, which means farmers could instead hand pick cows with mobility score 1 for inspection by professional hoof trimmers which could also potentially reduce the number of cows presenting with more severe type claw disorders at a later stage. As well as this thesis has provided associations between these mobility scores and the various production losses and economic consequences associated with them. Thus, when farmers practice routine mobility scoring on farm, cows with imperfect mobility can be drafted out for preventative trimming to potentially prevent the claw disorder worsening (which will incur production and performance losses and increased economic costs), and this avoids the need to routinely lift and inspect the claw of every cow.

For spring calving, pasture-based systems, as discussed throughout this thesis, there is a huge importance on keeping costs low while producing a high quality product. Therefore the conclusions presented in this thesis regarding the economic consequences of suboptimal mobility could potentially entice farmers to weight up the importance of reducing the prevalence of suboptimal mobility within their herd. 


\section{Main conclusions}

- Claw disorders are associated with suboptimal mobility, wherein even mild severities of claw disorders are associated with mild forms of suboptimal mobility (imperfect and impaired mobility) compared to optimal mobility.

- Cows with a lower body condition score are associated with an increased risk to have suboptimal mobility compared to optimal mobility.

- Higher parity cows have a greater risk to have suboptimal mobility compared to optimal mobility.

- The genetics for visible lameness is a good predictor of cow mobility, whereby cows with a high predicted transmitting ability for visible lameness have an increased risk to have suboptimal mobility.

- Long milking times and time spent standing in the collecting yard before and after the milking procedure is associated with an increased prevalence of impaired and severely impaired mobility at the herd-level.

- Higher yielding cows have an increased risk to have suboptimal mobility compared to lower yielding cows, however cows with impaired and severely impaired mobility are associated with a lower milk, fat and protein yield, elevated somatic cell count, a longer calving interval, and a greater risk to be culled, during the lactation in which they had suboptimal mobility, however higher yielding cows.

- Higher proportions of cows within a herd with mild suboptimal mobility results in reduced farm profit in pasture-based dairy herds, even when the base milk price is relatively high. 


\section{Summary}

Lameness is one of the major problems associated with dairy production. It affects animal welfare, increases the environmental impacts and reduces profitability on farm. Literature shows that there is quite some room to reduce the prevalence of lameness and hence improve the sustainability performance on dairy farms. Lameness, however, is a binary description of a cow's mobility, whereby a cow is either lame or not lame, where lame generally refers to severe mobility issues. Thus, when talking about lameness, the prevalence of cows with mild deviations to optimal mobility and its impacts are ignored.

In addition, despite much knowledge being available regarding the impact of severe mobility issues for cows in confinement and non-spring calving, pasture-based type systems, far less is known about mobility issues in spring calving, pasture-based systems, like those in Ireland. Claw disorders, specifically the non-infectious types, are the most common cause of suboptimal mobility in pasture-based dairy cows. Based on the incidence, duration and severity, these claw disorders can be quite painful and therefore a serious welfare concern. Along with this, mobility issues in dairy cows can reduce milk production, reproduction performance and longevity, therefore implying an economic cost associated with them. Although there are some studies which have shown risk factors, production effects and economic consequences of specific claw disorders and severe mobility issues, less attention has been given to the impacts of milder mobility issues, particularly in spring calving, pasture-based systems. Therefore, the main aim of this thesis is to understand suboptimal mobility in spring calving, pasture-based dairy systems, with a focus on risk factors, production performance and the economic consequences.

Data for this thesis were collected as part of another research project of which the aim was to collect claw health traits from a large sample of spring calving, pasture-based dairy cows ( $\sim 11,000$ cows from 68 herds), representative of the Irish dairy population, for consideration in the national genetic evaluations. Data included two mobility scores and body condition scores recorded at two time points throughout a single lactation as well as the presence and severity of claw disorders at a single time point throughout the same lactation.

So far little attention has been given to milder types of claw disorders and mild types of suboptimal mobility in pasture-based systems. In chapter 2, cow level attributes including the presence, type, and severity of specific claw disorders, body condition score, and cow parity were investigated to determine their association with specific mobility scores. Multinomial logistic regressions were performed in order to determine the associations between the cow level attributes and the mobility scores. Multinomial logistic regression assumes no order in the outcome variable in this case mobility scores, therefore the same model was run several times with varying reference categories for the outcome variable. For example, one model used mobility score 0 as a reference category, a second model used mobility score 1 as a reference category, and a third used mobility score 2 as a reference category. This method provided interesting insights into the difference in cow level attributes between mobility score 2 versus the reference category mobility score 1 for example, which 
would have been missed if the model was just run one with the reference category mobility score 0 . Non-infectious type claw disorders (overgrown claw, sole hemorrhage, white line disease, and sole ulcer) were by far the most prevalent with $85 \%$ of all cows having any severity of these disorders at least once throughout the lactation (of which most cases were mild). Digital dermatitis was the only infectious type claw disorder identified among these cows and only affected about $3 \%$ of the sample. All types of claw disorders were associated with mobility scores classified as suboptimal. On one hand, mild types of non-infectious claw disorders were even associated with an increased risk for a cow to have imperfect mobility (mobility score 1), which is often overlooked in other research. While on the other hand, severe types of both non-infectious and infectious type claw disorders were associated with an increased risk for a cow to have severely impaired mobility (mobility score 3 ). Therefore, it was concluded in Chapter 2 of this thesis, that the severity of claw disorders is directly associated with mobility scores. As well as, higher parity cows and cows with a lower body condition score were associated with suboptimal mobility. These results highlighted the potential of routine mobility scoring in order to facilitate the earlier identification and treatment of cows with imperfect mobility (with mild type claw disorders) before progressing to an impaired or severely impaired state (with moderate or severe type claw disorders).

As mentioned above, suboptimal mobility is a complex issue, influenced by a broad range of factors. Chapter 3, therefore, set out to identify the potential risk factors at the cow and herdlevel specific to spring calving, pasture-based systems, and determine their association with specific levels of mobility scores. This was achieved by completing a combined cow and herd-level analyses that incorporated repeated cow-level measures. Up to now, the majority of studies have focused on either cow-level risk factors or herd-level risk factors, and when studies have considered both, they were analysed separately. Binomial logistic regression analyses were completed to determine the cow and herd-level potential risk factors associated with the risk for having suboptimal mobility (mobility score $\geq 1$ ) compared to optimal mobility (mobility score 0), and for the risk for having impaired and severely impaired mobility (mobility score 2 and 3 ) compared to optimal mobility and imperfect mobility (mobility score 0 and 1). The results of Chapter 3 identified several cow-level potential risk factors associated with suboptimal mobility, including; higher milk yields (corrected for a 305 day lactation), elevated somatic cell count (average for the lactation), later calving dates, Holstein-Friesian breed types, low body condition score and a genetic predicting ability for 'visible lameness'. The identified potential risk factors for suboptimal at the herd-level included; longer time spent completing the milking process, fragmented grazing platforms (implying a longer distance cows must walk to and from pasture to be milked each day), time spent in the collecting yard before and after the milking process, and the use of footbaths. From this, it appeared that cow-level potential risk factors for suboptimal mobility in spring calving, pasture-based dairy herds were similar to those identified for other production systems. However, the herd-level risk factors identified in Chapter 3 are unique to such a system, and perhaps may have been missed if the cow and herd-level potential risk factors were analysed separately. 
In chapter 4 , the impact on the production, reproduction and longevity associated with specific mobility score of spring calving, pasture-based dairy cows was determined. Linear mixed-effects models were used to determine the impact on milk, fat, and protein production, somatic cell count performance and calving interval length based on mobility scores, while binomial logistic regression models were performed to determine the risk of death on farm and culling associated with mobility scores. Cows with impaired and severely impaired mobility were associated with significant yield losses, while cows with imperfect mobility were found to be associated with slightly higher yields ( $<1 \%$ higher for the lactation). Cows with any form suboptimal mobility were associated with elevated mean somatic cell counts for the lactation. Calving interval length was prolonged for cows with impaired and severely impaired mobility. Deaths on farm were not found to be associated with mobility scores, however the risk of culling increased for cows with suboptimal mobility.

To estimate the economic impact of suboptimal mobility in spring calving pasture-based systems, in Chapter 5 a sub model was developed within the Herd Dynamic Model (HDM) to predict mobility scores in a typical spring calving, pasture-based dairy herd. Firstly the prediction of claw disorders was completed utilizing the outputs of the regression analysis from Chapter 2, and then when and if a cow developed a claw disorder, the severity of this disorder was determined based on the prevalence in the actual dataset. Secondly, mobility score of each cow was predicted and this was dependent on the presence and severity of the claw disorders she may have developed (also based on the output of the regression analysis completed in Chapter 2). The third step was to estimate treatment costs for cows with claw disorders and routine preventative trimming costs for cows with imperfect mobility. The milk yield of each cow was simulated using the HDM whereby the effect on milk yield due to suboptimal mobility was estimated based on the outputs of chapter 3 of this thesis. The sub model simulated four different scenarios representing a good, average, poor and very poor mobility herd, of which the good, average, and poor scenarios were representative of the top, median, and bottom five farms with the actual dataset, and the very poor mobility herd scenario was not. It was concluded in Chapter 5 that not only having a higher prevalence of impaired and severely impaired mobility cows within a herd decreases overall farm net profit, but having a higher prevalence of cows with imperfect mobility also causes substantial negative economic consequences for spring calving, pasture-based dairy systems.

In Chapter 6 I reflect on the various causes and risk factors associated with specific levels of suboptimal mobility, as well as the impacts of suboptimal mobility on production and economics in pasture-based dairy systems. Although the prevalence of severe mobility issues is lower in spring calving, pasture-based systems, it is apparent the prevalence of mild claw disorders are quite high in such systems and perhaps overlooked up until now. This is an important finding due to the association between mild type claw disorders and imperfect mobility. Similarly, the substantial production and performance effects of milder forms of suboptimal mobility and the economic consequences unique to spring calving, pasture based dairy systems are discussed. Therefore, as discussed in Chapter 6, it is likely that an increased 
Summary | 122

awareness of cows with either mild type claw disorders and indeed cows with imperfect and impaired mobility could potentially result in the earlier treatment of these cows and possibly avoid the negative consequences in terms of production impacts and economic consequences associated with these mild mobility issues.

In conclusion, suboptimal mobility in spring calving, pasture-based dairy herds can reduce overall farm net profit. Having identified risk factors at the cow and herd level has given direction on how to diminish the prevalence of even mild forms of suboptimal mobility which should result in improved production performance of dairy cows and an increased overall farm net profit. 


\section{References}

AHDB DairyCo. 2007. Dairyco mobility scoring. DairyCo, Kenilworth, UK. https://dairy.ahdb.org.uk/technical-information/animal-healthwelfare/lameness/husbandry-prevention/mobility-scoring/\#.WdSfJbuFOos

Alawneh, J. I., R. A. Laven, and M. A. Stevenson. 2011. The effect of lameness on the fertility of dairy cattle in a seasonally breeding pasture-based system. Journal of Dairy Science. 94:5487-5493.

Alban, L. 1995. Lameness in danish dairy cows: Frequency and possible risk factors. Preventive Veterinary Medicine. 22:213-225.

Ali, A.K.A., Shook, G.E., 1980. An Optimum Transformation for Somatic Cell Concentration in Milk. Journal of Dairy Science. 63, 487-490.

Alvergnas, M., T. Strabel, K. Rzewuska, and E. Sell-Kubiak. 2019. Claw disorders in dairy cattle: Effects on production, welfare and farm economics with possible prevention methods. Livestock Science. 222:54-64.

Amory, J. R., Z. E. Barker, J. L. Wright, S. A. Mason, R. W. Blowey, and L. E. Green. 2008. Associations between sole ulcer, white line disease and digital dermatitis and the milk yield of 1824 dairy cows on 30 dairy cow farms in england and wales from february 2003-november 2004. Preventive Veterinary Medicine. 83:381391.

Amory, J. R., P. Kloosterman, Z. E. Barker, J. L. Wright, R. W. Blowey, and L. E. Green. 2006. Risk factors for reduced locomotion in dairy cattle on nineteen farms in the netherlands. Journal of Dairy Science. 89:1509-1515.

Archer, S. C., M. J. Green, and J. N. Huxley. 2010. Association between milk yield and serial locomotion score assessments in uk dairy cows. Journal of Dairy Science. 93:4045-4053.

Archer, S. C., M. J. Green, A. Madouasse, and J. N. Huxley. 2011. Association between somatic cell count and serial locomotion score assessments in uk dairy cows. Journal of Dairy Science. 94:4383-4388.

Armbrecht, L., C. Lambertz, D. Albers, and M. Gauly. 2019. Assessment of welfare indicators in dairy farms offering pasture at differing levels. Animal. 13:23362347.

Barker, Z., K. Leach, H. Whay, N. Bell, and D. Main. 2010. Assessment of lameness prevalence and associated risk factors in dairy herds in england and wales. Journal of Dairy Science. 93:932-941.

Berry, D. P., F. Buckley, and P. Dillon. 2007. Body condition score and live-weight effects on milk production in irish holstein-friesian dairy cows. Animal. 1:1351-1359. 
Beusker, N. 2007. Welfare of dairy cows: Lameness in cattle. Literature review. in The institute of Animal Hygiene, Animal Welfare and Animal Ethology, School of Veterinary Medicine. Hannover, Germany.

Bicalho, R. C., L. D. Warnick, and C. L. Guard. 2008. Strategies to analyze milk losses caused by diseases with potential incidence throughout the lactation: A lameness example. Journal of Dairy Science. 91:2653-2661.

Blowey, R. and N. Chesterton. 2012. Non-healing hoof lesions in dairy cows in chile. Veterinary Record. 170:187-188.

Booth, C. J., L. D. Warnick, Y. T. Gröhn, D. O. Maizon, C. L. Guard, and D. Janssen. 2004. Effect of lameness on culling in dairy cows. Journal of Dairy Science. $87: 4115-4122$.

Bran, J. A., R. R. Daros, M. A. G. von Keyserlingk, S. J. LeBlanc, and M. J. Hötzel. 2018. Cow- and herd-level factors associated with lameness in small-scale grazing dairy herds in brazil. Preventive Veterinary Medicine. 151:79-86.

Bruijnis, M. R. N., H. Hogeveen, and E. N. Stassen. 2010. Assessing economic consequences of foot disorders in dairy cattle using a dynamic stochastic simulation model. Journal of Dairy Science. 93:2419-2432.

Burow, E., P. T. Thomsen, T. Rousing, and J. T. Sørensen. 2012. Daily grazing time as a risk factor for alterations at the hock joint integument in dairy cows. Animal. 7:160-166.

Cambridge dictionary online. 2008. in Cambridge Dictionary Online. Open Educational Resources (OER) Portal at http://www.temoa.info/node/324.

Chapinal, N., A. K. Barrientos, M. A. G. von Keyserlingk, E. Galo, and D. M. Weary. 2013. Herd-level risk factors for lameness in freestall farms in the northeastern united states and california. Journal of Dairy Science. 96:318-328.

Charfeddine, N. and M. A. Pérez-Cabal. 2017. Effect of claw disorders on milk production, fertility, and longevity, and their economic impact in spanish holstein cows. Journal of Dairy Science. 100:653-665.

Chen, W., E. White, and N. M. Holden. 2016. The effect of lameness on the environmental performance of milk production by rotational grazing. Journal of Environmental Management. 172:143-150.

Chesterton, R. N. 2015. The lame game - chile vs. New zealand - can we both be winners? Pages 26-29 in Proc. 18th International Symposium and 10th Conference on Lameness in Ruminants, Valdivia, Chile.

Chesterton, R. N., D. U. Pfeiffer, R. S. Morris, and T. C.M. 1989. Environmental and behavioural factors affecting the prevalence of foot lameness in new zealand dairy herds - a case-control study. New Zealand Veterinary Journal. 37:135-142. 
Cook, N. B., T. B. Bennett, and K. V. Nordlund. 2004. Effect of free stall surface on daily activity patterns in dairy cows with relevance to lameness prevalence. Journal of Dairy Science. 87:2912-2922.

Cook, N. B., J. P. Hess, M. R. Foy, T. B. Bennett, and R. L. Brotzman. 2016. Management characteristics, lameness, and body injuries of dairy cattle housed in highperformance dairy herds in wisconsin. Journal of Dairy Science. 99:5879-5891.

Cramer, G., K. D. Lissemore, C. L. Guard, K. E. Leslie, and D. F. Kelton. 2008. Herd- and cow-level prevalence of foot lesions in ontario dairy cattle. Journal of Dairy Science. 91:3888-3895.

Department of Agriculture Food and the Marine (DAFM). Annual review and outlook for agriculture, food and the marine. Dublin, Ireland: Department of Agriculture and Food, Corporate Affairs Division.

De Vries, M., E. A. M. Bokkers, C. Van Reenen, B. Engel, G. Van Schaik, T. Dijkstra, and I. De Boer. 2015. Housing and management factors associated with indicators of dairy cattle welfare. Preventive Veterinary Medicine. 118:80-92.

Dillon, P. 2017. Irish dairying - challenges and opportunities. . in Proc. Irish Dairying Resilliant Technologies, Moorepark Open Day 2017, Cork, Ireland.

Dillon, P., J. Roche, L. Shalloo, and B. Horan. 2005. Optimising financial return from grazing in temperate pastures. Utilisation of grazed grass in temperate animal systems (ed JJ Murphy).131-147.

Doherty, N., S. J. More, and J. Somers. 2014. Risk factors for lameness on 10 dairy farms in ireland. Veterinary Record. 174:609-609.

EFSA. 2009. Scientific opinion on welfare of dairy cows in relation to leg and locomotion problems based on a risk assessment with special reference to the impact of housing, feeding, management and genetic selection. EFSA Journal. 7:1-57.

Enting, H., D. Kooij, A. A. Dijkhuizen, R. B. M. Huirne, and E. N. Noordhuizen-Stassen. 1997. Economic losses due to clinical lameness in dairy cattle. Livestock Production Science. 49:259-267.

Espejo, L. A., M. I. Endres, and J. A. Salfer. 2006. Prevalence of lameness in highproducing holstein cows housed in freestall barns in minnesota. Journal of Dairy Science. 89:3052-3058.

Ettema, J., S. Østergaard, and A. R. Kristensen. 2010. Modelling the economic impact of three lameness causing diseases using herd and cow level evidence. Preventive Veterinary Medicine. 95:64-73.

Fabian, J., R. A. Laven, and H. R. Whay. 2014. The prevalence of lameness on new zealand dairy farms: A comparison of farmer estimate and locomotion scoring. The Veterinary Journal. 201:31-38. 
Fell, L. R., I. G. Colditz, K. H. Walker, and D. L. Watson. 1999. Associations between temperament, performance and immune function in cattle entering a commercial feedlot. Australian Journal of Experimental Agriculture. 39:795-802.

Fjeldaas, T., Å. M. Sogstad, and O. Østerås. 2011. Locomotion and claw disorders in norwegian dairy cows housed in freestalls with slatted concrete, solid concrete, or solid rubber flooring in the alleys. Journal of Dairy Science. 94:1243-1255.

Flower, F., D. Sanderson, and D. Weary. 2006. Effects of milking on dairy cow gait. Journal of Dairy Science. 89:2084-2089.

Flower, F. C. and D. M. Weary. 2009. Gait assessment in dairy cattle. Animal. 3:87-95.

Fregonesi, J. A., C. B. Tucker, and D. M. Weary. 2007. Overstocking reduces lying time in dairy cows. Journal of Dairy Science. 90:3349-3354.

Geary, U., N. Lopez-Villalobos, N. Begley, F. McCoy, B. O’Brien, L. O’Grady, and L. Shalloo. 2012. Estimating the effect of mastitis on the profitability of irish dairy farms. Journal of Dairy Science. 95:3662-3673.

Geary, U., N. Lopez-Villalobos, D. J. Garrick, and L. Shalloo. 2010. Development and application of a processing model for the irish dairy industry. Journal of Dairy Science. 93:5091-5100.

Gelman, A., X.-L. Meng, and H. Stern. 1996. Postierior predictive assessment of model fitness via realized discrepancies. Statistica Sinica. 6:733-760.

Green, L. E., V. J. Hedges, Y. H. Schukken, R. W. Blowey, and A. J. Packington. 2002. The impact of clinical lameness on the milk yield of dairy cows. Journal of Dairy Science. 85:2250-2256.

Green, L. E., J. N. Huxley, C. Banks, and M. J. Green. 2014. Temporal associations between low body condition, lameness and milk yield in a uk dairy herd. Preventive Veterinary Medicine. 113:63-71.

Hanrahan, L., N. McHugh, T. Hennessy, B. Moran, R. Kearney, M. Wallace, and L. Shalloo. 2018. Factors associated with profitability in pasture-based systems of milk production. Journal of Dairy Science. https://doi.org/10.3168/jds.201713223.

Hernandez-Mendo, O., M. Von Keyserlingk, D. Veira, and D. Weary. 2007. Effects of pasture on lameness in dairy cows. Journal of Dairy Science. 90:1209-1214.

Hernandez, J., J. K. Shearer, and D. W. Webb. 2001. Effect of lameness on the calving-toconception interval in dairy cows. Journal of the American Veterinary Medical Association. 218:1611-1614.

Hernandez, J., J. K. Shearer, and D. W. Webb. 2002. Effect of lameness on milk yield in dairy cows. Journal of the American Veterinary Medical Association. 220:640644. 
Hirst, W. M., R. D. Murray, W. R. Ward, and N. P. French. 2002. Generalised additive models and hierarchical logistic regression of lameness in dairy cows. Preventive Veterinary Medicine. 55:37-46.

Horan, B., J. F. Mee, P. O'Connor, M. Rath, and P. Dillon. 2005. The effect of strain of holstein-friesian cow and feeding system on postpartum ovarian function, animal production and conception rate to first service. Theriogenology. 63:950-971.

Hosmer, D. W. and S. Lemeshow. 1989. Applied logistic regression. New York, NY.

Hund, A., J. Chiozza Logroño, R. D. Ollhoff, and J. Kofler. 2019. Aspects of lameness in pasture based dairy systems. The Veterinary Journal. 244:83-90.

Hutchinson, I. A., L. Shalloo, and S. T. Butler. 2013. Expanding the dairy herd in pasturebased systems: The role of sexed semen use in virgin heifers and lactating cows. Journal of Dairy Science. 96:6742-6752.

Huxley, J. N. 2012. Lameness in cattle: An ongoing concern. The Veterinary Journal. 193:610-611.

Huxley, J. N. 2013. Impact of lameness and claw lesions in cows on health and production. Livestock Science. 156:64-70.

Irish Cattle Breeding Statistics, 2018 Irish Cattle Breeding Statistics. Dairy calving statistics (2018)

Irish Farmers Association(IFA),. 2020. Vet day \& night charges. Vol. 2020.

Kovács, L., F. L. Kézér, V. Jurkovich, M. Kulcsár-Huszenicza, and J. Tőzsér. 2015. Heart rate variability as an indicator of chronic stress caused by lameness in dairy cows. PloS one. 10:e134792.

Kulberg, S., A. K. Storset, B. Heringstad, and H. J. S. Larsen. 2002. Reduced levels of total leukocytes and neutrophils in norwegian cattle selected for decreased mastitis incidence. Journal of Dairy Science. 85:3470-3475.

Lawrence, K. E., R. N. Chesterton, and R. A. Laven. 2011. Further investigation of lameness in cows at pasture: An analysis of the lesions found in, and some possible risk factors associated with, lame new zealand dairy cattle requiring veterinary treatment. Journal of Dairy Science. 94:2794-2805.

Leach, K. A., S. Dippel, J. Huber, S. March, C. Winckler, and H. R. Whay. 2009. Assessing lameness in cows kept in tie-stalls. Journal of Dairy Science. 92:1567-1574.

Leach, K. A., D. A. Tisdall, N. J. Bell, D. C. J. Main, and L. E. Green. 2012. The effects of early treatment for hindlimb lameness in dairy cows on four commercial uk farms. The Veterinary Journal. 193:626-632.

Lim, P. Y., J. N. Huxley, J. A. Willshire, M. J. Green, A. R. Othman, and J. Kaler. 2015. Unravelling the temporal association between lameness and body condition score in dairy cattle using a multistate modelling approach. Preventive Veterinary Medicine. 118:370-377. 
Manske, T., J. Hultgren, and C. Bergsten. 2002. Prevalence and interrelationships of hoof lesions and lameness in swedish dairy cows. Preventive Veterinary Medicine. 54:247-263.

McConnel, C. S., J. E. Lombard, B. A. Wagner, and F. B. Garry. 2008. Evaluation of factors associated with increased dairy cow mortality on united states dairy operations. Journal of Dairy Science. 91:1423-1432.

Mee, J. F. and L. Boyle. 2020. Assessing whether dairy cow welfare is 'better' in pasturebased than in confinement-based management systems. New Zealand Veterinary Journal. 10.1080/00480169.2020.1721034:1-24.

Mee, J. F., J. Marchewka, and L. A. Boyle. 2019. Dairy cow welfare - perceptions vary significantly between key industry stakeholder groups. Pages 766-772 in Proceedings of the 9th European Conference on Precision Livestock Farming., Cork, Ireland.

Merck. 2015. The merck veterinary manual. Lameness in cattle.

Mostert, P. F., C. E. van Middelaar, I. J. M. de Boer, and E. A. M. Bokkers. 2018. The impact of foot lesions in dairy cows on greenhouse gas emissions of milk production. Agricultural Systems. 167:206-212.

Murray, R., D. Downham, M. Clarkson, W. Faull, J. Hughes, F. Manson, J. Merritt, W. Russell, J. Sutherst, and W. Ward. 1996. Epidemiology of lameness in dairy cattle: Description and analysis of foot lesions. The Veterinary Record. 138:586-591.

Navarro, G., L. E. Green, and N. Tadich. 2013. Effect of lameness and lesion specific causes of lameness on time budgets of dairy cows at pasture and when housed. The Veterinary Journal. 197:788-793.

Norring, M., J. Häggman, H. Simojoki, P. Tamminen, C. Winckler, and M. Pastell. 2014. Short communication: Lameness impairs feeding behavior of dairy cows. Journal of Dairy Science. 97:4317-4321.

O'Brien, D., B. Moran, and L. Shalloo. 2018. A national methodology to quantify the diet of grazing dairy cows. Journal of Dairy Science. 101:8595-8604.

O'Callaghan, K. 2002. Lamneness and associated pain in cattle-challenging traditional perceptions. In Practice. 24:212-219.

O’Connor, A. H., E. A. M. Bokkers, I. J. M. de Boer, H. Hogeveen, R. Sayers, N. Byrne, E. Ruelle, B. Engel, and L. Shalloo. 2020a. Cow and herd-level risk factors associated with mobility scores in pasture-based dairy cows. Preventive Veterinary Medicine. 181:105077.

O'Connor, A. H., E. A. M. Bokkers, I. J. M. de Boer, H. Hogeveen, R. Sayers, N. Byrne, E. Ruelle, and L. Shalloo. 2019. Associating cow characteristics with mobility scores in pasture-based dairy cows. Journal of Dairy Science. 102:8332-8342. 
O'Connor, A. H., E. A. M. Bokkers, I. J. M. de Boer, H. Hogeveen, R. Sayers, N. Byrne, E. Ruelle, and L. Shalloo. 2020b. Associating mobility score with production and reproductive performance in pasture-based dairy cows. Journal of Dairy Science, In press.

O’Driscoll, K., M. McCabe, and B. Earley. 2015. Differences in leukocyte profile, gene expression, and metabolite status of dairy cows with or without sole ulcers. Journal of Dairy Science. 98:1685-1695.

Olechnowichz, J. and J. M. Jaskowski. 2015. Associations between different degrees of lameness in early lactation and the fertility of dairy cows. Medycyna Weterynaryjna. 71.

Olmos, G., L. Boyle, A. Hanlon, J. Patton, J. J. Murphy, and J. F. Mee. 2009. Hoof disorders, locomotion ability and lying times of cubicle-housed compared to pasture-based dairy cows. Livestock Science. 125:199-207.

Petersc, D. 1. 1985. Breeding. In: Cattle footearc and claw trimming. Farming Press Ltd., Ipswich.

R: A language and environment for statistical computing. 2013. in R Foundation for Statistical Computing. R. C. Team, ed, Vienna, Austria.

RStudio Team (2016). RStudio: Integrated Development for R. RStudio, Inc., Boston, MA URL http://www.rstudio.com/.

Ranjbar, S., A. R. Rabiee, A. Gunn, and J. K. House. 2016. Identifying risk factors associated with lameness in pasture-based dairy herds. Journal of Dairy Science. 99:7495-7505.

Ring, S. C., A. J. Twomey, N. Byrne, M. M. Kelleher, T. Pabiou, M. L. Doherty, and D. P. Berry. 2018. Genetic selection for hoof health traits and cow mobility scores can accelerate the rate of genetic gain in producer-scored lameness in dairy cows. Journal of Dairy Science. 101:10034-10047.

Ruelle, E., L. Delaby, M. Wallace, and L. Shalloo. 2016. Development and evaluation of the herd dynamic milk model with focus on the individual cow component. Animal. 10:1986-1997.

Ruelle, E., L. Delaby, M. Wallace, L. Shalloo, A. Pol-van Dasselaar, H. Aarts, A. d. Vliegher, A. Elgersma, D. Reheul, and J. Reijneveld. 2015. Using models to establish the most financially optimum expansion strategy for irish dairy farms. Pages 119-121 in Proc. Grassland and forages in high output dairy farming systems. Proceedings of the 18th Symposium of the European Grassland Federation, Wageningen, The Netherlands, 15-17 June 2015. Wageningen Academic Publishers. 
Ruelle, E., D. Hennessy, and L. Delaby. 2018. Development of the moorepark st gilles grass growth model (most gg model): A predictive model for grass growth for pasture based systems. European Journal of Agronomy. 99:80-91.

Rushen, J. 2001. Assessing the welfare of dairy cattle. Journal of Applied Animal Welfare Science. 4:223-234.

Schlageter-Tello, A., E. A. Bokkers, P. W. G. Groot Koerkamp, T. Van Hertem, S. Viazzi, C. E. Romanini, I. Halachmi, C. Bahr, D. Berckmans, and K. Lokhorst. 2014. Manual and automatic locomotion scoring systems in dairy cows: A review. Preventive Veterinary Medicine. 116:12-25.

Shalloo, L., A. Cromie, and N. McHugh. 2014. Effect of fertility on the economics of pasture-based dairy systems. Animal. 8:222-231.

Shalloo, L., P. Dillon, M. Rath, and M. Wallace. 2004. Description and validation of the moorepark dairy system model. Journal of Dairy Science. 87:1945-1959.

Sogstad, Å. M., O. Østerås, and T. Fjeldaas. 2006. Bovine claw and limb disorders related to reproductive performance and production diseases. Journal of Dairy Science. 89:2519-2528.

Solano, L., H. W. Barkema, E. A. Pajor, S. Mason, S. J. LeBlanc, J. C. Zaffino Heyerhoff, C. G. R. Nash, D. B. Haley, E. Vasseur, D. Pellerin, J. Rushen, A. M. de Passillé, and K. Orsel. 2015. Prevalence of lameness and associated risk factors in canadian holstein-friesian cows housed in freestall barns. Journal of Dairy Science. 98:6978-6991.

Somers, J. and L. O'Grady. 2015. Foot lesions in lame cows on 10 dairy farms in ireland. Irish Veterinary Journal. 68:10.

Somers, J. G. C. J., K. Frankena, E. N. Noordhuizen-Stassen, and J. H. M. Metz. 2003. Prevalence of claw disorders in dutch dairy cows exposed to several floor systems. Journal of Dairy Science. 86:2082-2093.

Somers, J. R., J. N. Huxley, M. L. Doherty, and L. E. O’Grady. 2019. Routine herd health data as cow-based risk factors associated with lameness in pasture-based, spring calving irish dairy cows. Animals. 9:204.

Sprecher, D. J., D. E. Hostetler, and J. B. Kaneene. 1997. A lameness scoring system that uses posture and gait to predict dairy cattle reproductive performance. Theriogenology. 47:1179-1187.

Van Nuffel, A., I. Zwertvaegher, L. Pluym, S. Van Weyenberg, V. M. Thorup, M. Pastell, B. Sonck, and W. Saeys. 2015. Lameness detection in dairy cows: Part 1. How to distinguish between non-lame and lame cows based on differences in locomotion or behavior. Animal. 5:838-860.

Veerkamp, R. F., P. Dillon, E. Kelly, A. R. Cromie, and A. F. Groen. 2002. Dairy cattle breeding objectives combining yield, survival and calving interval for pasture- 
based systems in ireland under different milk quota scenarios. Livestock Production Science. 76:137-151.

Vermunt, J. and T. Parkinson. 2002. Claw lameness in dairy cattle: New zealand-based research. New Zealand Veterinary Journal. 50:88-89.

Walker, S. L., R. F. Smith, J. E. Routly, D. N. Jones, M. J. Morris, and H. Dobson. 2008. Lameness, activity time-budgets, and estrus expression in dairy cattle. Journal of Dairy Science. 91:4552-4559.

Weary, D. M. and I. Taszkun. 2000. Hock lesions and free-stall design. Journal of Dairy Science. 83:697-702.

Weary, D. M. and M. A. G. von Keyserlingk. 2017. Public concerns about dairy-cow welfare: How should the industry respond? Animal Production Science. 57:12011209.

Wells, S. J., A. M. Trent, W. E. Marsh, P. G. McGovern, and R. A. Robinson. 1993. Individual cow risk factors for clinical lameness in lactating dairy cows. Preventive Veterinary Medicine. 17:95-109.

Westwood, C. T., E. Bramley, and I. J. Lean. 2003. Review of the relationship between nutrition and lameness in pasture-fed dairy cattle. New Zealand Veterinary Journal. 51:208-218.

Winckler, C., C. B. Tucker, and D. M. Weary. 2015. Effects of under- and overstocking freestalls on dairy cattle behaviour. Applied Animal Behaviour Science. 170:1419.

Yan, M.-J., Humphreys, J., Holden, N.M., 2011. An evaluation of life cycle assessment of European milk production. Journal of Environmental Management. 92, 372-379. 


\section{Acknowledgements}

After almost four years, my own personal ' $\mathrm{PhD}$ journey' has come to an end, a journey that was much more than just creating this book, and a journey that brought with it many challenges, along with endless new knowledge, skills, and unimaginable personal development. To get to this point in the journey I have many people to thank and to express my gratitude to. To begin with, I wish to acknowledge the opportunity to complete this $\mathrm{PhD}$ programme at the Animal \& Grassland Research and Innovation Centre at Teagasc Moorepark and Wageningen University \& Research. In addition, I wish to acknowledge the Teagasc Walsh Fellowship Programme for providing my PhD fellowship.

Then I will start by acknowledging the team of people responsible for guiding me through the 'PhD journey'. Firstly, I would like to thank my supervisors: Laurence, Eddie, Imke, and Henk. I vividly remember during my interview for this $\mathrm{PhD}$, it was brought to my attention that having a large supervision team can bring with it many advantages and disadvantages. The disadvantages being; conflicting suggestions, opinions and ideas, however we seemed to work quite well as a team! Thank you all for your kindness, support, openness and constructive feedback right to the end. Being based in Teagasc for the majority of the time I spent completing this thesis, I would like to especially thank Laurence for always having an 'open door' policy even when you were there (haha). Imke and Eddie, I would really like to thank you for making me feel so welcome and at home during my time spent in Wageningen. I really enjoyed all my short trips to Wageningen to complete course work and especially my longer stay during May and June in 2019. Thank you to both Imke and Paul for welcoming me to your home during many of my trips to Wageningen. Secondly, I would like to thank my unofficial supervisor - Elodie. Your support throughout the past four years really helped me, and you're 'refereeing' skills during some meetings were much appreciated. Finally, I would like to thank Noel and Siobhan for their help and advice when I started in September 2016 with explaining how the data was collected, and Celine for her being my first ever MSc student!

One of the things I learnt throughout the 'PhD journey' was the importance of the working and living environment for a $\mathrm{PhD}$. That being said, although there were some unforeseen obstacles, I was truly blessed to be among such a supportive group here in Moorepark. Thanks to my 'old and new' office mates (Liam, Dara, Johnny, Puneet, Donagh Tom, and Ben) for some serious discussions on the 'simple salad' and the constant reminders of bank holidays and half days ;). I would also like to thank the lunch time walking club, for the breath of fresh air that we all needed every day (weather permitting!!!). I would like to give a special thank you to Emer, Katie, Maryanne, Niamh and Phoebe for being such good listeners, especially through difficult times in 2018. On that note, I would like to thank the Durlas ladies for taking me in when I was in search of a new home, and of course Michelle for welcoming me to my new and current home in Springfield. I would also like to thank Abi, Akke and indeed all the APS group for really making me feel like part of the 'APS family'. I would also like to thank Grange ladies LGFA junior ladies team and management 


\section{4 | Acknowledgements}

(especially Anna, Mags, Fiona and Liam) for looking after me and bringing me to hospital appointments after suffering from a fractured clavicle (in service), and for making me feel a part of the community here in Fermoy.

The next thank you is one I did not foresee writing when I started this ' $\mathrm{PhD}$ journey' but finalising a $\mathrm{PhD}$ thesis during a global pandemic brings with it uncertainties to say the least. My little ball of joy "Winny" and my housemates Shauna and Phoebe kept me sane! Thank you. And Colm, I really can't thank you enough. But I'll try....Thank you so much for listening to me and putting up with my 'sass' during the final couple of weeks. The many flasks of tea (with no milk) and sandwiches in the jape exploring 'the real wesht' (and the $10 \mathrm{~km}$ walks $><$ ) were a beautiful escape from reality and the thesis!

Next, I would like to thank the 'gowls' (Amy, Anthony, Aoife, Chloe, Jessica and Maggie). Although you are all dispersed across the globe, our annual gathering/pilgrimage to Karma each Christmas and video chats in-between really helped me throughout this process. Especially I would like to extend my gratitude to Chloe, the talented lady whom designed the cover of this thesis!

Lastly, I would like to thank my family - my grandparents for introducing me to the art of milking cows and for sparking my interest in all things dairy and agriculture. My mother Helen (where the ' $\mathrm{H}$ ' in the Aisling H. O'Connor comes from haha), thank you for listening to me, supporting me, for getting me this far in life, and for starting our wonderful tradition of our annual getaways near and afar. Thank you. My father Robert senior, thanks for working so hard to get me where I am today, and thanks for spotting typos in the reading version of my thesis almost instantly ;). And my brother Robert junior, we have both matured greatly over the last 4 years and reconnecting meant a lot to me. Finally, my favourite uncle (and godfather) - Michael, thank you so much for showing enormous interest in my thesis progress over the years, for coming to the Moorepark Open day (and Ann), and thanks for always being available for a quick chat during some tricky times! 


\section{About the author}

Aisling H. O'Connor was born and raised in Roscommon, Ireland, in 1994. She obtained honours BSc. Degree in Animal Sciences from University College Dublin, Ireland (2016). After graduation, she proceeded as a Walsh Fellowship $\mathrm{PhD}$ candidate working in conjunction with Teagasc Moorepark and the Animal Production Systems Group at Wageningen University \& Research. Her research has focused on mobility issues for dairy cows in spring calving, pasture-based production systems. She has presented her research at international conferences in countries such as the Ireland, the UK and Croatia, and has attended a number of courses in both Ireland and the Netherlands.

Currently, Aisling is a research officer at the VistaMilk SFI Research Centre (Teagasc, Moorepark) working in the area of optimizing precision in pasture-based dairy farming. 


\section{Publications}

\section{Refereed scientific journals}

O'Connor, A. H., E. A. M. Bokkers, I. J. M. de Boer, H. Hogeveen, R. Sayers, N. Byrne, E. Ruelle, and L. Shalloo. 2019. Associating cow characteristics with mobility scores in pasturebased dairy cows. Journal of Dairy Science. 102:8332-8342.

O'Leary, N. W., D. T. Byrne, A. H. O'Connor, and L. Shalloo. 2020. Invited review: Cattle lameness detection with accelerometers. Journal of Dairy Science. 103:3895-3911.

O'Connor, A. H., E. A. M. Bokkers, I. J. M. de Boer, H. Hogeveen, R. Sayers, N. Byrne, E. Ruelle, B. Engel, and L. Shalloo. 2020. Cow and herd-level risk factors associated with mobility scores in pasture-based dairy cows. Preventative Veterinary Medicine Journal. $181: 105077$

O'Connor, A. H., E. A. M. Bokkers, I. J. M. de Boer, H. Hogeveen, R. Sayers, N. Byrne, E. Ruelle, and L. Shalloo. Associating mobility scores with production and reproductive performance in pasture-based dairy cows. Journal of Dairy Science. (In press). https://doi.org/10.3168/jds.2019-17103.

\section{Conference proceedings and abstracts}

O’Connor, A. H., E.A.M. Bokkers, I.J.M. de Boer, H. Hogeveen, R. Sayers, N. Byrne, E. Ruelle and L. Shalloo. Associating cow characteristics with sub-optimal mobility in dairy cows in Irish pasture-based systems. In: Proceedings of European Grassland Federation General Meeting: Sustainable meat and milk production from grasslands, Cork, Ireland $17^{\text {th }}$ $-21^{\text {st }}$ September (2018), Vol.23.

O’Connor, A.H., E.A.M. Bokkers, I.J.M. de Boer, H. Hogeveen, R. Sayers, N. Byrne, E. Ruelle and L. Shalloo. Associating types of hoof disorders with mobility score in dairy cows in pasture-based systems. In: Proceedings of European Federation of Animal Science General Meeting: Book of abstracts, Dubrovnik, Croatia 27 $7^{\text {th }}-31^{\text {st }}$ August (2018), No. 24. 
O’Connor, A. H., E. A. M. Bokkers, I. J. M. de Boer, H. Hogeveen, R. Sayers, N. Byrne, E. Ruelle and L. Shalloo. Associating hoof disorders with sub-optimal mobility in dairy cows in pasture-based systems. In: Proceedings of the 10th International Symposium on the Nutrition of Herbivores: Herbivore nutrition supporting sustainable intensification and agro ecological approaches, Clermont-Ferrand $2^{\text {nd }}-6^{\text {th }}$ September $(2018), 9: 583$

O’Connor, A. H., E. A. M. Bokkers, I. J. M. de Boer, H. Hogeveen, R. Sayers, N. Byrne, E. Ruelle and L. Shalloo. Effects of sub-optimal mobility on production performance of pasturebased dairy cows. In: Proceedings of British Society of Animal Science: Animal Science Fit for the Future, Edinburgh, Scotland $9^{\text {th }}-11^{\text {th }}$ April (2019), Vol.10.

O’Connor, A. H., E. A. M. Bokkers, I. J. M. de Boer, H. Hogeveen, R. Sayers, N. Byrne, E. Ruelle and L. Shalloo. Suboptimal mobility in spring calving, pasture-based dairy cows. In: Proceedings of WIAS Annual Conference: Frontiers in Animal Science, Lunteren, The Netherlands $13^{\text {th }}-14^{\text {th }}$ February $(2020), 30$.

O’Connor, A. H., E. A. M. Bokkers, I. J. M. de Boer, H. Hogeveen, R. Sayers, N. Byrne, E. Ruelle and L. Shalloo. Associating body condition score and parity with sub-optimal mobility in pasture-based dairy cows. In: Proceedings of European Conference on Precision Livestock Farming, ECPLF 2019, Cork, Ireland $26^{\text {th }}-29^{\text {th }}$ August (2019), 798-802.

\section{Technical articles}

Conneely, M., O'Connor, A. H, and Byrne, N. Lameness in dairy cattle. In: Proceedings of Moorepark Open day - Irish Dairying, Resilient Technologies, Moorepark, Ireland $3^{\text {rd }}$ June (2017), 148-149.

O’Connor, A. H., E. A. M. Bokkers, I. J. M. de Boer, H. Hogeveen, R. Sayers, N. Byrne, E. Ruelle and L. Shalloo. Sub-optimal mobility in pasture-based dairy cows. In: Proceedings of Moorepark Open day - Irish Dairying, Growing Sustainably, Ireland $3^{\text {rd }}$ June (2019), 174175 . 


\section{Education certificate}

Completed training and supervision plan ${ }^{1}$

\section{The basic package (3.0 ECTS)}

- WIAS Introduction course (2016)

- Scientific integrity and ethics in animal science (2017)

- Course on essential skills (2019)

- Farm to fork - sustainability in the bio-economy (2017)

\section{Disciplinary competences (15.0 ECTS)}

- Writing research proposal (2016-2017)

- Environmental impact assessment of livestock systems (2017)

- $\quad$ Statistic for the life sciences (2017)

- $\quad$ Farm to fork - sustainability (2017)

\section{Professional competences (7.2 ECTS)}

- $\quad$ Scientific writing and presenting skills for the agriculture-food researcher (2018)

- $\quad$ Techniques for scientific writing and presenting (2018)

- Course on supervising BSc and MSc thesis students (2018)

- Reviewing a scientific paper (2019)

- $\quad$ PhD workshop carousel (2019)

\section{Presentations (4.0 ECTS)}

- $\quad$ EGF, Cork, Ireland, Cork, Ireland, poster (2018)

- ISNF, Clermont-Ferrand, France, poster (2018)

- EAAP, Dubrovnik, Croatia, theatre (2018)

- $\quad$ BSAS, Edinburgh, Scotland, theatre (2019)

- $\quad$ ECPLF, Cork, Ireland, poster (2019)

- WIAS annual conference, Wageningen, the Netherlands, theatre (2020)

\section{Teaching competences (1.6 ECTS)}

- $\quad$ Supervision of one MSc student (2018-2019)

- $\quad$ BSc lecturing (2016-2020)

\section{Total: 30.8 ECTS}

${ }^{1}$ Listed activities demonstrate that the PhD candidate has satisfied the educational requirements set by the Graduate School of Wageningen Institute of Animal Science (WIAS). One ECTS equals a study load of 28 hours. 


\section{Colophon}

The research described in this thesis was possible thanks to funding from the Irish Department of Agriculture, Food and the Marine STIMULUS research grant HealthyGenes. Cover design by Chloe Lennon, email: info@chloelennon.com

Printed by ProefschriftMaken, Wageningen 



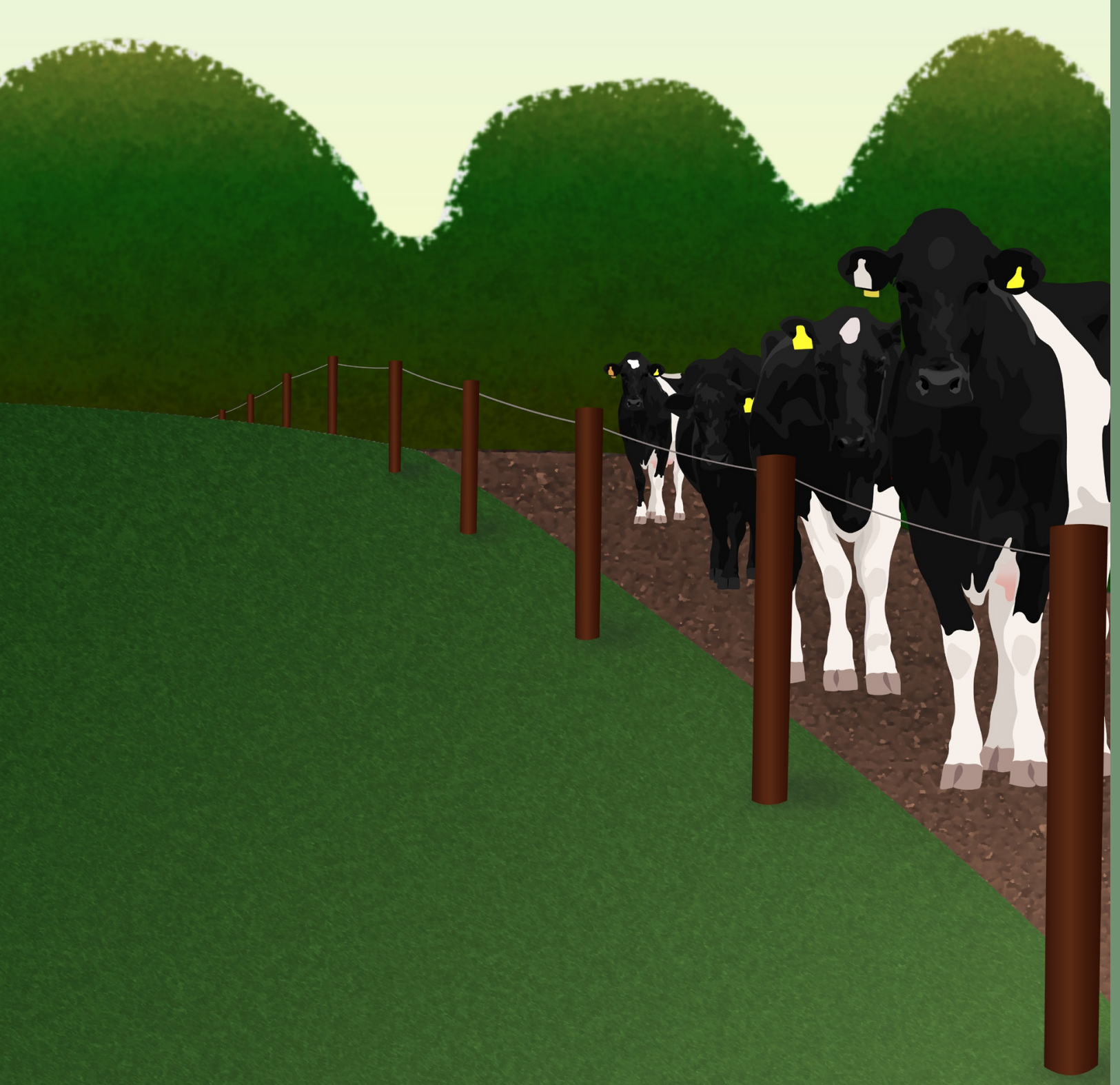

